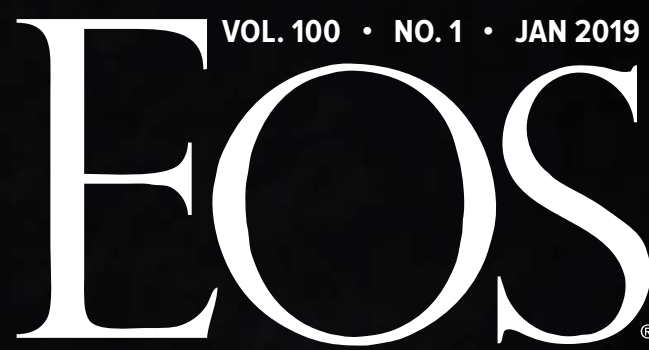

Earth \& Space Science News
100 YEARS

\section{c}

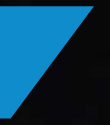

Finding the Source of Dead Sea Sinkholes

Want Tenure? Maybe It's Time to Go Back to High School

The Lightning Task Force
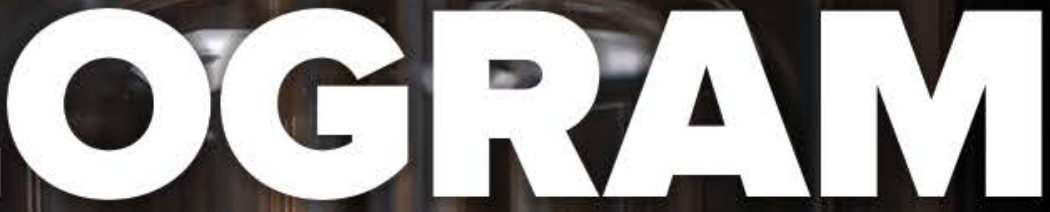

-

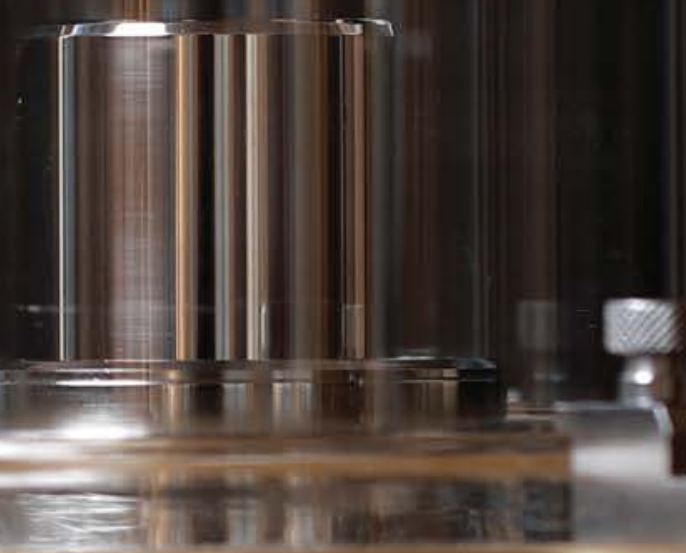




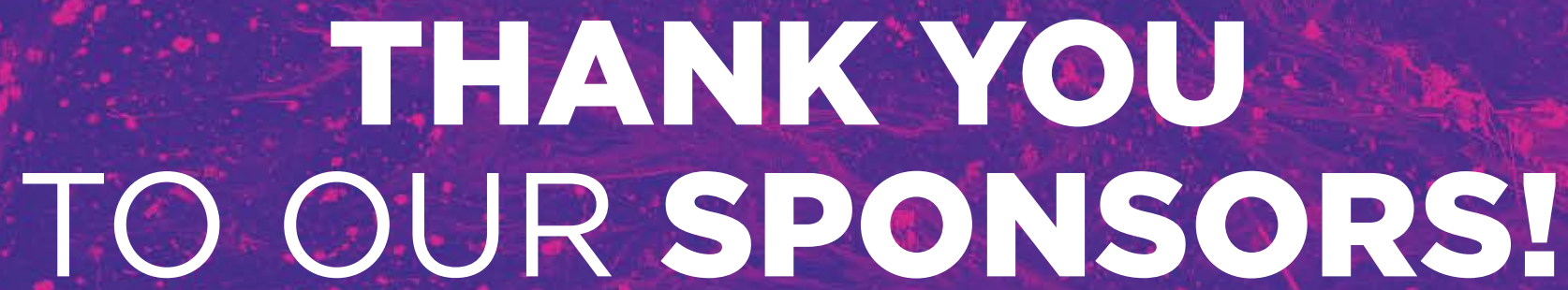

AGU would like to thank all of our generous partners and sponsors, whose contributions helped support Fall Meeting 2018.
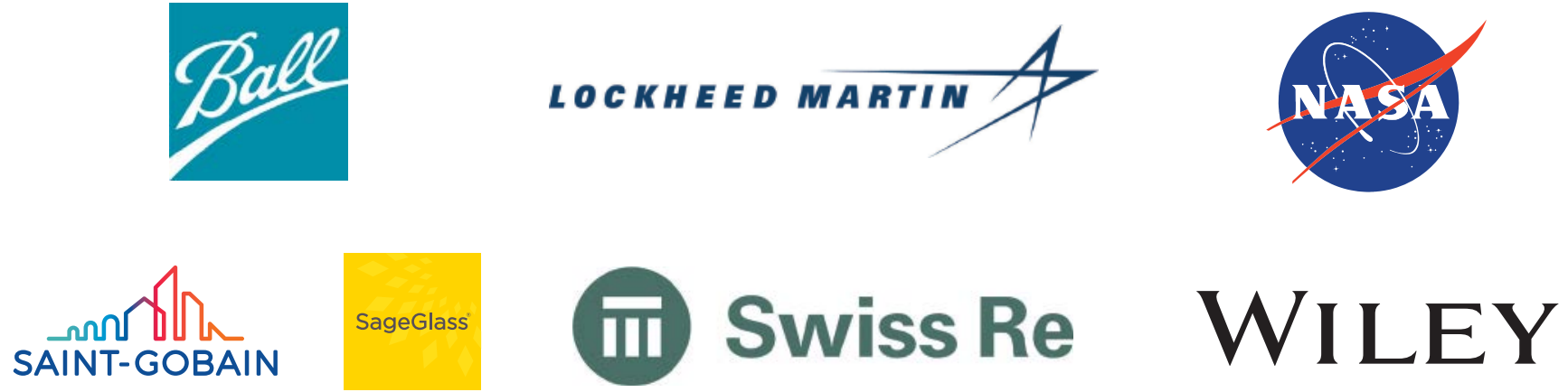

2G Enterprises
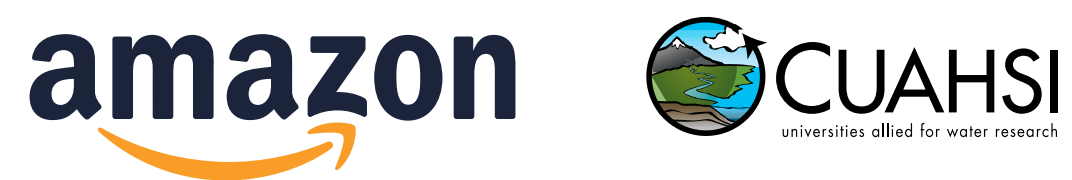

N三ANTHORKS
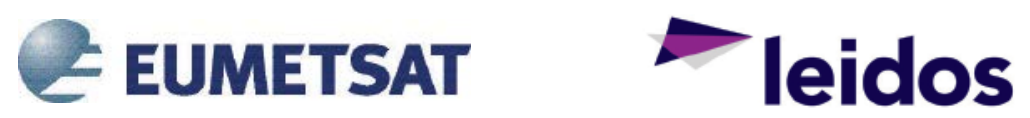

\section{OneEarth}

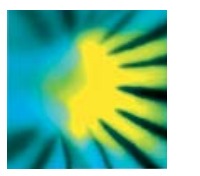

New Phytologist Trust

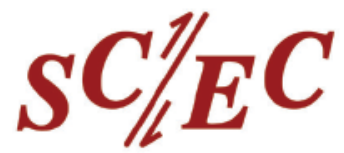




\section{Years of Advancing Science}

I n 1919, two small science committees merged with the goal of supporting and

promoting geoscience research. Soon after, the newly named American Geophysical Union held its first meeting, with 25 members, all elected to the society. About a decade later, membership restrictions lifted, and the organization grew rapidly, creating a community that embraced both the joy of science and its practical applications in fostering a sustainable world.

From these humble beginnings 100 years ago, AGU evolved to become an influential voice and leader in science around the world. We're continuously looking inward and outward by working to make pathways to science more inclusive and finding new ways to communicate research to the public. Today, our membership soars beyond 60,000 , we publish 20 journals that featured nearly 6,000 peer-reviewed articles last year, and our annual meeting attracts more than 25,000 attendees from all over the world. And that's just what we accomplished in the first 100 years.

It's now 2019, and we are thrilled to kick off our Centennial celebrations, starting right here in the pages of Eos.

Each month, we'll turn our focus to different fields, starting with the atmospheric sciences and the study of climate change. Read about how a task force from the Global Climate Observing System is studying lightning as both a symptom and a cause of climate change (p. 22). Be motivated by a scientist who was frustrated by the long wait for an aircraft to survey a California neighborhood after a serious gas leak. He turned that frustration into an initiative, launching this month, that will donate $\$ 100,000$ of flight time to atmospheric scientists who help communities in urgent situations (p. 6).

Climate change is an interdisciplinary topic we'll surely come back to again and again this year. On page 4, learn about the "escalator to extinction," through which mountain species flee upslope as their environment changes, until there's nowhere left to go. Meanwhile, climate policy leaders are getting prepared for the new session of Congress to convene on 3 January after a shake-up in the 2018 midterm elections. Read about their work, along with the fallout from several energyrelated ballot initiatives around the country on page 7 .

And don't forget about stories that can be found only on Eos.org: When the Fourth

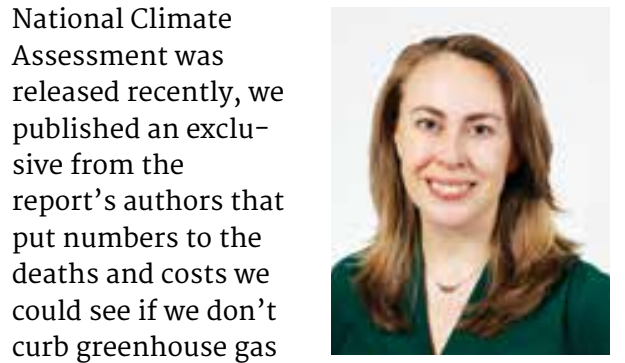
emissions and adapt quickly to our changing environment (bit.ly/ Eos_climate-assessment).

Throughout 2019, Eos will celebrate AGU's Centennial by looking at the evolution of scientific fields over the last 100 years. We'll also be taking a deeper look at the trends and critical research going on today. Finally, we'll do our best to peer as far into the next century as we can to predict what Earth and space science might reveal to us.

Explore more at AGU's official Centennial site, centennial.agu.org. There you can learn about-and apply for-grants for projects that demonstrate innovative ways to promote the value of Earth and space science. Find facts and figures from every field of Earth and space science to share on social media, or browse ways to volunteer your time and expertise. We think you'll enjoy our AGU Narratives, featuring stories recorded from scientists working in the field today, many of which we collected last month at Fall Meeting 2018. You can record your own story on your phone and share it with us through the StoryCorps app, using the community code AGU100.

This month is a special one for Eos as well. Established as Transactions in 1920, we added the name Eos in 1969, evolving hand in hand with AGU. In 2014 we launched our website and, soon after, the monthly magazine you're holding now-January 2019 is the first issue of our 10oth volume. In that time, we've already won awards for overall website excellence, print design, and opinion writing; brought you news from myriad Earth and space science projects under way around the world; and provided one more way for AGU members to connect with one another.

For both AGU and Eos, I eagerly look forward to the next 100 years.

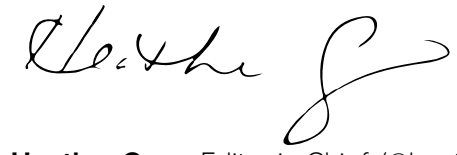

Heather Goss, Editor in Chief, (@heathermg)

Editor in Chief

Heather Goss, AGU, Washington, D. C., USA; Eos_EIC@agu.org

Editors

Christina M. S. Cohen

California Institute of Technology

Pasadena, Calif., USA cohen@srl.caltech.edu

José D. Fuentes

Department of Meteorology Pennsylvania State University University Park, Pa., USA

juf15@meteo.psu.edu

Wendy S. Gordon

Ecologia Consulting

Austin, Texas, USA

wendy@ecologiaconsulting.com

Editorial Advisory Board

Mark G. Flanner, Atmospheric

Sciences

Nicola J. Fox, Space Physics and Aeronomy

Peter Fox, Earth and Space

Science Informatics

Steve Frolking, Biogeosciences

Edward J. Garnero, Study of the

Earth's Deep Interior

Michael N. Gooseff, Hydrology

Brian C. Gunter, Geodesy

Kristine C. Harper, History of

Geophysics

Sarah M. Hörst, Planetary

Sciences

Susan E. Hough, Natural Hazards

Emily R. Johnson, Volcanology,

Geochemistry, and Petrology

Keith D. Koper, Seismology

Robert E. Kopp, Geomagnetism

and Paleomagnetism

Staff

Production and Design

Faith A. Ishii, Manager, Production

and Operations

Melissa A. Tribur, Senior

Production Specialist

Beth Bagley, Manager

Design and Branding

Travis Frazier, Senior

Graphic Designer

Valerie Friedman, Senio

Graphic Designer

Marketing

Jessica Latterman, Director,

Marketing, Branding \& Advertising

Liz Zipse, Assistant Director,

Marketing \& Advertising

Angelo Bouselli, Marketing

Program Manager

Nathaniel Janick, Senior

Specialist, Digital Marketing

Ashwini Yelamanchili, Digital

Marketing Coordinator

C2019. AGU. All Rights Reserved. Material in this issue may be photocopied by individual scientists for research or classroom use. Permission is also granted to use short quotes, figures, and tables for publication in scientific books and journals. For permission for any other uses, contact the AGU Publications Office.

EOS (ISSN 0096-3941) is published monthly by AGU, 2000 Florida Ave., NW, Washington, DC 20009, USA. Periodical Class postage paid at Washington, D. C. and at additional mailing offices. POSTMASTER: Send address changes to Member Service Center, 2000 Florida Ave., NW, Washington, DC 20009, USA.

Member Service Center: 8:00 a.m.-6:00 p.m. Eastern time; Tel: +1-202-462-6900; Fax: +1-202-328-0566; Tel. orders in U.S.: 1-800-966-2481; service@agu.org. Use AGU's Geophysical Electronic Manuscript Submissions system to submit a manuscript: eos-submit.agu.org.

Views expressed in this publication do not necessarily reflect official positions of AGU unless expressly stated.

Christine W. McEntee, Executive Director/CEO 


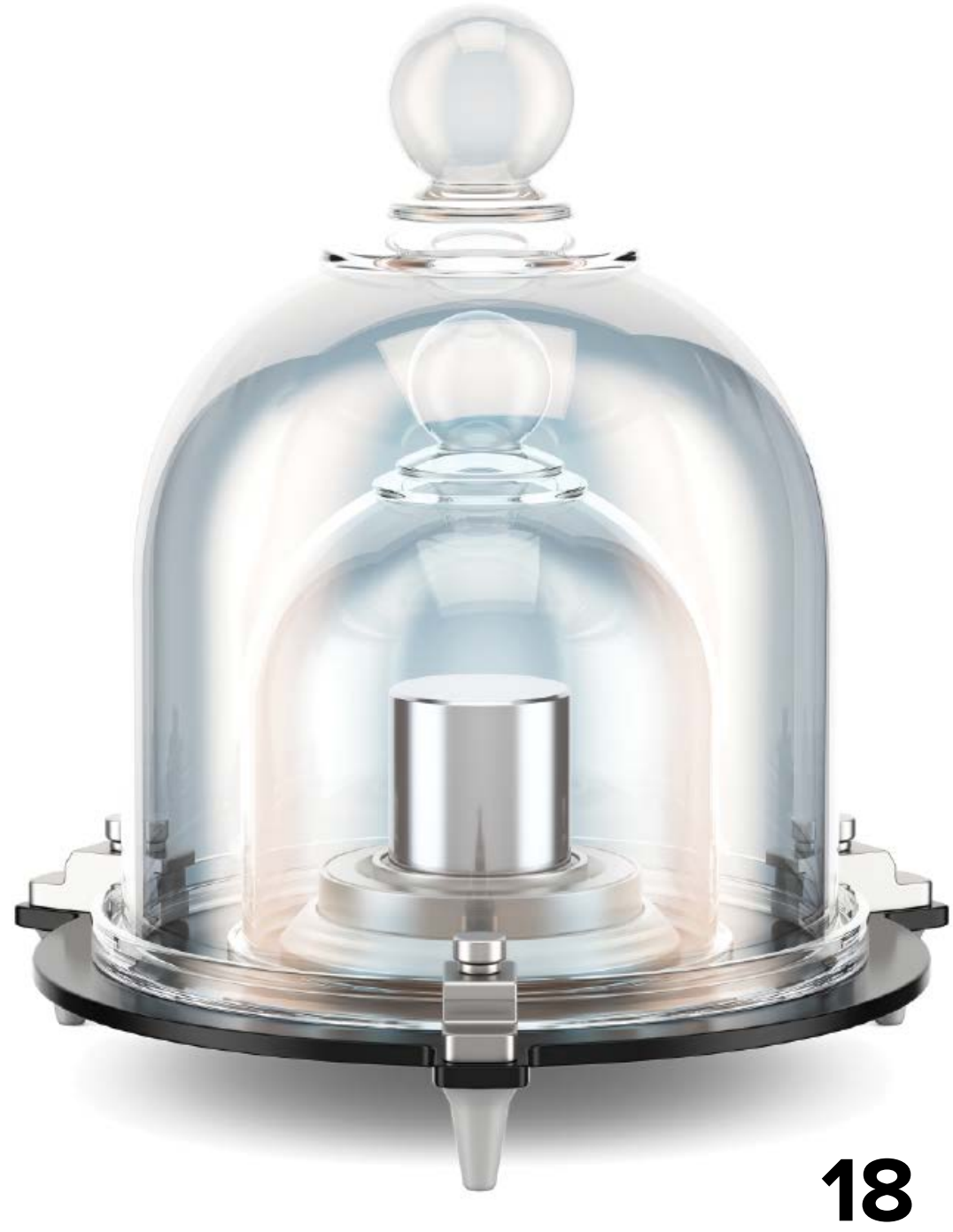

Cover Story

\section{Universal Units Reflect Their Earthly Origins}

\section{By Michel J. Van Camp et al.}

In November, the kilogram joined its fellow metric units with a definition based on fundamental physical constants, but these units maintain links to their roots in the geosciences

\section{On the Cover}

A 3-D rendering of the International Prototype Kilogram, which has been supplanted.Credit: REUTERS/Benoit Tessier
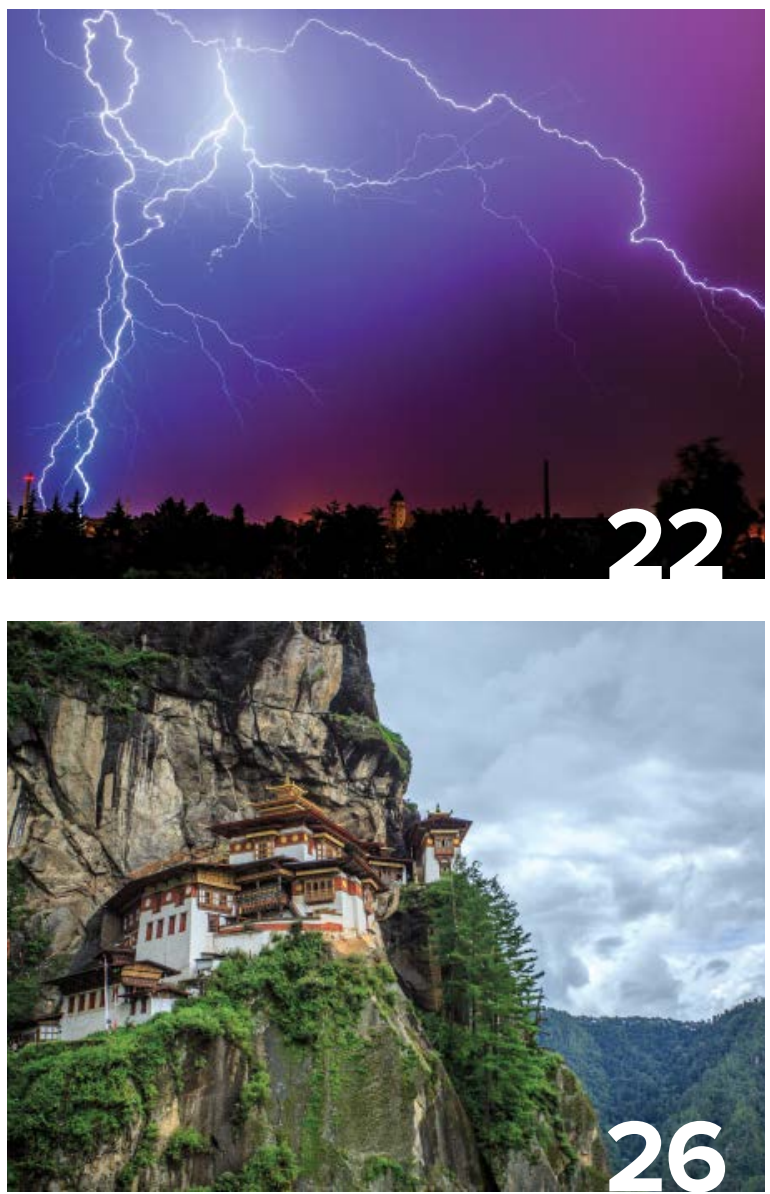

Features

\section{Lightning: A New Essential Climate Variable}

By Valentin Aich et al.

Lightning is a symptom and a cause of climate change. A task team is working to make lightning data available and useful for climate science and service applications

\section{Bhutan Earthquake} Opens Doors to Geophysical Studies

By György Hetényi et al.

A multinational research team discovered an underestimated earthquake hazard during its 7-year exploration of the unique geodynamics of the eastern Himalayas in Bhutan 

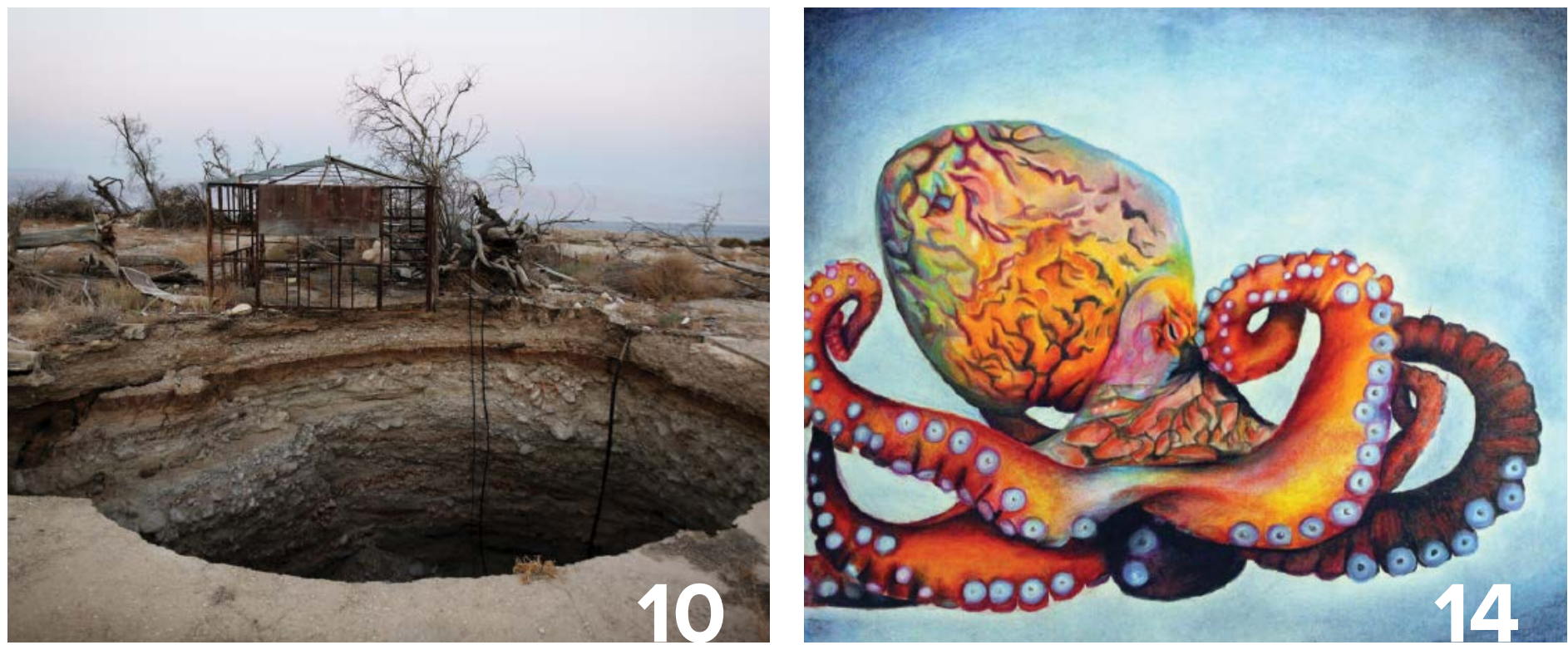

From the Editor

1100 Years of Advancing Science

\section{News}

4 Peruvian Mountain Birds Take an "Escalator to Extinction"

5 Could Life Be Floating in Venus's Clouds?

6 Free Flight Time for Projects in Atmospheric Sciences

7 Election Results Offer Hope for Climate Action

9 How Old Is the Mekong River Valley?

10 Subsurface Imaging Sheds Light on Dead Sea Sinkholes

11 How Did Life Learn to Breathe?

\section{Opinion}

12 High School Teaching Is the New Tenure-Track Job

\section{GeoFIZZ}

14 Dive into Stunning Sea-Inspired Art

\section{AGU News}

32 Medalists Honored at 2018 AGU Fall Meeting

42 Mentoring365: New and Improved Mentoring Interface

\section{Research Spotlight}

43 Invasive Freshwater Mussels Drive Changes in Estuary Sediments

44 Karst Groundwater Contributes to Deformation in Eastern Alps

45 A Closer Look at Turbulent Transport in Gravel Streambed

46 The Case of the Missing Lunar Heat Flow Data Is Finally Solved

\section{Positions Available}

47 Current job openings in the Earth and space sciences

\section{Postcards from the field}

53 Visiting a collapsing glacier in the Andes 


\section{Peruvian Mountain Birds Take an "Escalator to Extinction"}

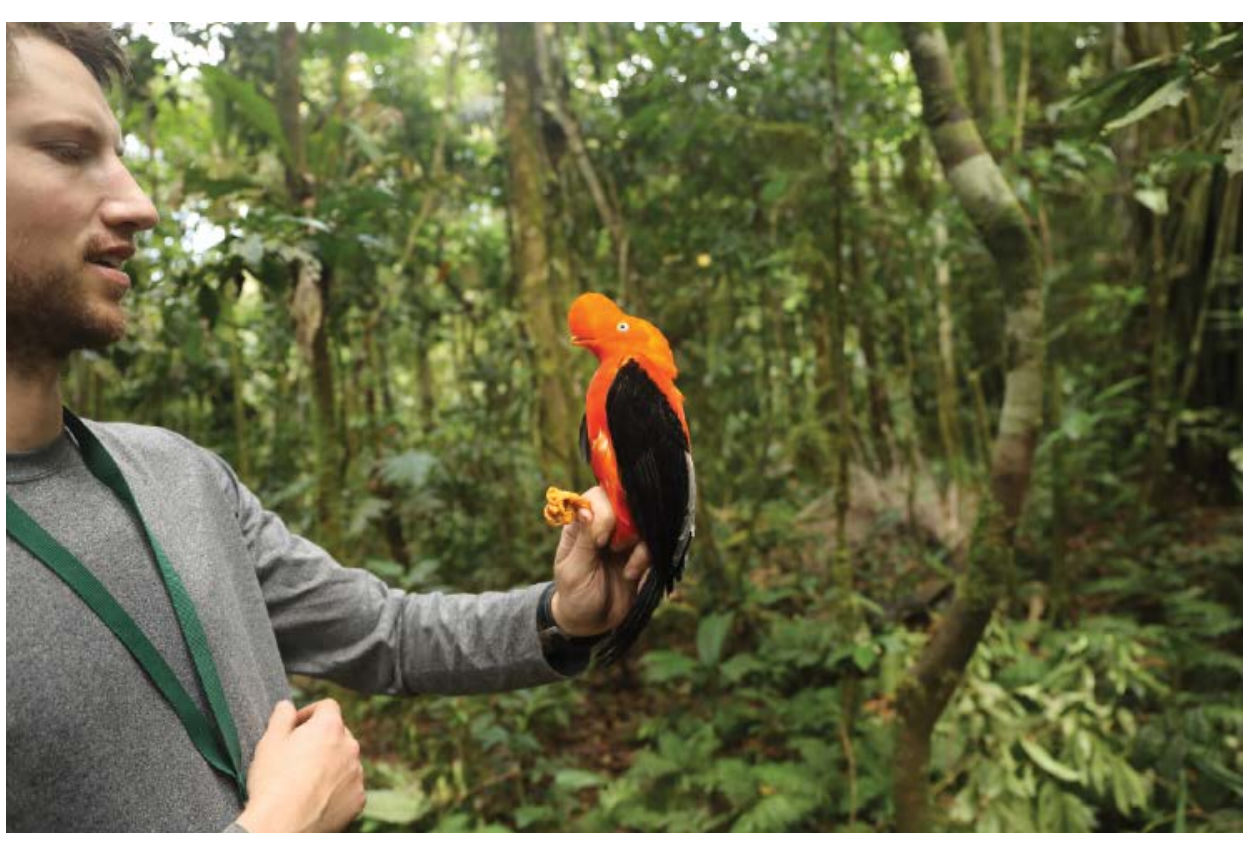

Ecologist Ben Freeman holds an Andean cock-of-the-rock during fieldwork on Pantiacolla Ridge in Peru. Credit: Graham Montgomery

A round the world, species are fleeing warming temperatures resulting from climate change. For those living on mountains, however, they face a hard truth: Once they've retreated to the top of a mountain, they may have nowhere left to go.

Tropical birds are particularly at risk from rising temperatures. The birds are born, live, and die within the same section of woods, and they don't migrate like temperate bird species often do.

Now researchers have found that tropical birds living at high elevations are disappearing and that temperature increases are to blame. The study, which retraces the steps of a survey in Peru conducted 30 years ago, pinpoints local extinctions that are already occurring because of a warming climate.

Of the 16 species of tropical birds that previously lived at high elevations in the study area, "we failed to find eight of the 16," Ben Freeman, lead author of the study and a postdoctoral fellow at the University of British Columbia in Vancouver, Canada, told Eos. The results were published late last year in the Proceedings of the National Academy of Sciences of the United States of America (bit.ly/PNAS -Extinction).

\section{Tropical birds living at high elevations are disappearing, and temperature increases are to blame.}

\section{Metaphors for Extinction}

Ecologists coined the term "escalator to extinction" to describe the plight of mountain species fleeing upslope. "It's catchy, and it makes sense," said Freeman. "But in my reading of the literature, there wasn't much previous evidence that the metaphor is valid."

In the latest study, Freeman and his colleagues traveled to southeastern Peru to a site called the Cerro de Pantiacolla, which was studied previously in 1985 . The area warmed by $0.43^{\circ} \mathrm{C}$ in the intervening years, with little change to land use in the area. The researchers counted the birds by netting them and by recording their songs. The latter allows researchers to pick out individual birds' voices in the absence of visual sightings. The team then compared its findings to the historical data.

\section{Upslope Losses}

With the modern-day numbers in hand, the researchers found that many of the species had relocated to higher ground. Of the 65 species surveyed, 43 of them had "shifted upslope," the study finds. And as the researchers suspected, the birds that had previously lived at the highest elevations were the most vulnerable to disappearance.

"Nearly all of them are shrinking in size and declining in abundance, and some of them have disappeared," Freeman said. "I was very surprised that the signal was so strong." Of the 16 species found in 1985 , eight were nowhere to be found in the latest survey, and the researchers believe that four of those species are locally extinct.

As the authors write in their paper, "highelevation birds on the Cerro de Pantiacolla are indeed riding an escalator to extinction."

\section{One Mountain or a Worldwide Trend?}

For Freeman, the results describe an ecosystem losing its richness. But does this directly affect people? "For me, I'd be hard-pressed to make a raw economic argument that somehow life is worse for people with those four species gone," he said.

"I think it really comes down to ethics, and aesthetics, that the world is a more vibrant and interesting place with these species in it," Freeman added.

Morgan Tingley, an assistant professor at the University of Connecticut in Storrs who was not involved with the study, said that the research confirms scientists' fears. "This study is our worst-case scenario come true. It shows that even just a half degree Centigrade of warming can lead to species extirpations," Tingley told Eos.

But he cautions against applying these results to a broad area. "This study was done on one isolated mountain, so there could be something just odd or atypical about that site," Tingley noted. "We need to scour the planet to see if this is happening elsewhere."

By Jenessa Duncombe (@jenessaduncombe), News Writing and Production Intern 


\section{Could Life Be Floating in Venus's Clouds?}

M ars, Europa, Titan: These familiar locations frequently pop up in discussions about life in the solar system. But what about the search for life on planetary neighbors closer to the Sun?

A recent study suggests that clouds in Venus's lower atmospheric layer might have the right conditions to support microorganisms. Furthermore, the existence of microbial life at those altitudes could help explain anomalous atmospheric patterns that scientists over the past century have seen in ultraviolet images of Venus.

"If you accept the arguments about water and life on Mars, then why shouldn't we include Venus in that?" Sanjay Limaye, a planetary scientist at the University of Wisconsin-Madison, told Eos. "Venus had liquid water. It could have had the chance to evolve or sustain life that could be living in the habitable clouds."

Limaye is lead author on a recent paper published in Astrobiology that discusses this idea (bit.ly/Venus-Life). The paper was part of a column that the journal calls Hypothesis Articles.

\section{Habitable Clouds}

There's a good reason that Venus's surface is often ignored in discussions about life on the surfaces of other planets. With an average temperature of $465^{\circ} \mathrm{C}$, an atmospheric pressure 89 times greater than that at Earth's sea level, and sulfuric acid rain, the Venusian surface is typically considered more of a hellscape than a viable habitat.

But Venus is more than its surface, Limaye noted. "We have chosen to define the habitable zone as the surface conditions, ignoring the planet's atmosphere completely" as a potential habitat, he said.

But Venus's lower atmosphere, 47.5-50.5 kilometers above the surface, checks all the boxes for habitability, the team noted. Pressures and temperatures at those altitudes are mild, $0.4-2$ atmospheres and $0^{\circ} \mathrm{C}-60^{\circ} \mathrm{C}$, respectively. For as long as 2 billion years, the planet may have sustained liquid surface water that is now present as water vapor in the atmosphere. Carbon dioxide, sulfuric acid compounds, and ultraviolet (UV) light would give microbes food and energy.

Moreover, the researchers noted, bacteria, mold spores, pollen, and algae have been discovered in Earth's atmosphere as high as

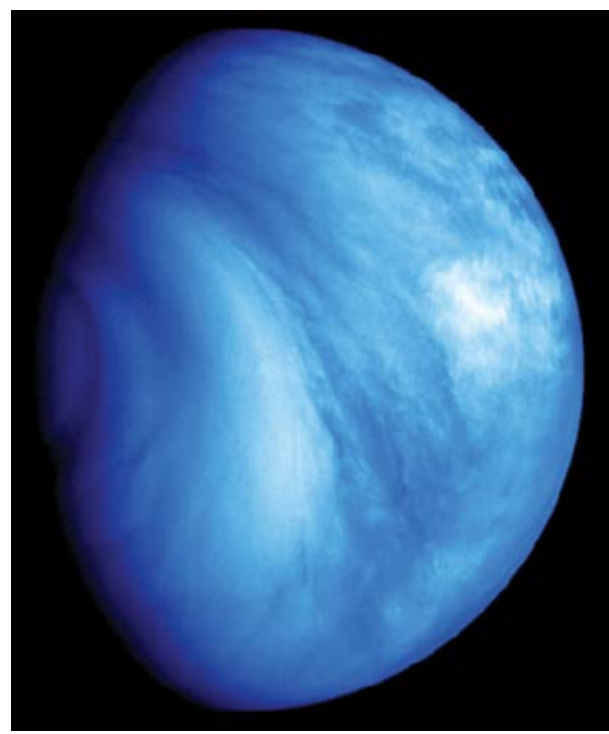

Venus's southern hemisphere is seen here in falsely colored ultraviolet light, from the planet's south pole (left) to its equator (right). Light and dark patches mark locations where UV light is preferentially reflected or absorbed. Credit: ESA (c) 2007 MPS/DLR-PF/IDA

15 kilometers. These microorganisms likely reached such heights through evaporation, storms, eruptions, or meteor impacts, all processes that may have occurred on Venus, they said.

\section{A Venusian Oddity}

The dense clouds that cover all of Venus appear almost featureless in visible light. In the UV range, however, Venus's atmosphere looks decorated in dark patches and streaks. In those darker areas, which were first documented in 1927, an unknown substance absorbs up to $40 \%$ more UV light than surrounding areas do.

Earth-based, space-based, and Venusorbiting imagers have shown that the size $\Omega$ and the contrast ratio of the UV dark patches evolve on a timescale of days, weeks, or months. Strong weather can sometimes cause similar variations on Earth, Limaye explained, but Venus has no seasons or seasonal weather.

Venus's UV patterns “evolve completely differently than anything else seen on Jupiter, on Saturn, on Neptune," Limaye said. "These dark patches are just bizarre."
The identity of the UV absorber itself has remained elusive. Could it be iron chloride or sulfur dioxide aerosols? Each is present in Venus's atmosphere and absorbs UV light in a pattern similar to that observed in the dark patches on Venus.

Unlikely, Limaye explained. Venus's sulfur is not abundant enough to produce such strong UV contrasts on its own, and iron chloride quickly reacts with even a small amount of sulfur, rendering it too volatile and short-lived to produce the observed patterns.

\section{Could Microbes Be the Answer?}

Venus's UV dark patches, Limaye noted, grow and shrink in extent, move around the globe, and become lighter or darker over time. In fact, the evolving UV patterns evoke images of bacteria growing in petri dishes or algae blooming in lakes and oceans, he added.

It's an intriguing idea that Limaye and his team couldn't shake. UV-absorbing microorganisms, they posit in their paper, might bloom, die, migrate, and drift in the atmosphere, changing the aerial extent and brightdark contrast of Venus's atmosphere. The microbes might be similar to Earth's sulfureating, acid-resistant, and UV-absorbing bacteria, like Acidithiobacillus ferrooxidans or members of the genus Stygiolobus.

At last year's meeting of the American Astronomical Society's Division of Planetary Sciences, a researcher suggested that 1.4 billion tons, or about the biomass of Earth's oceans, could survive in Venus's atmosphere, given the pressures and temperatures known to exist at various altitudes (bit.ly/Venus -Biomass). The estimate, Limaye said, is consistent with his team's work.

\section{Venus Mission Necessary}

The concept that Venus's clouds could host life has been in circulation at least as far back as a 1967 journal article coauthored by Carl Sagan (bit.ly/Venus-1967). However, no spacecraft have gathered samples of Venus's atmosphere or performed long-term in situ measurements of its composition.

Such a spacecraft is needed, Limaye explained. "Spectroscopically, it is not easy to detect" these kinds of microbes from Earth, he said. "We have to actually go there to learn about these absorbers."

Finding life's signatures isn't the endgame for Limaye, however. "I won't be disappointed if we don't find any bacteria," he explained. "My curiosity is to know what is causing the absorption."

By Kimberly M. S. Cartier (@AstroKimCartier), Staff Writer 


\section{Free Flight Time for Projects in Atmospheric Sciences}

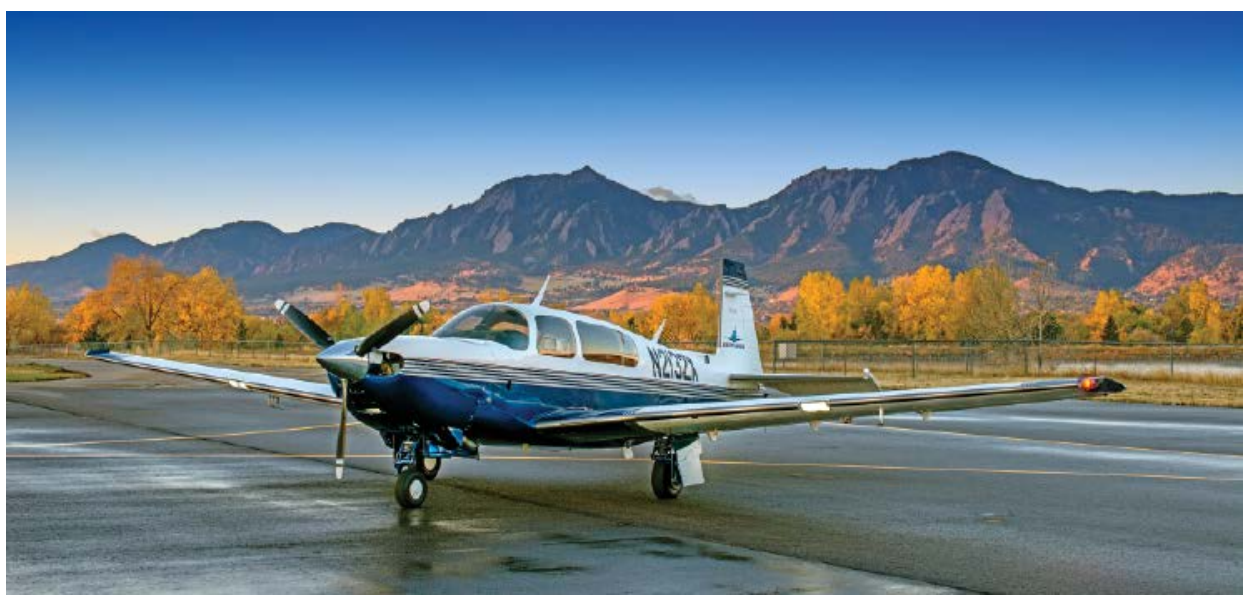

A modified Mooney aircraft in its home airport in Boulder, Colo. The plane is one of three owned by Scientific Aviation, an airborne scientific research company that will be donating free flight time next year to scientists with urgent and innovative projects in the continental United States. Credit: Scientific Aviation

n October 2015, a worker at the Aliso Canyon oil field just north of Los Angeles reported a gas leak. Within days, a resident in a Porter Ranch neighborhood complained of the smell of gas to the California Public Utilities Commission.

As days turned to weeks, those living near Aliso Canyon began experiencing headaches and nausea. State officials called on Scientific Aviation, a chemically instrumented airborne research company, to sample air quality over Aliso Canyon.

The company's measurements helped to show that by the time the gas leak was contained some 3 months later, at least 97,000 metric tons of methane had escaped into the atmosphere. However, the uncertainty during the early days of the accident troubles Stephen Conley, chief scientist and president of Scientific Aviation.

"It took 2 weeks before the state of California got us down to Aliso Canyon," he explained. "And now the biggest debate about the whole emission is, What happened during the first 2 weeks? Because no one was measuring it."

Conley is now on a mission to help prevent such surveying delays. And he's offering the scientific community the full force of his company's equipment and expertise to help.

\section{Free Flights, Free Flight Experience}

Starting this month, his company will launch a new project called Scientific Aviation Fund- ing for Innovative Research Experiments (SAFIRE). This project will donate an estimated $\$ 100,000$ worth of flight time and company expenses to help communities rapidly investigate urgent situations.

In addition to helping with rapid responses after disasters, Conley realized that Scientific Aviation's experience could help principal

\section{Conley is now on a} mission to help prevent surveying delays. And he's offering the scientific community the full force of his company's equipment and expertise to help.

investigators (PIs) - particularly those early in their careers-perform airborne research.

"It's been a constant complaint in the field that unless you have that PI flight experience you just can never get it," said Conley.

Conley wants to change that too. So as part of the application process for the free flight time, Scientific Aviation will consider an applicant's one- or two-page proposal without regard for the researcher's level of airborne research experience.

"We want to pick ones that are sort of the best bang for the buck," said Conley. "Like this is going to matter and is reasonably likely to succeed." Through such experience-blind selection, awards will be able to "take someone who had zero experience as a principal investigator" and give them a chance, he explained. And after their flights, "they'll have an airborne project under their belt."

\section{Innovation Required}

Scientific Aviation has three Mooney aircraft, each modified to have four air inlets for sampling the atmosphere. Depending on the project, the planes can carry various measurement equipment supplied by Scientific Aviation or the researcher it is working with.

"What I am hoping for is something new," said Conley. "If someone comes to us with a project about measuring methane out of an oil and gas field, we've done that for thousands of hours. That won't be very innovative, so what I'm really hoping for is that people will come to us with something we haven't done."

The scientific community, of course, is not without innovative ideas.

Xinrong Ren, a senior research scientist at the University of Maryland, wonders what could be learned if you "fly on air quality alert days to measure air pollution over a city like Baltimore or New York to understand the mechanisms that form photochemical smog." He also thinks that flight time could be used to compare atmospheric measurements with those made on the ground to help improve meteorological models.

Robina Shaheen, an associate project scientist at the University of California, San Diego, said that she would love to collect air samples over Southern California's urban areas and the Mojave Desert to help tease out whether some spikes in ground-level ozone concentrations can originate from intrusion from the stratosphere. She's also intrigued by getting "high resolution, multiyear atmospheric data before and after fire activity in order to investigate impacts on agriculture, the ecosystem, and human health," she said.

\section{Support from NOAA}

The National Oceanic and Atmospheric Administration (NOAA), which has contracts 


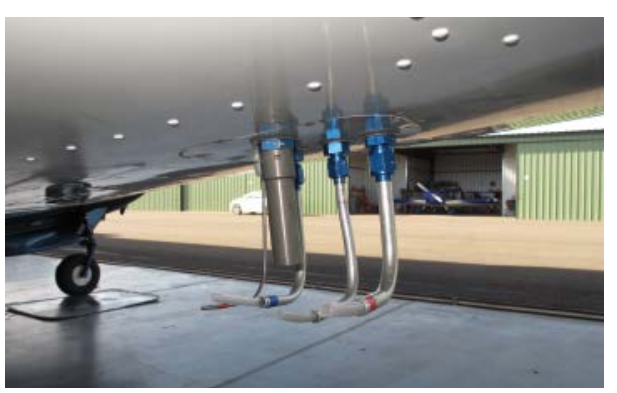

Four inlets for collecting samples and a temperature and humidity probe on the underside of a wing of a modified Mooney aircraft. Credit: Scientific Aviation

with Scientific Aviation, is supporting the SAFIRE program by lending, on select flights, NOAA equipment to collect up to 12 discrete air samples per flight, which will then be analyzed for free. NOAA's analysis can supply information that is not available from the measurements that can be made during the flight. That data will then be available to NOAA and the scientists who proposed the project.

Russell Schnell, deputy director of the NOAA Earth System Research Laboratory's Global Monitoring Division, committed the NOAA resources to the project. Schnell explained that some of the obtained data "might be very valuable, some might just be interesting, and some will be useless." However, small exploratory projects, such as those SAFIRE is supporting, might not have the scientific credibility or have the scale to warrant the time and expense of the proposal process for an organization like NOAA, he explained.

So Scientific Aviation's donation is giving the scientific community, including NOAA, the opportunity to obtain data it wouldn't otherwise get. "Someone might come up with a really neat project that we hadn't thought of," Schnell added. "If Scientific Aviation will go fly it for you in a rare area that we normally wouldn't get to, we will get some really new information."

Currently, potential projects are restricted to the contiguous United States. Despite these logistical limitations, the sky's pretty much the limit, Conley explained. "If someone has done the homework and it is a crazy idea that might be right, I want to be a part of that," he said.

For more information on the application process, visit SAFIRE's website (scientificaviation.com/safire).

By Bailey Bedford (baileybedford42@gmail.com; @BBedfordScience), Science Communication Program Graduate Student, University of California, Santa Cruz

\section{Election Results Offer Hope for Climate Action}

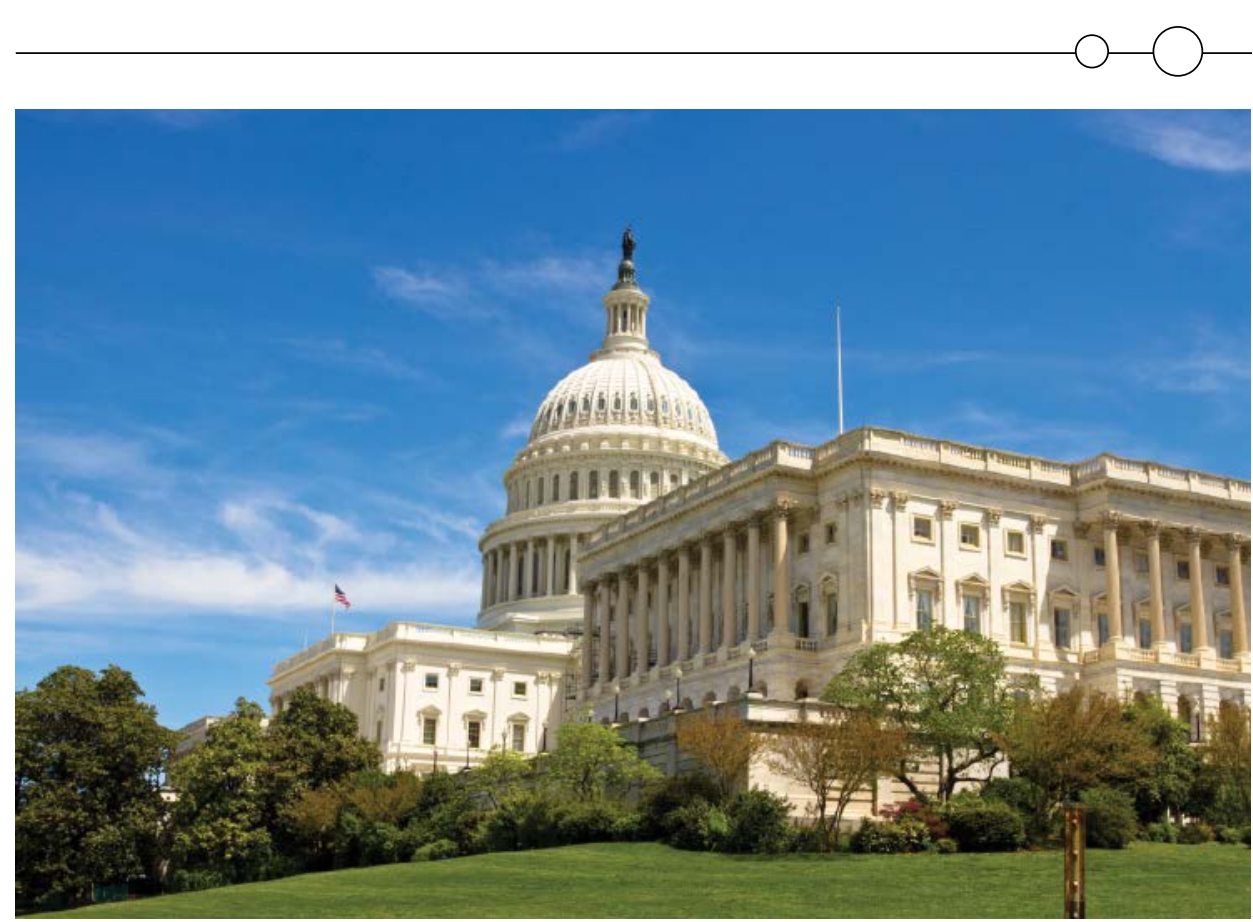

The U.S. Capitol Building. Credit: iStock.com/FrozenShutter

$\mathbf{U}$ S. president Donald Trump touted the 2018 midterm elections as a "tremendous success," with Republicans gaining seats in the Senate and picking up some other wins. But now that Democrats have won the majority in the House of Representatives, environmentalists are trumpeting the election results as good news for the environment and for action on climate change.

Environmental leaders say that the new Democratic majority in the House will provide checks and balances on the Trump administration in a newly divided Congress, which convenes this month. They also point to pickups in governorships and other races in which successful candidates have pledged to support $100 \%$ clean energy by 2050 .

However, voters rejected several state ballot initiatives to protect the environment, and the bipartisan House Climate Solutions Caucus was weakened with the defeat of caucus chair Rep. Carlos Curbelo (R-Fla.) and other Republican members.

"We've witnessed [in] the last 2 years the most antienvironment president in history, and we've seen the most antienvironment Congress in history," Gene Karpinski, president of the League of Conservation Voters (LCV), said at a briefing by environmental leaders in Washing- ton, D. C., following the election. "The good news is that the voters said enough is enough and we need to go in a new direction." LCV is a Washington, D. C.-based group that supports environmental issues, elected officials, and candidates through the electoral process.

Karpinski said that the new direction includes taking action on climate change and holding the Trump administration accountable for its efforts to weaken environmental regulations.

The House needs to conduct "intensive oversight" into the Trump administration's policies and activities, Karpinski added. He cited the administration's efforts to repeal the Clean Power Plan and clean car rules and corruption at the Environmental Protection Agency and the Department of the Interior.

\section{Opportunity to Play Offense for the First Time in a Long Time}

Karpinski also said that much more needs to be done about climate change. "We need action. We have a chance to be on the offense in the House for the first time in a long time," he said.

At the briefing, Michael Brune, executive director of the Sierra Club, an environment group based in Oakland, Calif., said that his group anticipates a lot of specific action in the 
House on climate change. "We fully expect the House to enact a series of measures on climate change, on climate action, on clean energy, [and] holding polluters accountable, and then put pressure on the Senate to do the same thing," he said.

Tom Steyer, president of NextGen Climate Action, put the need for Congress to act on climate change and what's at stake in stark terms. It's not enough to "give it the good college education try," said Steyer. "The [United Nations] described not solving the climate problem by 2030 as causing unimaginable suffering."

Some influential members of Congress are planning to give it more than a good college try. Rep. Eddie Bernice Johnson (D-Texas) said that climate change needs to be high on the committee's agenda. The agenda should "address the challenge of climate change, starting with acknowledging it is real, seeking to understand what climate science is telling us, and working to understand the ways we can mitigate it," she said.

Johnson, who supports the scientific consensus on climate change, is in line to be the next chair of the House Committee on Science, Space, and Technology, taking over from retiring Rep. Lamar Smith (R-Texas), who has called climate scientists "alarmists."

\section{Climate Solutions Caucus Takes a Hit}

The Climate Solutions Caucus will need to regroup following the electoral defeat of 16 of its previously 45 Republican members and the retirement of seven others.

The Heartland Institute, an Arlington Heights, Ill.-based think tank that focuses on free-market solutions to social and economic problems, blames caucus member defeats on "climate alarmist politics." However, Steve Valk, director of communications for the Citizens' Climate Lobby, calls Heartland's public relations "total BS." The Citizens' Climate Lobby is a grassroots advocacy organization based in Coronado, Calif., that has worked closely with the caucus.

Valk said, for example, that Curbelo nearly saved his House seat in a heavily Democratic leaning district because of his leadership on the caucus.

"For all the Republicans in the caucus who lost their elections, being in the caucus had absolutely nothing to do with their defeat. They lost because they were in toss-up or Dem-leaning districts in a year when Democratic voters turned out in droves," he said.

"The Climate Solutions Caucus is here to stay," Valk told Eos. "More Republicans will replace the ones not returning. Bottom line is that the [Intergovernmental Panel on Climate Change] is telling us we can't kick the can down an ever shortening road, so we need to
"We fully expect the House to enact a series of measures on climate change, on climate action, on clean energy, [and] holding polluters accountable, and then put pressure on the Senate to do the same thing."

be working on an effective national policy now. With a divided Congress, that means we have to take a bipartisan approach, and the Climate Solutions Caucus provides the space for that to happen."

At Wednesday's briefing, several speakers said that they value bipartisan efforts on climate change but questioned whether some Republicans have used their caucus membership to "greenwash" otherwise poor environmental voting records. "Our hope at the Sierra Club is that the Climate Solutions Caucus will be replaced, perhaps by the climate action caucus," Brune said. He added sarcastically that perhaps it could be replaced by "the caucus on climate honesty or the caucus on climate opportunism."

\section{Some Key Ballot Initiatives Defeated} Regarding state ballot questions, Nevadans approved an initiative to require electric utilities to acquire $50 \%$ of their electricity from renewable resources by 2030 . However, a similar initiative failed in Arizona, where the state's largest electric company, Arizona Public Service (APS), poured in more than \$30 million to defeat the measure. In addition, Arizona attorney general Mark Brnovich included extraneous wording-that the measure would be "irrespective of cost to consumers" - in a plain-language summary that appeared on every ballot, leading critics to charge that he helped tip the scales against the measure. Brnovich reportedly has received hundreds of thousands of dollars in campaign contributions from APS.

At the briefing, Steyer, whose group financially supported the Nevada and Arizona initiatives, said that "Americans in purple states support renewable energy overwhelmingly, as long as you're allowed to talk honestly about it." He charged that Brnovich's actions are "a straightforward reflection of the corruption that reflects our political situation."
Also falling short at the polls was Washington State's Initiative 1631, which asked voters to approve the nation's first statewide fee on carbon emissions. There, too, the initiative was heavily opposed by the oil and gas industry.

"The oil industry spent the most money in our state's history and were willing to lie to voters about their support and mislead them on the facts," Nick Abraham, communications director for the Yes on 1631 group, told Eos. "Regardless of the final [election] outcome, our coalition is sticking together. We know the longer we wait, the worse this problem is going to get. Climate pollution isn't going anywhere, and neither are we," he said.

Another ballot measure that failed would have established a bigger buffer zone to keep new oil and gas drilling away from houses, parks, and water bodies in Colorado.

\section{Lessons for the 2020 Campaign}

At the briefing, Brune and others said that the strategy for winning the presidency and other elections in 2020 needs to include clearly articulating the economic, environmental, and societal benefits of climate and clean energy. What's more, candidates need to offer ambitious and workable solutions.

"People who were elected [in 2018] both to Congress and to governors' houses and to state houses were elected with the most ambitious climate and clean energy agenda that we've seen from candidates in any past cycle, particularly on climate and particularly on clean energy," Brune said. "So our strategy, at least in the Sierra Club, is centered around ambitious solutions that will actually solve the problem."

Kevin Curtis, executive director of the NRDC Action Fund, which is affiliated with the Natural Resources Defense Council, said that between the election of President Trump in 2016 and the 2018 midterm election, the pendulum has shifted from environmental protection rollbacks to the potential for "a stronger environmental position."

He said, however, that with the "ticking time clock of climate change," climate action needs to happen quickly. "That's what we're all focused on," Curtis said. "The 2020 presidential [election] is absolutely the opportunity to do that."

"We fully expect all the Democrats to be fighting on climate," he added, "and we hope they will be joined by more and more Republican candidates who see that the path to victory is to be good on climate, to actually address it, and not to greenwash it."

By Randy Showstack (@RandyShowstack), Staff Writer 


\section{How Old Is the Mekong River Valley?}

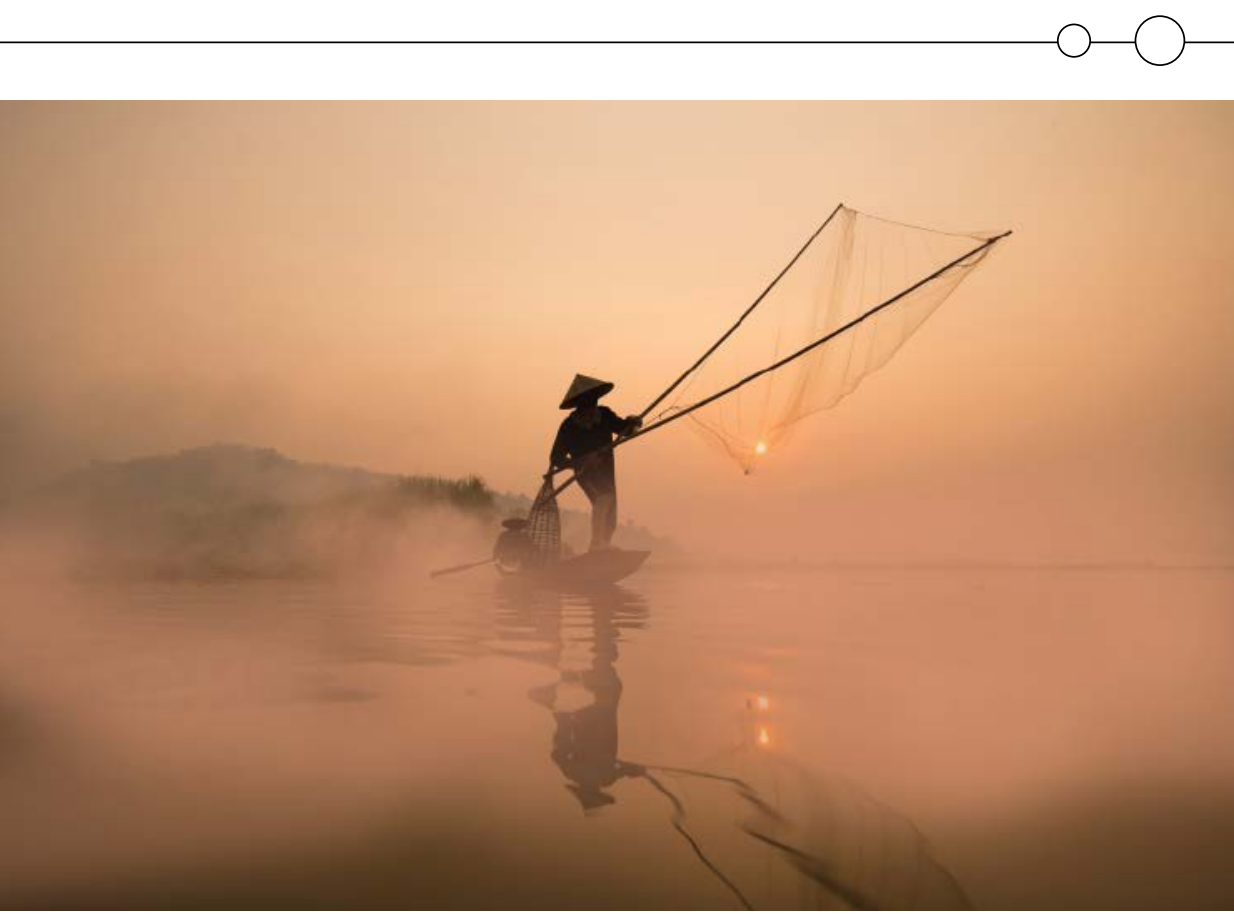

Two men fish in the Mekong River. Credit: iStock.com/prachanartk

$\mathbf{T}$ he Mekong River winds more than 4,000 kilometers through Southeast Asia, where millions of people rely on it for food, income, and transportation. But estimates of the age of this mighty river, one of the world's largest, are wildly inconsistent.

Now scientists have age dated samples of bedrock granite from the Mekong River valley and have shown that the river likely incised its path from its headwaters through the Tibetan Plateau roughly 17 million years ago. This timing is coincident with a warm period of heavier-than-usual monsoon rains, which triggered increased erosion that formed the Mekong River, the researchers proposed.

\section{Important but Overlooked}

Despite the importance of the Mekong River to many people in Southeast Asia, the history of its formation "has largely been overlooked," said Peter Clift, a geologist at Louisiana State University in Baton Rouge who was not involved in the research.

That knowledge gap piqued the curiosity of Junsheng Nie, a geologist at Lanzhou University in Lanzhou, China. Prior research showed that the Tibetan highlands began to rise $30-40$ million years ago, creating the elevation differences needed for a river to cut through sur- rounding rock. But when exactly did the river incise?

To learn more, Nie and his team collected six samples of granite from sites along the Mekong River spanning 1,300 meters in elevation. The researchers applied an age-dating technique to the samples to estimate when, roughly, the river incised its path. This method doesn't date the rocks themselves, Nie noted, but, rather, the time when they were raised to near Earth's surface, which would cause the river to erode the terrain.

\section{This method doesn't date the rocks themselves but, rather, the time when they were raised to near Earth's surface.}

The technique involves measuring two heavier "parent" elements (uranium and thorium) and one lighter "daughter" element (helium) produced when uranium and thorium decay. By knowing the elements' half-lives and measuring the concentrations of the parent elements and the daughter element, Nie and his team calculated how long ago the rocks were brought to near the surface.

This technique works because it hinges on the rocks containing helium, Nie said. This light element tends to escape from rocks when their surrounding environment is too hot, like the conditions found deep within Earth. However, when rocks are uplifted, they start to retain helium. As a result, ratios of helium to uranium and thorium in a rock help to give a time stamp of when the rock uplifted.

\section{Increased Precipitation}

Nie and his team found that the rocks were raised to near Earth's surface roughly 17 million years ago. This age corresponds to an interval known as the Middle Miocene Climate Optimum, the researchers noted.

During this interval, which spanned roughly $14^{-17}$ million years ago, Earth's climate went through a warm phase with high levels of carbon dioxide. When the climate is warmer, it's more dynamic, Nie said. "There's more water evaporating from the ocean...which can cause an increase in monsoon precipitation." This increased precipitation, in turn, increases erosion as water sluices off highlands.

Prior studies have indicated that precipitation rates during the Middle Miocene Climate Optimum were about double that of current conditions. The researchers then asked, Could this have been enough to cut a river?

To answer this question, they turned to a computer model of a simulated landscape devoid of rivers that stretched from Tibet. Using the higher precipitation rates, the scientists found that their models reproduced a kilometer-scale incision in the rock, similar to the modern-day Mekong River Valley.

"The Mekong River in its modern extent probably did not exist prior to 17 million years ago," the researchers conclude in their paper published in Nature Geoscience (bit.ly/Mekong -Age).

Nie and his colleagues plan to return to the Mekong River to collect more rocks and determine when they were brought to near the surface. By better pinpointing the age of this river, the researchers hope to refine techniques that will allow them to better constrain the age of other major rivers nearby, like the Yangtze, Salween, and Red Rivers.

By Katherine Kornei (hobbies4kk@gmail.com @katherinekornei), Freelance Science Journalist 


\section{Subsurface Imaging Sheds Light on Dead Sea Sinkholes}

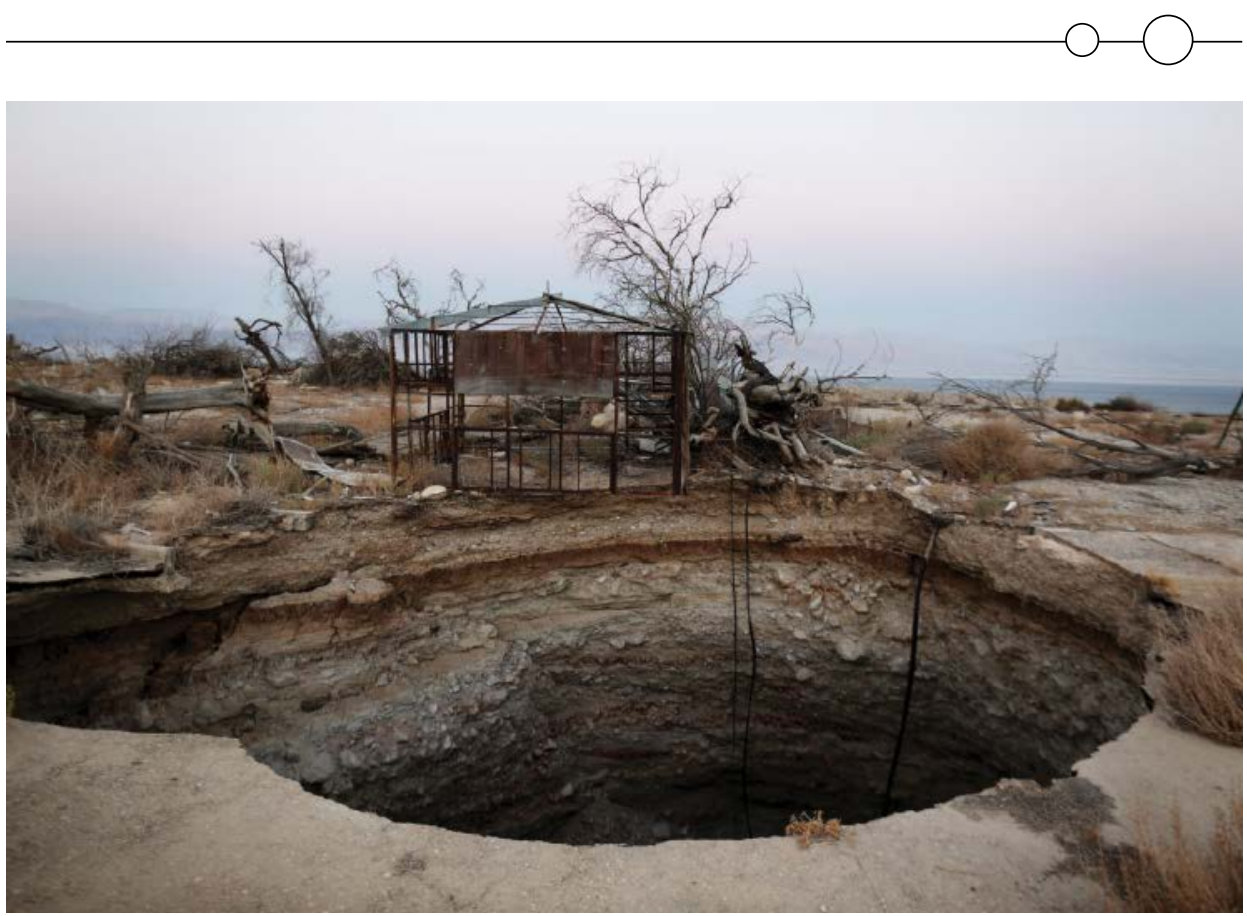

Sinkholes forced the closure of Ein Gedi (above), an Israeli tourist resort on the shore of the Dead Sea, in 2016. Credit: Menahem Kahana/AFP/Getty Images

O n 3 January 1998, an 8-meter-deep sinkhole suddenly opened up at a campsite bordering the Dead Sea, swallowing up a member of the camp's staff. Since then, thousands of other sinkholes have developed in the area-a matter of great concern in this region, which draws tourists seeking to stand at Earth's lowest point on land and float in water 10 times saltier than the oceans.

These maws, some of which are several tens of meters in diameter, have destroyed numerous buildings and roads and have forced local farmers to abandon their fruit orchards. Researchers now have used seismic waves to study an area near the southeastern tip of the Dead Sea that is riddled with sinkholes. They showed that the layering of buried sediments, rather than a thick band of salt, as was previously thought, likely predisposes the region to sinkhole formation.

\section{An Artificial Earthquake}

Sinkholes around the Dead Sea are not just destructive, explained Hussam Alrshdan, a geophysicist at the Ministry of Energy and Mineral Resources in Amman, Jordan. They're also unpredictable. "Suddenly sinkholes appear," he said. "It's a big problem."
In this new study, Alrshdan and his colleagues relied on a technique called shear wave reflection seismic imaging to trace how materials like clay, silt, salt, and sediments were layered in an alluvial fan near Ghor Al-Haditha, Jordan. Using a wheelbarrow-mounted vibrating source, the scientists launched seismic waves into the earth. "It's an artificial earthquake," Alrshdan said of the method.

These waves penetrated to a depth of roughly 200 meters. Seismic waves travel through different materials with different telltale veloci-

\section{"Suddenly sinkholes appear. It's a big problem."}

ties. By studying how quickly the waves propagated underground before being picked up again by seismic receivers positioned some distance away, the researchers could, in essence, take an "ultrasound" of the buried material.

With this ultrasound, Alrshdan and his colleagues inferred the composition and layering of the material in the alluvial fan with meterscale resolution. Although the researchers studied only this one alluvial fan, these features are found around the Dead Sea in other areas characterized by sinkholes, they noted.

One finding immediately stood out in the data. "We were surprised that we didn't find any salt layer," said Alrshdan. Previously, scientists studying the Dead Sea had suggested that a 2- to 10-meter layer of compacted salt lay roughly 40 meters below the surface. This salt, the reasoning went, played a key role in sinkhole formation: As freshwater runoff down nearby valleys slowly eroded this layer, it would weaken and produce cavities that eventually would turn into sinkholes.

But Alrshdan and his colleagues didn't find any evidence of salt. The seismic wave speeds they recorded were several times slower than what would be expected if salt were present. Furthermore, two boreholes drilled at Ghor Al-Haditha down to 45 and 51 meters, respectively, showed no evidence of a salt layer. What then was responsible for the numerous sinkholes pockmarking the area?

\section{Weakening Layers}

The researchers found their answer in their seismic imaging, which showed regions that reflected seismic waves poorly. Instead of forming compact, ordered layers, the material in these areas was "loosening and cracking," they reported last year in Solid Earth (bit.ly/ DeadSea-Sinkholes). The team hypothesized that water washed away fine-grained sediments like sand from the upper layers of the ground, weakening those layers' structure. Over time, as these sediments were transported to the Dead Sea, they would leave behind an increasingly porous matrix of coarser materials - gravels and boulders - that would eventually give way and create a sinkhole, Alrshdan and his colleagues proposed.

The results indicate that shear wave reflection seismic imaging can be applied to determine the factors that help form sinkholes in other settings and at other locations, noted Pauline Kruiver, a geophysicist at Deltares, an independent research institute in the Netherlands, who was not involved in this work.

On a more immediate level, this research is important for ensuring that future construction projects in the Dead Sea region aren't built on sinkhole-prone ground, said Alrshdan. He knows that he and his team can't stop nature; all of this work, Alrshdan says, is to help people "live in peace with these sinkholes."

By Katherine Kornei (hobbies4kk@gmail.com; @katherinekornei), Freelance Science Journalist 


\section{How Did Life Learn to Breathe?}

$\mathbf{L}$ ife, as far as we know, has existed on Earth for about 3.5 billion years. At some point early on in that history, living things evolved the ability to breathe oxygen.

What factors opened the door for this evolution? The answers have been hazy, but in new research, geoscientists may have unearthed a key piece of the puzzle: Nitrous oxide $\left(\mathrm{N}_{2} \mathrm{O}\right)$, more popularly known as laughing gas, once made up a significant part of Earth's atmosphere. This gas helped lay the groundwork for organisms to eventually evolve the ability to breathe oxygen, researchers hypothesize.

It's likely that "life respired other things, like nitrous oxide, before oxygen," said Jennifer Glass, a biogeochemist at the Georgia Institute of Technology in Atlanta who led the new work. Although scientists had suspected this before, through Glass and her team's research, we now have a mechanism for how nitrous oxide could have first existed in the ancient atmosphere.

And in clearing the air surrounding the oxygen breathing mystery, the current research also helps solve another geological riddle: the "faint young Sun paradox."

\section{The Irony of It}

For their study, Glass and her team sought to re-create ancient seawater chemistry from a stretch of time between 1.6 billion and

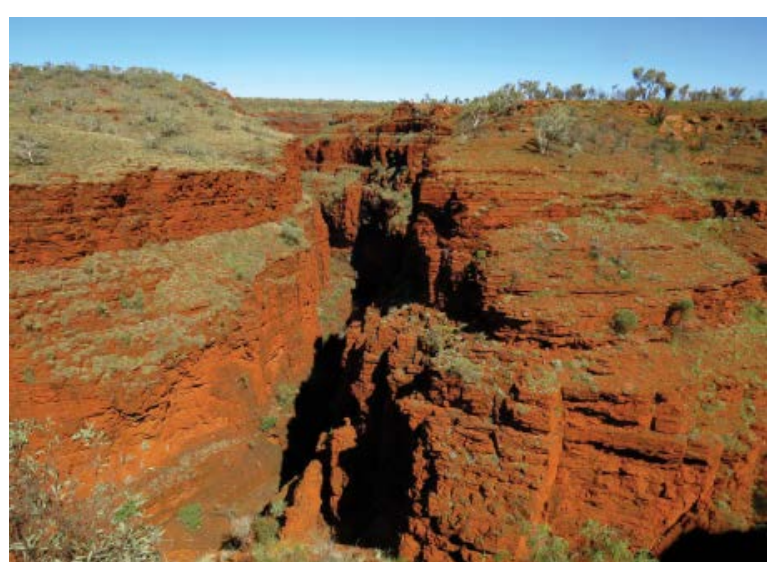

A banded iron formation in Australia. These rocks, rich in iron, formed about 2.5 billion years ago. Before the rocks formed, this iron was dissolved in seawater. Researchers report that the dissolved iron was key in helping nitrous oxide bubble up out of the ancient oceans, which made the gas available for microbes to breathe. As oxygen levels rose, the iron precipitated out of solution, creating the thick deposits seen here. Credit: Georgia Tech/Jennifer Glass 1.o billion years ago. Back then, the team reported last year in Geobiology (bit.ly/Evolve -N2O), the oceans were different from today's in a key way: They had lots of dissolved iron.

In their lab experiments, the researchers filled bottles with artificial seawater that was devoid of oxygen. They then added iron to the seawater and found that the iron provided the impetus for $\mathrm{N}_{2} \mathrm{O}$ to form. Their tests showed that in a process called denitrification, the iron reacted with nitrogen in the seawater to form $\mathrm{N}_{2} \mathrm{O}$ gas, which then bubbled up out of the water and into the air. Up until now, denitrification - the conversion of dissolved nitrogen ions into gas-was thought to be facilitated only by organisms, but Glass's team discovered a way that the process could proceed in an abiotic way.

This abiotic denitrification explains "how you could've gotten a lot of the nitrous oxide around for the organisms to be breathing," Glass said. Such a chemical reaction would not be very common today because the oceans don't contain nearly enough dissolved iron. The reason there is no iron, Glass added, is that today there is plenty of oxygen in the atmosphere. This oxygen reacts with iron in seawater (in the same reaction that creates rust), causing solid iron oxides to form and settle to the seafloor.

\section{A Fuzzy Timeline}

But before oxygen in the atmosphere climbed to its current levels, $\mathrm{N}_{2} \mathrm{O}$ built up in the atmosphere. By calculating the rate at which $\mathrm{N}_{2} \mathrm{O}$ formed in their lab experiments, Glass and her team determined that levels of the gas in the ancient air were maybe 10 times greater than today's atmospheric levels of about $0.00003 \%$.

Such levels would have been helpful to early microbes, which scientists think breathed $\mathrm{N}_{2} \mathrm{O}$, just as many microbes still do today. Two enzymes that enable $\mathrm{N}_{2} \mathrm{O}$-respiring organisms to breathe "came together and created what became cytochrome $\mathrm{c}$ oxidase," Glass said, which is the enzyme that enables oxygenrespiring organisms like us to breathe.
In other words, somehow "the key enzyme for us to breathe oxygen came from denitrification," Glass said.

Solidifying the evidence that this was exactly how oxygen breathing evolved, however, is not so straightforward, explained Aubrey Zerkle, a biogeochemist at the University of St. Andrews in Scotland who was not involved in the new work.

"We have indisputable evidence that there was already oxygen around during this time period," she said. From the fossil record and other studies, she explained, we know that "life was undoubtedly already producing and respiring oxygen."

If oxygen was already in the air and if life was already breathing it, the ability to breathe oxygen might have evolved before $\mathrm{N}_{2} \mathrm{O}$ came onto the scene. Whether this was the case is "very difficult to test," Zerkle said. "The question is the sequence of evolutionary events - whether this $\left[\mathrm{N}_{2} \mathrm{O}\right.$ respiration] evolved before oxygen respiration or after."

\section{Under a Faint Young Sun}

These evolutionary changes occurred in the midst of the faint young Sun paradox. First coined by the astronomer Carl Sagan in 1972, the term refers to how the Sun was about 10\% less luminous than it is today. Under such low-light conditions, Earth should have been mostly frozen, scientists have argued, but it wasn't. Why?

The answer again may lie with $\mathrm{N}_{2} \mathrm{O}$, Glass explained. $\mathrm{N}_{2} \mathrm{O}$ is an extremely potent greenhouse gas that at even minute levels can help to warm a planet. And the $\mathrm{N}_{2} \mathrm{O}$ concentrations that the team calculated equate, she added, to a rise in atmospheric temperatures of about $3^{\circ} \mathrm{C}-5^{\circ} \mathrm{C}$, a heat increase great enough to help moderate the planet's temperatures and prevent global ice ages.

"It's an interesting ingredient to the cocktail of what kept Earth habitable," said Noah Planavsky, a biogeochemist at Yale University who was not involved in the work. Planavsky added that figuring out how Earth remained clement while basking under the rays of a dim Sun has been a lingering problem for researchers, but this new research reveals one of the mechanisms that was likely at work.

$\mathrm{N}_{2} \mathrm{O}$ as a warming mechanism under a faint young Sun "is something that people haven't considered in the past," said Zerkle. "I don't think it's a smoking gun," she added, as it is very hard to say how much any one factor helped keep Earth warm. But at least for now, a part of the paradox appears to be demystified.

By Lucas Joel (lucasvjoel@gmail.com), Freelance Journalist 


\section{High School Teaching Is the New Tenure-Track Job}

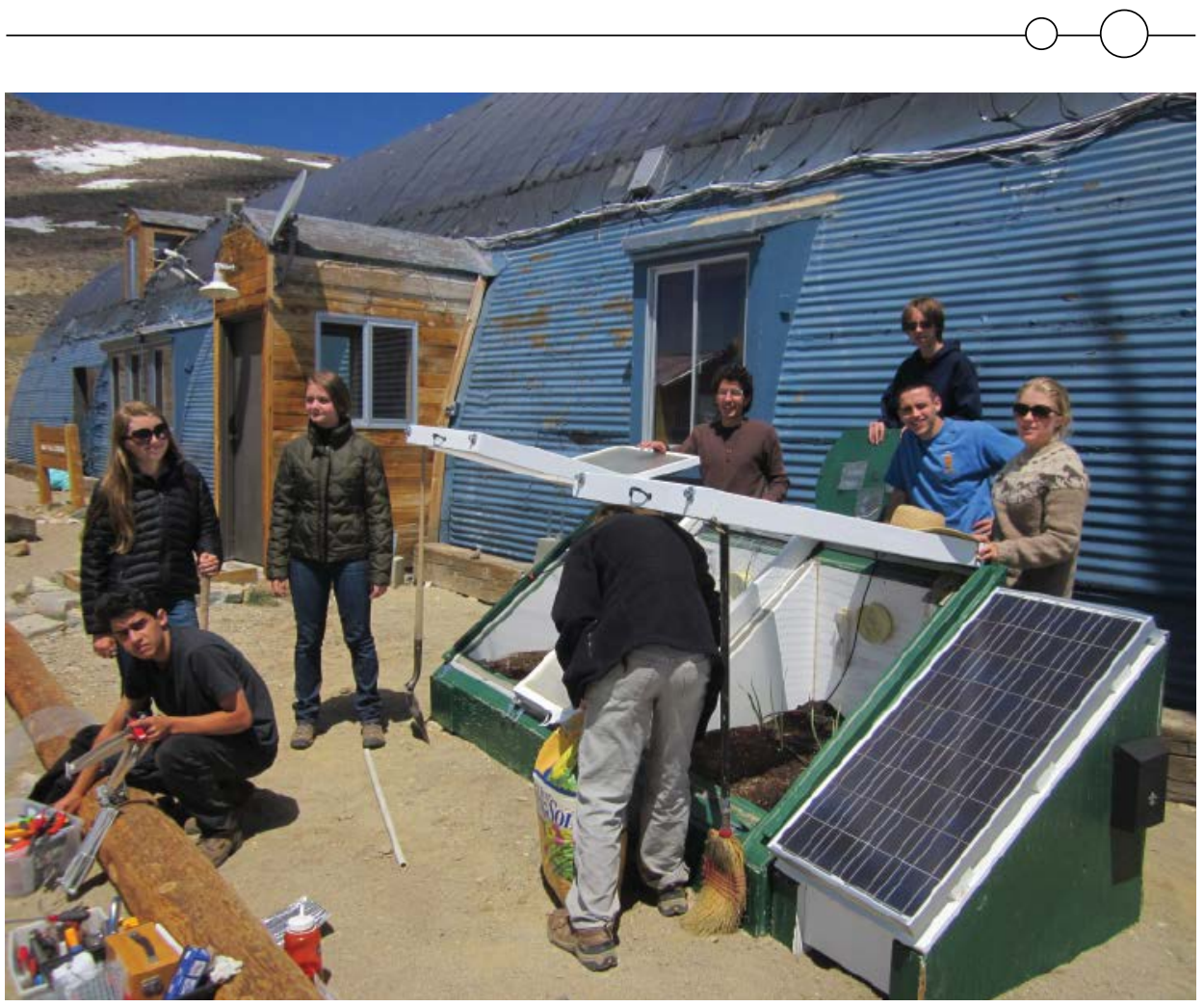

High school students tend to a horticulture project at an elevation of 3,800 meters in California's White Mountains. The goal of the project was to simulate growing conditions on Mars. Credit: Michael Wing

M ore than 2.9 million people in the United States have Ph.D.s. Half of them teach at colleges and universities, but most are part time, and fewer than a quarter of these have tenure-track positions. Even tenure-track opportunities are declining as academia relies more heavily on low-wage, temporary adjuncts. And there are thousands more graduate students in the pipeline.

Clearly, the majority of doctorate holders will never obtain a tenure-track position at a university, no matter how hard they work or how much they want it. The positions simply don't exist.

But I see another option. In fact, I took another option.

I have a bachelor's degree from the University of Chicago and a Ph.D. from the Scripps Institution of Oceanography. I never did a postdoc. For 20 years I've taught at Sir Francis Drake High School, a medium-sized suburban public school in San Anselmo, Calif. That choice has allowed me to earn a decent salary with full benefits; live where I want; enjoy life; and do fieldwork, get grants, and publish in peer-reviewed journals.

I'm living proof that a tenured faculty position at a major university isn't the only path to fulfillment for a Ph.D. scientist.

\section{Few University Jobs...}

Many graduate students aspire to tenured faculty positions because of the prestige and autonomy inherent in the job and because it would allow them to live a life of intellectual inquiry. But universities overproduce Ph.D.s.

If every university professor had, on average, one graduate student who earned a Ph.D. in his or her entire career, then in a time of little growth in academia, we would be in a steady state. The actual ratio of graduate students to professors is far higher, around 8 to 1 in most fields of science and engineering [Larson et al., 2014]. Ph.D. support groups for the underemployed. Tuhus-Dubrow [2013] describes such a gathering on New York's Upper West Side. The cult
Indeed, the situation is so bad that there are of academia has such a strong grip on the thinking of these otherwise mature and intelligent people that they need a great deal of support to even start to examine their nonuniversity options.

\section{...But I Have It Pretty Good}

There is another path forward. I have many of the perks of a university faculty position, without the years spent trying to get myself onto the tenure track. I have a long-term microbiology project that takes me to deserts, polar regions, and mountaintops around the world. I've traveled to Namibia, the United Arab Emirates, the Canadian Arctic, California's White Mountains, the Mojave Desert, and the Himalayas for this project. Often, I accompany some NASA scientists I know who visit these places.

The National Geographic Society has supported my work; some preliminary results have been published in the Journal of Geophysical Research [Warren-Rhodes et al., 2013]. I've also led 14 trips with my students to the University of California's White Mountain Research Center. We have a variety of ongoing projects there; a study we did on spiral grain in bristlecone pines has been published in the Springer-Verlag journal Trees [Wing et al., 2014].

Lots of programs will send $\mathrm{K}-12$ teachers overseas: I've traveled for free to the Galápagos (courtesy of the Toyota International Teacher Program), Alaska and Finland (through PolarTREC), Costa Rica (through the Earthwatch Institute), and the Pacific Ocean (through the National Oceanic and Atmo-

\section{I'm living proof that a tenured faculty position at a major university isn't the only path to fulfillment for a Ph.D. scientist.}

spheric Administration's Teacher at Sea Program). The Finland trip was a monthlong archaeology expedition to the Arctic Circle. When I returned, my students and I employed the same surveying techniques to study an enigmatic line of granite boulders in our own county; we published the study in California Archaeology [Wing et al., 2015].

The editor of that journal is a professor at the California Polytechnic State University, 
and one of my students ended up going there. The first week of her freshman year, this 18-year-old visited him during his office hours and said, "Hi, I'm Emily. I am an entering freshman, and you published my paper!" In all, I've had five high school students as coauthors on my papers.

\section{The Resources Are There}

$\mathrm{K}-12$ teachers have access to a lot of resources. We are well educated and intellectually curious. We have free time during summers, winter breaks, and spring breaks. We have students who will work for free or for academic credit as long as the work is interesting. We have access to some laboratory and field equipment from our schools. Many free travel and professional development opportunities are open only to teachers.

It's probably easier for teachers to get grants of a few thousand dollars for their projects than it is for graduate students, postdocs, or professors-teachers don't need large grants because they aren't paying anyone's salary. Most of all, we get a lot of goodwill from institutions like universities, museums, corporations, government labs, and national parks. Everyone feels that they should be doing more to help the public schools - they just don't know how. So when a teacher calls with a specific and unusual request, the answer is often yes.

I know this firsthand. I got the go-ahead from the administrators of the White Mountain Research Center the same day I pitched an idea to them, and it was a pretty wacky idea: We built a vegetable garden at an elevation of 3,800 meters!

\section{High School Teaching Versus College Teaching}

In terms of the pay and benefits, it's a draw. I earn around $\$ 120$,000 per year. That's more than most tenured professors nationwide earn and much more than adjunct instructors. It's also more than most $\mathrm{K}-12$ teachers earn; there are whole states where $\mathrm{K}-12$ teachers earn less than half of that. Teacher pay is highly dependent on geography. However, most high school teachers are full-time tenured employees who receive a living wage and health and retirement benefits.

As far as job security is concerned, high school wins, hands down. I got tenure in 2 years. University employees have better access to resources like equipment, grants, and labor, but high school teachers can frequently get access to these things by asking for them.

Many academics place a high value on the freedom to do what they want and live how they want; here again, high school teaching wins, particularly when you consider geogra- phy. If you're lucky enough to win a tenure-track university job, you have to move to that location, even if it's a place where you and your family don't really want to live. In contrast, you can teach high school almost anywhere.

Of course, it's not always rosy; $17 \%$ of new teachers leave the field in their first 5 years [Gray et al., 2015]. But that compares pretty well with most other professions.

What about status? It's more prestigious to be a professor, but even that is not a particularly high-status job today (particularly if you're not tenure track) compared with other fields requiring similar expertise and education. High school teachers enjoy a certain local prominence, and if this matters, thousands of people know who I am.

But anyway, we don't go into the Earth sciences to win glory; most of us do it to get out in the field, to explore nature. If we wanted fame, we would have gone into some other line of work. Instead, we started by collecting rocks and fossils, tide pooling at the beach, designing spaceships with crayons and construction paper. We sought - and still seek - to engage with and understand the world around us.

Teaching means you have students. High school students can be lazy, distracted, funny, entitled, emotionally honest, and brilliant, often all at the same time. If they sense that you care about them and their developmentthe whole point of the job-they will reciprocate. You can take them with you out in the field, like the trips I've led to the White Mountains. You don't ever have to pay them. You don't even necessarily have to like them at first; I was a bit afraid of teenagers when I started teaching. That changed. Now they're the best part of my job.

\section{If You Need a Job, a School Somewhere Needs You}

If you're reading this piece and are not a professor, you may be wistful about having the good things that come with a professor's job. If you're a graduate student or postdoc, it might feel as though the older generation took all of the interesting jobs, leaving you nothing.
Maybe you're a working professional who wants something more from your career.

Take it from me: You can get a permanent job with benefits at a school and have the intellectual and emotional life you want.

If you are a professor, you know that most of your students have little chance of following in your footsteps. Your good opinion means a lot to them. Please be supportive as they start to explore their postacademic job options.

The world needs curious, engaged scientists everywhere, not just in academia.

\section{References}

Gray, L., S. Taie, and I. O'Rear (2015), Public School Teacher Attrition and Mobility in the First Five Years: Results from the First Through Fifth Waves of the 2007-08 Beginning Teacher Longitudinal Study, Rep. NCES 2015-337, Natl. Cent. for Educ. Stat., U.S. Dep. of Educ., Washington, D. C., nces.ed.gov/pubs2015/2015337.pdf.

Larson, R. C., N. Ghaffarzadegan, and Y. Xue (2014), Too many PhD graduates or too few academic job openings: The basic reproductive number $R_{0}$ in academia, Syst. Res. Behav. Sci., 31(6), 745-750, https://doi.org/10.1002/sres.2210.

Tuhus-Dubrow, R. (2013), The repurposed Ph.D.: Finding life after academia - And not feeling bad about it, New York Times, 1 Nov., www.nytimes.com/2013/11/03/education/edlife/finding-life-afteracademia-and-not-feeling-bad-about-it.html.

Warren-Rhodes, K. A., et al. (2013), Physical ecology of hypolithic communities in the central Namib Desert: The role of fog, rain, rock habitat, and light, J. Geophys. Res. Biogeosci., 118, 1,451-1,460, https://doi.org/10.1002/jgrg.20117.

Wing, M. R., et al. (2014), Spiral grain in bristlecone pines (Pinus longaeva) exhibits no correlation with environmental factors, Trees, 28 487-491, https://doi.org/10.1007/s00468-013-0965-y.

Wing, M. R., K. lida, and E. Wearing (2015), Stone-by-stone metrics shed new light on a unique stone alignment at the Point Reyes National Seashore, Marin County, Alta California, Calif. Archaeol., 7(2), 245-264, https://doi.org/10.1080/1947461X.2015.1108565.

\section{By Michael Richardson Wing (mwing@}

tamdistrict.org), Science Department, Sir Francis Drake High School, San Anselmo, Calif. 


\section{Dive into Stunning Sea-Inspired Art}

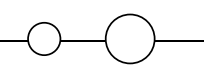

n the early 2000s, the Stellwagen Bank National Marine Sanctuary offshore of Massachusetts held its first art contest. Cosponsored by the Massachusetts Marine Educators, the competi-

tion challenged students in grades $\mathrm{K}-12$ to draw sea life that can be found in the sanctuary and then mail in their submissions.

The contest, which runs from fall until late April, started off as a local affair but now receives entries from around the world. Last school year, students submitted more than 750 entries; winners get a small cash prize and passes to museums. Their art also becomes part of a traveling exhibit to national parks, nature centers, and other community spaces across the country.

The sanctuary, located at the mouth of the Massachusetts Bay, is home to many types of fish, whales, and migratory birds. Contest rules provide students with a detailed list of native species.

Eos can't get enough of this art-science fusion, which gives us a window into a teeming undersea world. From scientific illustrations to impressionistic imaginings, from detailed landscapes to lifelike portraits, the artwork invites viewers to tour the sanctuary through canvas, pencil, ink, and paint. There's even a division for photography and computer-generated art.

We selected just a few of the many entries from the past few years to feature here. Immerse yourself in these lifelike works of art and learn a few facts about the creatures that inspired them. And if you know a student who may want to tap into his or her creativity and compete this year, the 2019 contest is now open. For rules, see the contest's web page (bit.ly/Marine-Art-Contest).

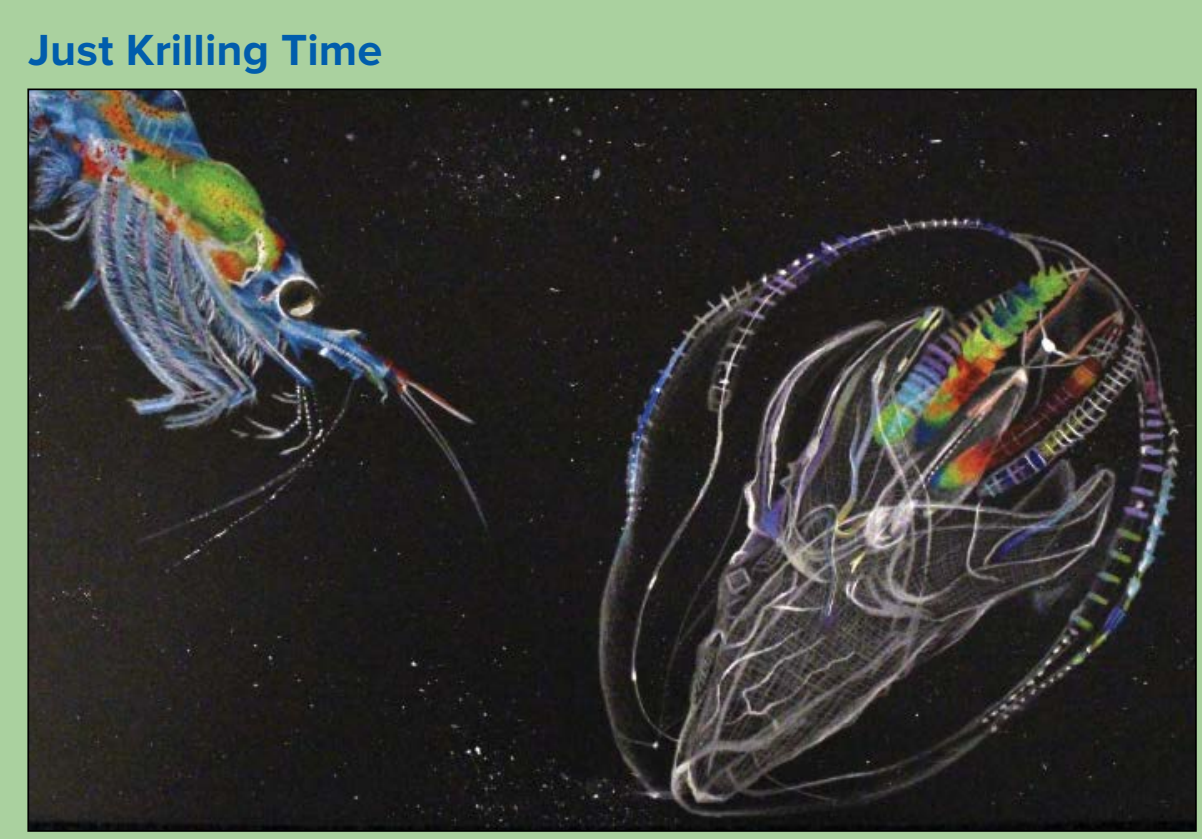

Krill and Beroe's Comb Jelly. First place in the 2018 High School Division. Credit: Linda Palominos, Grade 12, Rio Hondo High School, Rio Hondo, Texas

In this piece, a krill (left) and a comb jelly of the species Beroe cucumis (right) float side by side, illuminated in rainbow colors. Comb jellies have no bones or shell and consist of $95 \%$ water, but don't underestimate them-their stomachs can expand to half their size, and they like to eat other comb jellies for breakfast (and lunch and dinner).

Krill, on the other hand, are shrimplike crustaceans that stand at the bottom of much of the ocean's food chain. You can spot these two floating through Stellwagen's waters, and when the light is right, the hairlike plates along the comb jelly can make flickering rays of rainbows.

\section{Do You Think They Can Roar?}

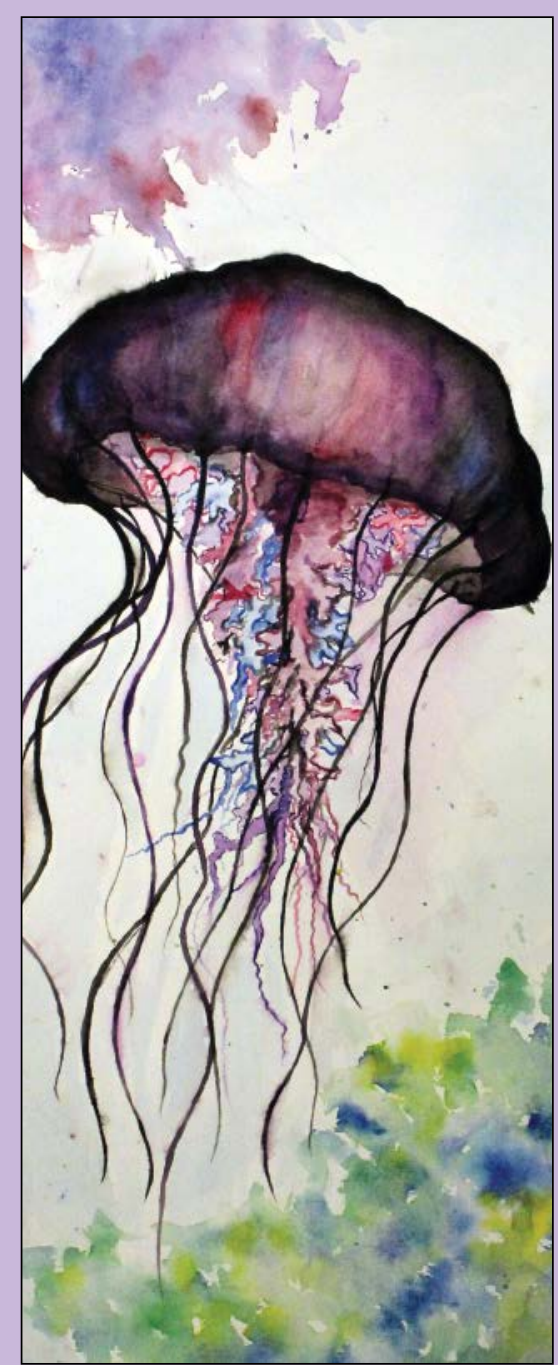

Lion's Mane Jellyfish. Sixth place in the 2016 High School Division. Credit: Lili Barba, Grade 11, Swampscott High School, Swampscott, Mass.

The majestic lion's mane jelly is the largest known species of jellyfish on Earth, reaching 2.4 meters in diameter. With tentacles flowing like a lion's mane that have been known to stretch more than 36 meters, this jellyfish is one of the longest known animals in the world.

Lion's mane jellies commonly float through the waters of Stellwagen, and despite their beauty, swimmers beware: These jellies are toxic and can be deadly to humans. 


\section{Those Fields Must Have Smelled Interesting...}

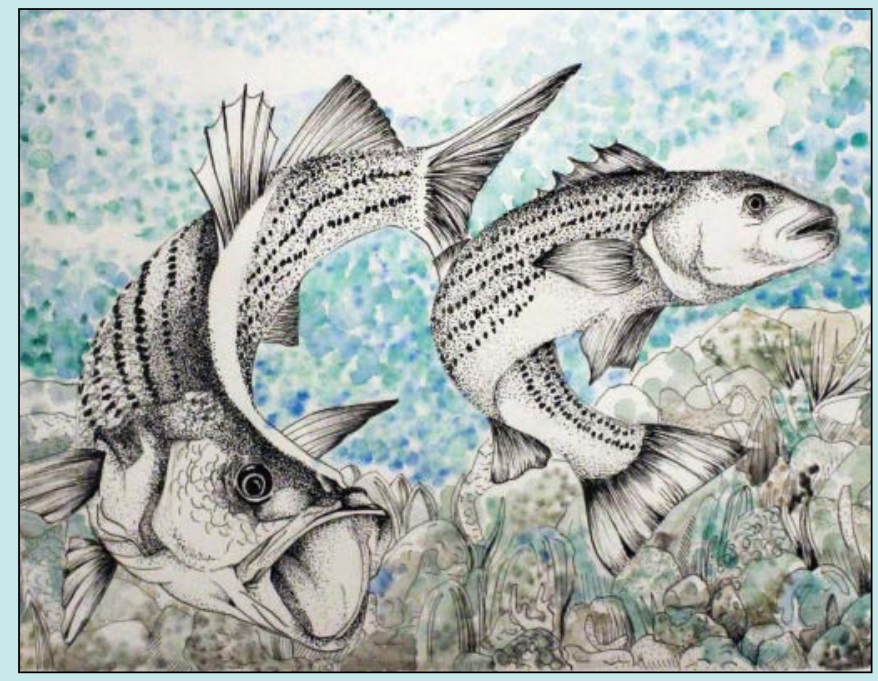

Striped Bass. Second place in the 2018 High School Division. Credit: Gabrielle Gu, Grade 10, Westborough High School, Westborough, Mass.

The shimmering striped bass get their name from the half dozen horizontal stripes streaking down their bodies. Striped bass are a crucial species for the fishing industry along the East Coast, where they were once so plentiful that farmers sprinkled them over their fields as fertilizer!

The fish stock in the Atlantic dwindled in the 1980s, however, after overfishing and environmental conditions made it hard for the fish to survive. Luckily, the stock rebounded, and striped bass are one of the many species that make Stellwagen such a fertile commercial fishing ground.

\section{Here Comes the Sun(fish)}

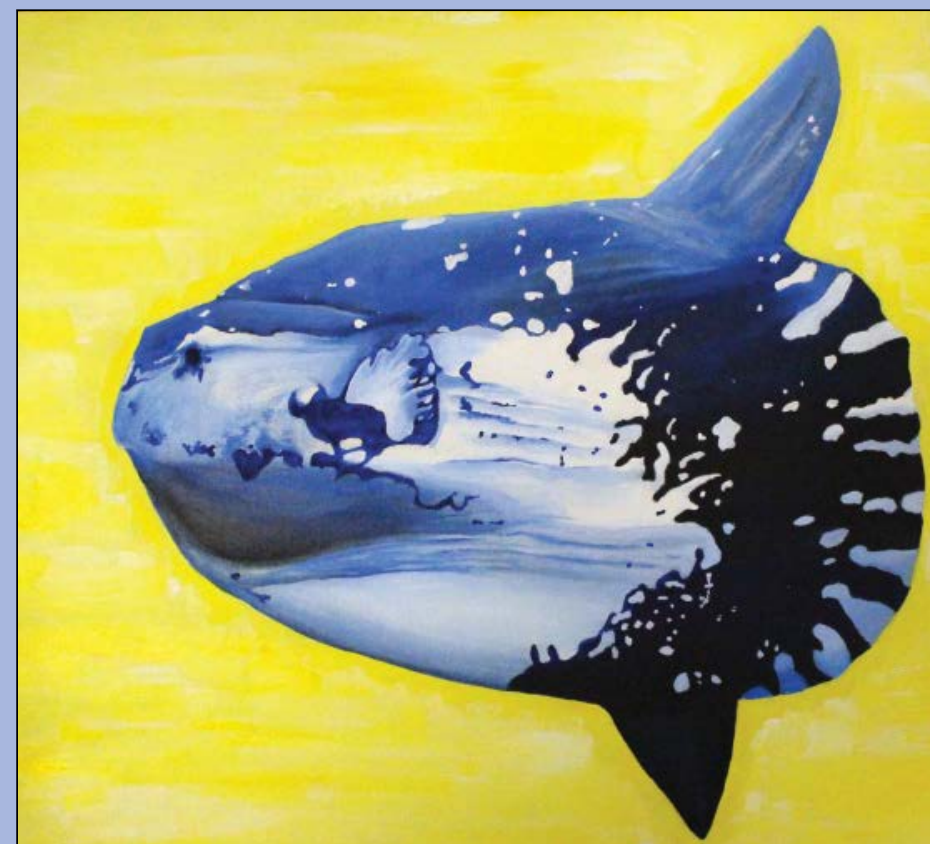

Ocean Sunfish. Third place in the 2017 High School Division. Credit: Paige Meadel, Grade 11, Falmouth High School, Falmouth, Mass.

With no tail and a pancake-shaped body, sunfish may be one of the most curious creatures at Stellwagen. They can span $4 \times 3$ meters, and they like to bask in the Sun's rays by floating on the ocean's surface. The fin from a sunfish can look startlingly similar to that of a shark, leading to false alarms on beaches. These fish like to catch the Sun's rays at Stellwagen in the summer months.

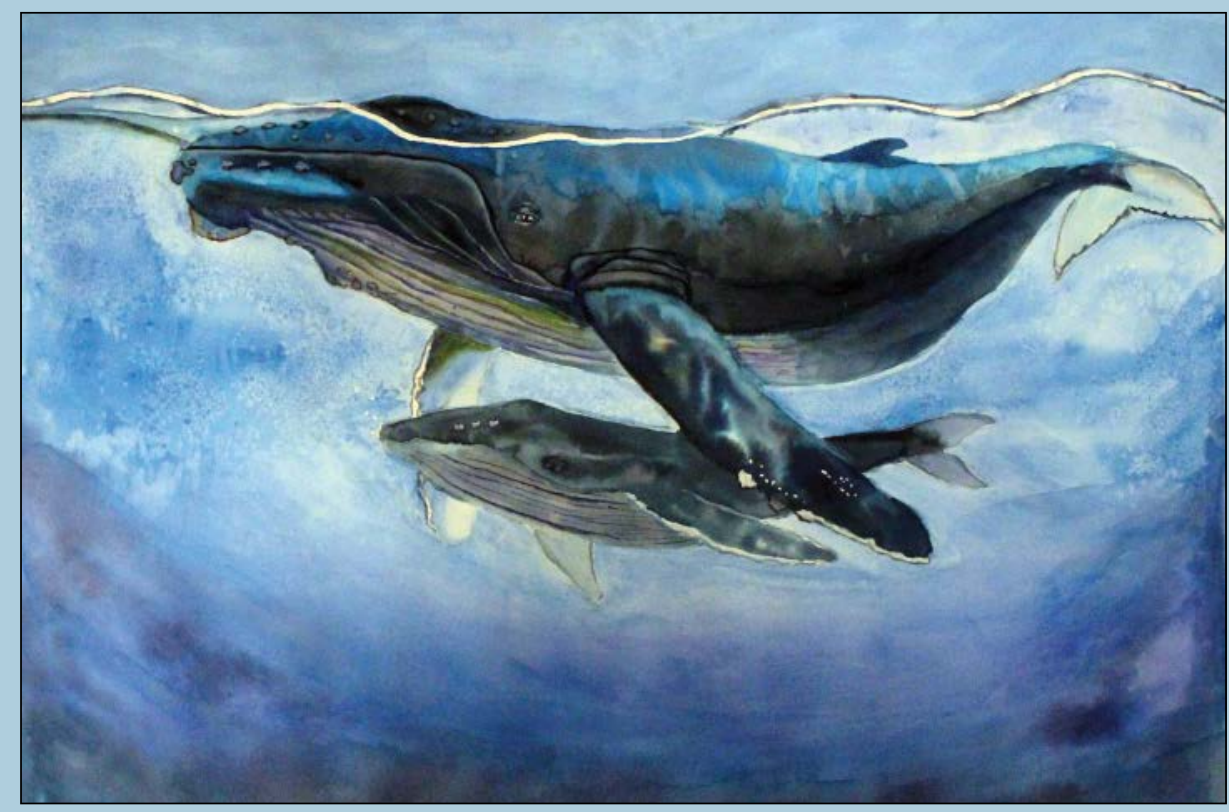

\section{Charismatic Megamama}

We love good charismatic megafauna, especially when they come in twos. Humpback whales, like the mother and calf in this painting, often stay side by side for the first year of the calf's life. A mother can even be seen frequently touching her flipper to her offspring in affection, like in this painting.

Calves eventually go their own way, setting out to find small pods of other whales to wander the ocean beside. Dozens of female humpbacks visit Stellwagen each year, many of which bring a calf in tow. 
International Ocean Discovery Program 1 IODP

CALL FOR APPLICATIONS

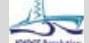

Apply to participate in JOIDES Resolution Expeditions

\section{Amazon Margin Expedition (387)}

26 April to 26 June 2020

Expedition 387 (based on IODP Proposals 859-Full2 \& 859-PRL) will drill the upper portion of the Foz do Amazonas basin of the equatorial margin of Brazil to recover a complete, high-resolution sedimentary sequence spanning nearly the entire Cenozoic. This expedition is the marine complement to the Trans-Amazon Drilling Project transect of continental drill sites, and will address fundamental questions about the Cenozoic climatic evolution of the Amazon region, the origins and evolution of the neotropical rain forest and its incomparable biodiversity, the paleoceanographic history of the western equatorial Atlantic, and the origins of the transcontinental Amazon River. Core and log data from sites on the uppermost continental slope will be used to: (1) generate a continuous record of climate and biodiversity in Cenozoic South America at unprecedented resolution; (2) reconstruct the oceanographic conditions of the western tropical Atlantic; (3) provide critical marine biostratigraphic control for correlation with the Trans-Amazon Drilling Project; (4) determine the onset and history of trans-continental drainage of the proto-Amazon River into the Atlantic; and (5) test major hypotheses about the originations and extinctions of tropical South American biota.

**Apply to Participate by 1 March 2019

\section{Equatorial Atlantic Gateway Expedition (388)}

\section{June to 26 August 2020}

Expedition 388 (based on IODP proposals 864-Full2 \& 864-Add) will study the tectonic, climatic, and biotic evolution of the Equatorial Atlantic Gateway (EAG) at three sites on and near the Pernambuco Plateau (northeastern Brazilian continental shelf). These will target Late Cretaceous-Recent sediments and oceanic crust and are strategically located both near the continental margin and at paleo-water depths that are shallow enough $(<2000 \mathrm{~m})$ to provide well-preserved organic biomarkers and calcareous microfossils for proxy reconstructions of greenhouse climates. Core and log data will address four key themes: (1) the early rift history of the Equatorial Atlantic; (2) the biogeochemistry of the restricted Equatorial Atlantic; (3) the long-term paleoceanography of the EAG; and, (4) the limits of tropical climates and ecosystems under conditions of extreme warmth. This expedition will constrain the long-term interactions between tectonics, oceanography, ocean biogeochemistry and climate, and the functioning of tropical ecosystems and climate during intervals of extreme warmth.

**Apply to Participate by 1 April 2019

For more information about the expedition science objectives and the JOIDES Resolution Expedition Schedule see http://iodp.tamu.edu/scienceops/ - this includes links to the individual expedition web pages with the original IODP proposal and expedition planning information.

WHO SHOULD APPLY: Opportunities exist for researchers (including graduate students) in all shipboard specialties - including but not limited to sedimentology, micropaleontology, paleomagnetics, geochemistry, microbiology, petrology, petrophysics, and borehole geophysics.

WHERE TO APPLY: Applications for participation must be submitted to the appropriate IODP Program Member Office - see http://iodp.tamu.edu/participants/applytosail.html

\section{Eight-Armed Brainiac}

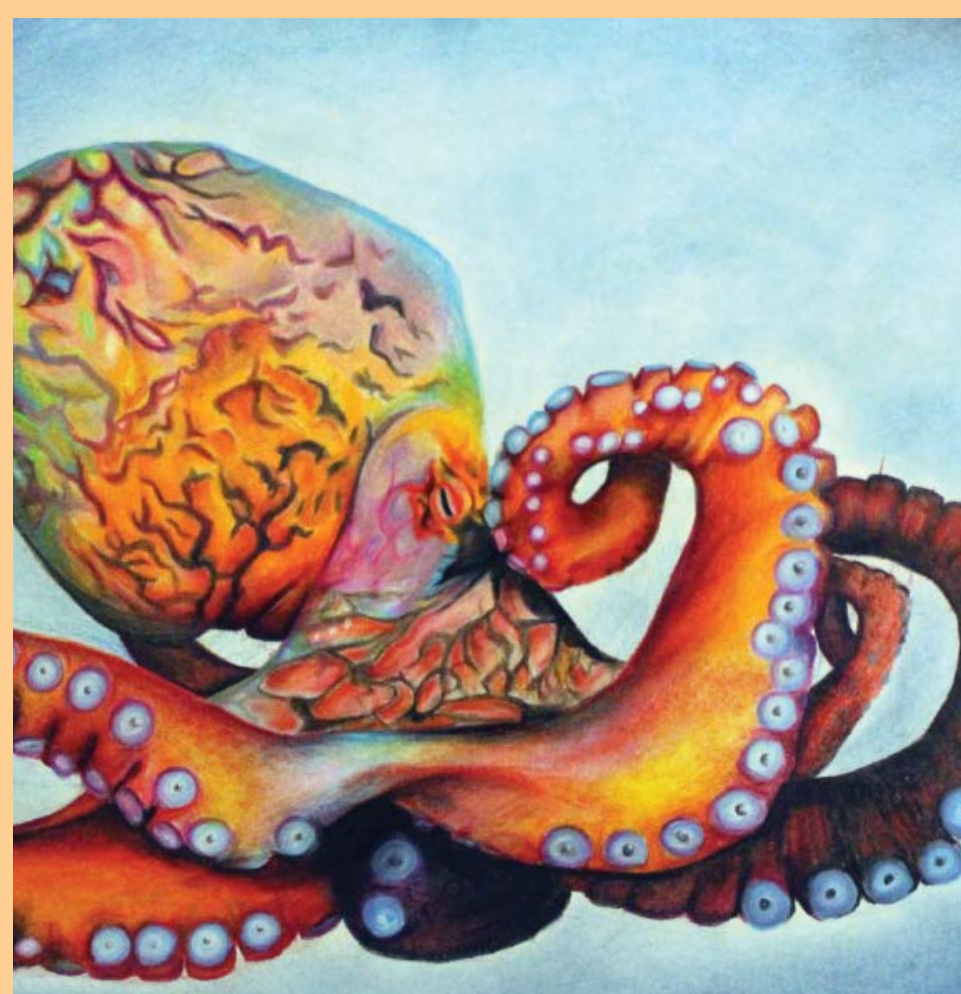

Octopus. Third place in the 2016 High School Division. Credit: Xindi Chang, Grade 10, Huron High School, Ann Arbor, Mich

The common octopus is the most intelligent of invertebrates, and it can do all kinds of tricks to get away from its predators. The octopus can squirt ink, detach arms, and even camouflage itself in its surroundings. When the octopus isn't being sneaky, it's curled up in small holes on the seafloor, where it likes to live out its life in solitude. Discerning eyes may be able to spot one on the seafloor at Stellwagen. 


\section{We support the Future of Science}

AGU connects community leaders with scientists to solve local challenges. Our Thriving Earth Exchange program has helped over 70 communities around the world.

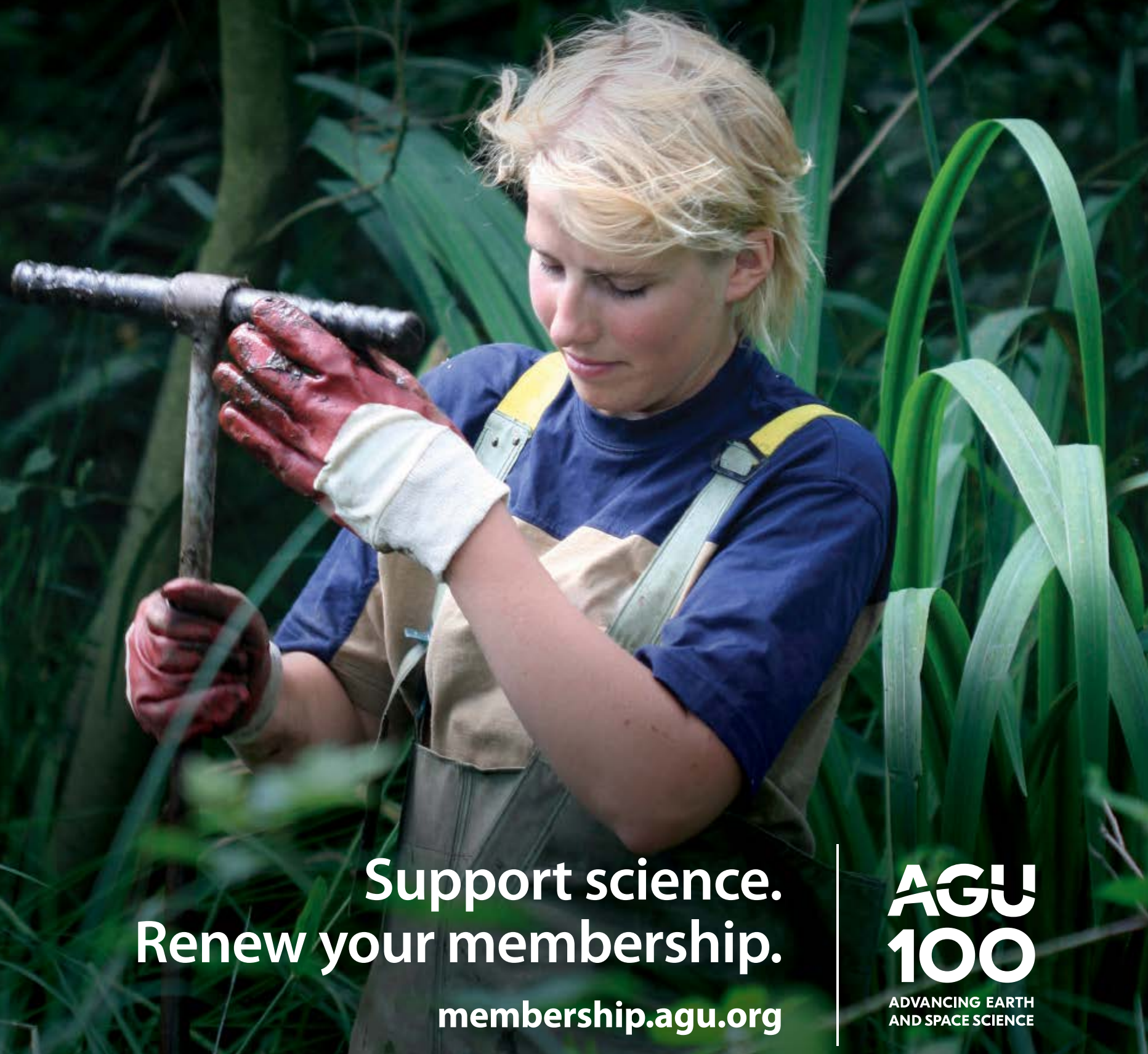




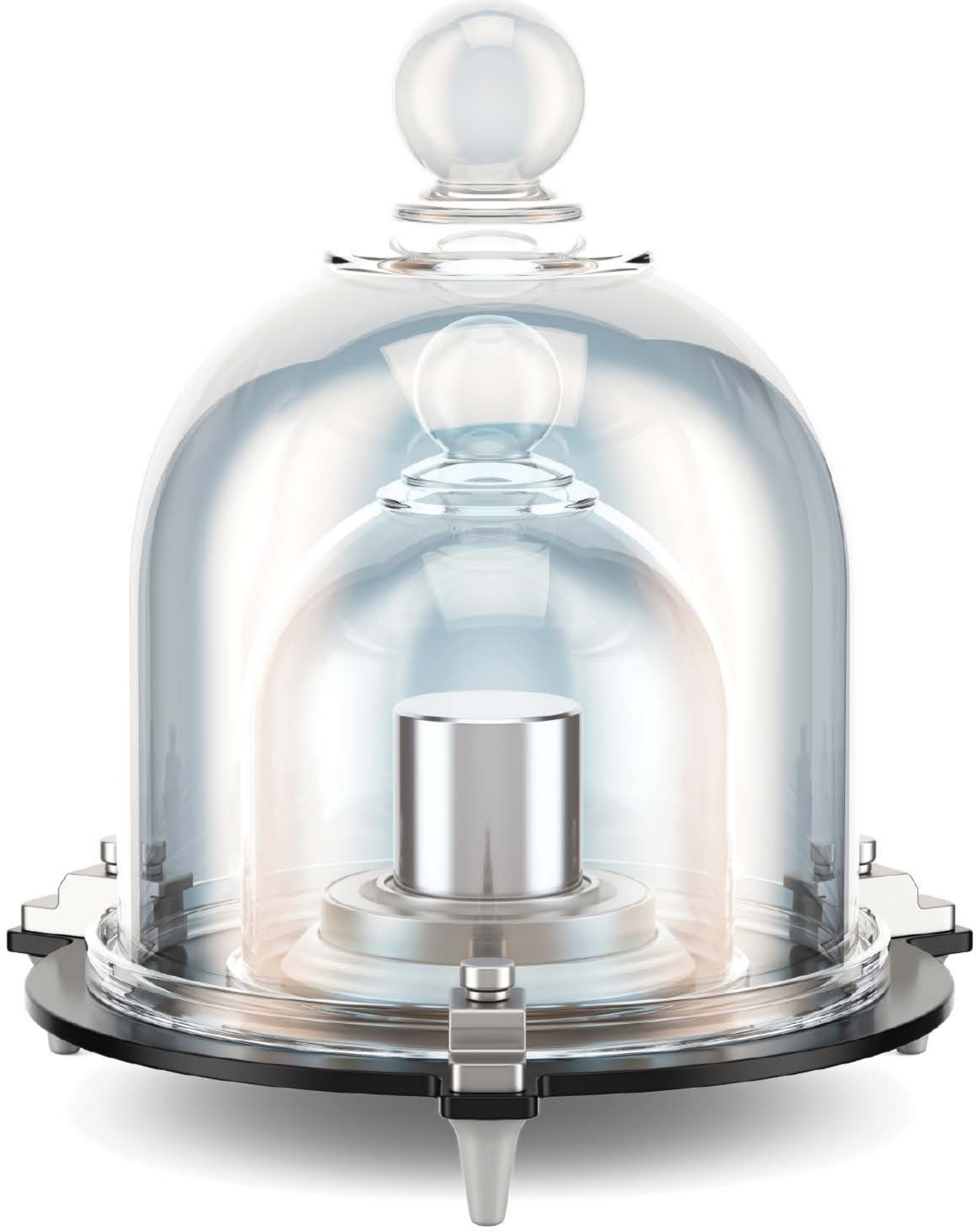




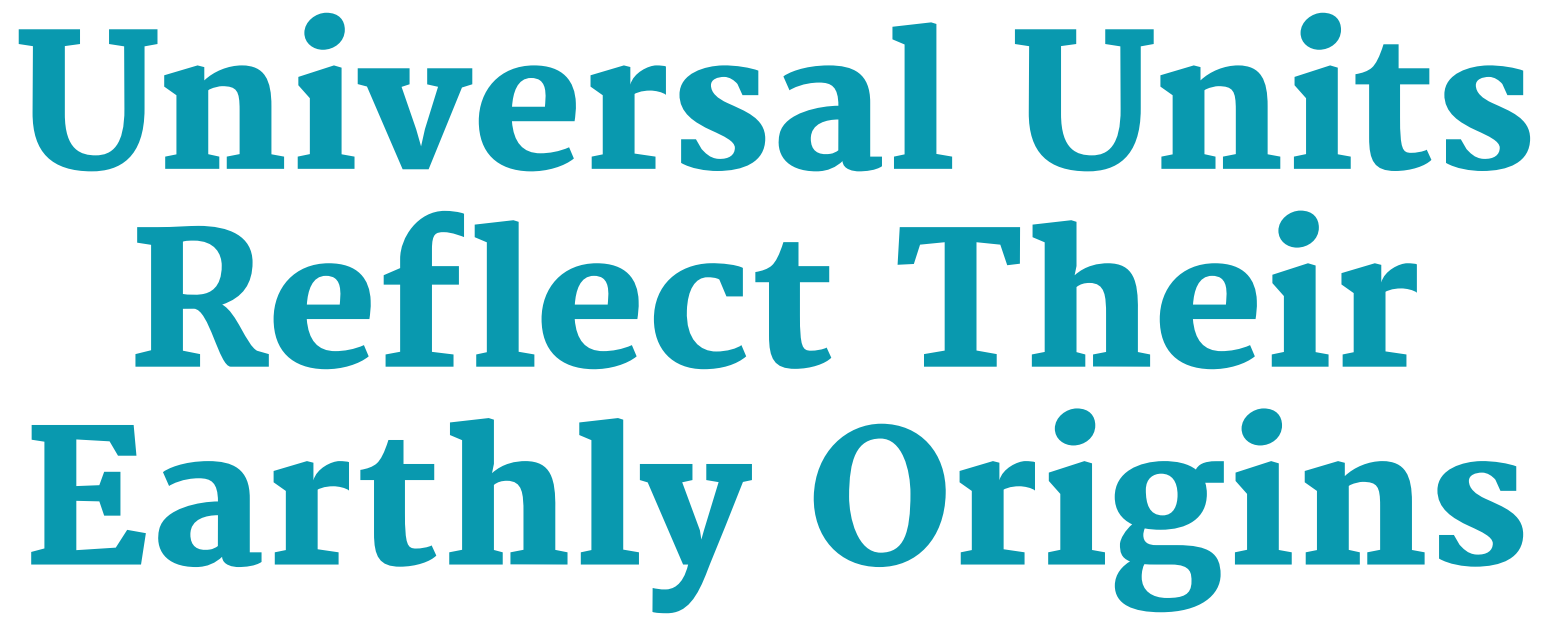

By Michel J. Van Camp, Philippe Richard, and Olivier de Viron

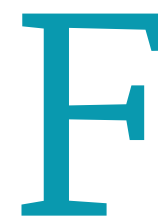

or the past 2 centuries, scientists, surgeons, shipping companies, and shoppers have relied on a common system of measurements: the metric system. The basic units of this system have their origins in Earth's spatial dimensions, timescales, and material masses. As our ability to make measurements became ever more precise, these units were redefined, one by one, in terms of fundamental physical constants rather than material objectsexcept for the kilogram.

This basic unit of mass remained tethered to a 139-yearold metal cylinder about the size of a plum that sits in air under three bell jars in France. But on 16 November 2018, that tie was severed when the kilogram's new physicsbased definition was officially adopted (see bit.ly/SI-units).

Scientists around the world rely on the International System of Units as a common basis on which to record and report their findings. The units used in this system are based on the meter, kilogram, second, kelvin, ampere, mole, and candela. Even though all scientific fields, including the geosciences, use these units every day, many geoscientists may not realize how important Earth's properties were in developing these units and how the new definition maintains its ties to terrestrial dimensions.

The change in definition shows that in an era when units are increasingly defined by the properties of atomic physics, Earth's properties remain important in metrology, the science of measurement.

Measuring the Earth

Earth, which at the time was thought to represent imperishability and stability, was the initial base for the International System of Units (Système International d'Unités;
SI) of length, time, and, indirectly, mass. Geodesy, the science of the shape of the Earth, its orientation in space, and its gravity field, was key in the definition of the metric system during the French Revolution.

In 1791, the French Academy of Sciences defined the meter as $1 / 10,000,000$ the length of a quadrant of Earth's meridian. However, since 1983, the meter has been defined as the length of the path traveled by light in a vacuum during an interval of $1 / 299,792,458$ of a second. Hence, $c$, the speed of light in a vacuum, was fixed to a given value, and the definition of the meter now derives from that of the second.

Translating this concept into practical measurements requires some method that is both precise and repeatable. Several methods compete for the practical realization of the definition of the meter (also called mise en pratique). Today the SI meter is often derived from the wavelength of an iodine-stabilized red helium-neon laser.

The SI unit of time, the second, was originally defined as $1 / 86,400$ of the mean solar day. Subsequently, clocks reached a precision that allowed monitoring irregularities in the Earth's rotation and revolution. In 1967, the General Conference on Weights and Measures (Conférence Générale des Poids et Mesures; CGPM) changed the definition of the second to "the duration of 9,192,631,770 periods of the radiation corresponding to the transition between the two hyperfine levels of the ground state of the cesium-133 atom" [International Bureau of Weights and Measures, 2006].

By this definition, the above frequency (abbreviated in metrology to $\left.\Delta v\left({ }^{133} \mathrm{Cs}\right)_{\mathrm{hfs}}\right)$ is exactly equal to $9,192,631,770$ transitions per second, and the second is defined accordingly. 


\section{The Drifting Kilogram}

In 1799 , the kilogram was defined as the mass of 1 cubic decimeter of water at a temperature of $4^{\circ} \mathrm{C}$. Until last November, this unit was unique in that the standard was based on a manufactured object rather than on a physical constant. The prototype kilogram from 1799 (the "kilogram of the archives") and the present artifact from 1875 (the international prototype kilogram, or IPK) were manufactured to be consistent with this definition. The IPK is a cylinder of 39-millimeter height and diameter, made of $90 \%$ platinum and $10 \%$ iridium. At present, the IPK is kept at the Bureau International des Poids et Mesures in Sèvres, France.

Forty replicas of the IPK were manufactured in 1884, and 34 of them were distributed to the signatories of the Meter Convention. The United States was allocated prototype numbers 4 and 20; Belgium received numbers 28 and 37; and Switzerland got number 38 and, more recently, number 89 . These replicas have been used as national standards ever since.

The kilogram joined the other SI units, and its prototypes became museum items when the kilogram was officially redefined in terms of the Planck constant (see bit.ly/kilogram-redefined). This change in definition was necessary because the use of the IPK, a physical artifact, posed various problems. There was no way to ensure its long-term stability, it could have been destroyed or damaged, and it posed logistical problems when it had to be compared with copies at other national metrology institutes (NMIs).

Comparisons of the mass of the IPK to those of official copies and the national prototypes in 1889, 1948, 1989, and 2014 indicated that the IPK seems to have lost about

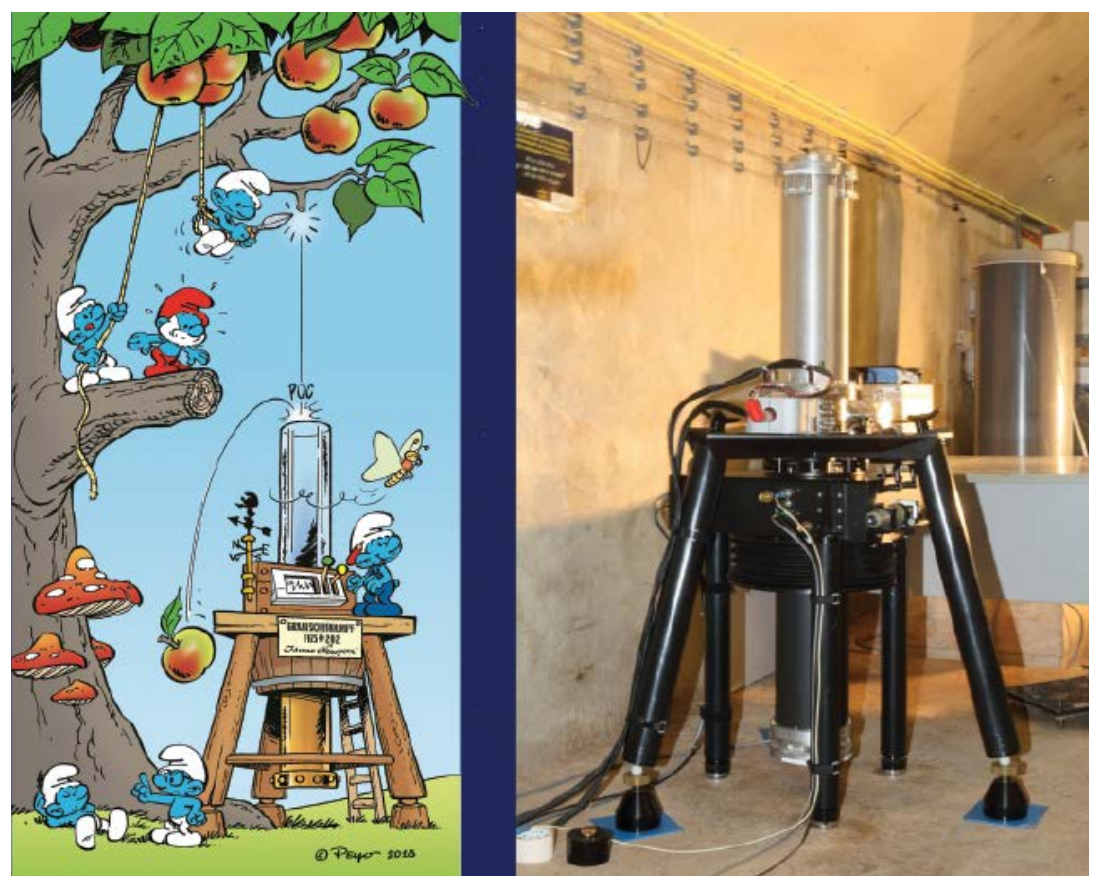

The Smurfs try their hand at measuring gravitational acceleration (left), perhaps inspired by the FG5\#202 absolute gravimeter at the Royal Observatory of Belgium's underground geophysical monitoring station near Membach (right). Credit: ( Peyo - 2018, Lic. Lafig Belgium - www.smurf.com; Kris Vanneste, Royal Observatory of Belgium
50 micrograms over 100 years (five parts in 100 million). It is also possible that all the prototypes show a common mass drift, which cannot be detected by intercomparisons. We thus faced a strange situation: By definition, the mass of the IPK is invariant, but there is no means to check its stability using an absolute reference.

The instability of the IPK propagated to other base units that are tied to the kilogram, such as the candela (luminous intensity), the mole (number of atoms in a mass of material), and the ampere (electric current). It also influenced the derived quantities such as force, density, and pressure. Consequently, for the past 25 years, several NMIs worked to replace the IPK with a definition based on a fundamental constant of nature [Richard et al., 2016].

\section{Based in Physics, Measured in Geodesy}

Although Earth's properties are not stable enough to serve as a basis for the SI, geodesy has not said its last word. The new definitions of the second and the meter, previously derived from geodesy, now rely on laboratory physics experiments. The new definitions, however, must be consistent with the previous ones and are thus still related to Earth's shape and motion.

On 16 November 2018, the 26th CGPM (see bit.ly/CGPM -26) ratified the revised SI based on seven constants: the frequency of the ground state hyperfine splitting of the cesium-133 atom $\Delta v\left({ }^{133} \mathrm{Cs}\right)_{\mathrm{hfs}}$, the speed of light in a vacuum $c$, Planck's constant $h$, the elementary charge $e$, Boltzmann's constant $k$, Avogadro's constant $N_{\mathrm{A}}$, and the luminous efficacy $K_{\mathrm{cd}}$. These constants exist independent of our ability to measure them, and thus, the definition and practical realization of the units will be decoupled.

In short, this means that the practical derivations of mass can be established and replicated by different experiments with everincreasing accuracy, while the definitions remain unchanged.

Henceforth, the magnitude of the kilogram $(\mathrm{kg})$, the unit of mass, will be derived from the value of Planck's constant ( $h=6.62607015 \times 10^{-34}$ jouleseconds; see Fischer and Ullrich [2016]), used in Einstein's energy formula $E=m c^{2}=h v$. Because a joule is a kilogram meter squared per second squared $\left(\mathrm{kg} \mathrm{m}^{2} / \mathrm{s}^{2}\right)$, the kilogram standard will now rely on SI units of length and time, which were already previously standardized.

\section{A New Balance}

Just how do we derive the kilogram from those known quantities?

After the redefinition, a first route to standardizing the kilogram consists of counting the number of atoms in a silicon-28 


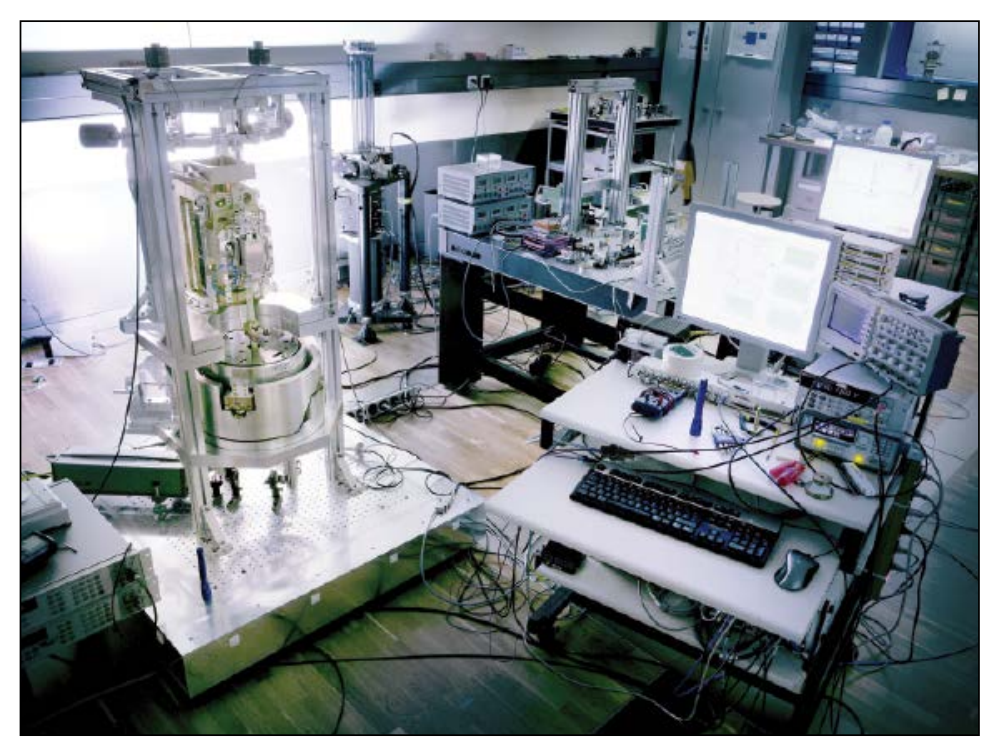

The new definition of the kilogram lends itself to measurements using a Kibble balance (at left) and an absolute gravimeter (in the background, with the black tripod and the transparent, cylindric dropping chamber), like these instruments at the Federal Institute of Metrology (METAS) in Switzerland. Credit: André Roth, Roth und Schmid Fotografie for Mettler Toledo

cal value of $h$ is such that at the time the definition was adopted, the redefined kilogram was equal to the mass of the IPK within the uncertainty of the combined best estimates of the value of Planck's constant. The same holds true for $c$ and $\Delta v\left({ }^{133} \mathrm{Cs}\right)_{\mathrm{hfs}}$, which, like $h$, remain historically related to the Earth's dimension and rotation.

The accurate gravity measurements required to determine the kilogram using the Kibble balance would not have been possible without research to measure and monitor gravitational acceleration and to understand its variations in time and space [Van Camp et al., 2017]. Geoscientists have worked on this problem since Galileo Galilei investigated the motion of falling masses in the 16th century and showed that acceleration due to Earth's gravitational field is the same for all masses (and thus cannot be used to define any specific mass, including the kilogram).

However, using the Kibble balance method requires dropping objects, not to measure their mass but to determine an

$\left({ }^{28} \mathrm{Si}\right)$ single-crystal sphere using the $\mathrm{X}$-ray crystal density approach. This is also known as the Avogadro experiment because it was originally used to yield an accurate value for Avogadro's constant, the number of carbon-12 atoms that amass to exactly 12 grams. (Avogadro's number of hydrogen atoms, the lightest element, would weigh 1 gram, but carbon is much easier to weigh than hydrogen.)

Another route to the kilogram is based on the Kibble balance [Robinson and Schlamminger, 2016]. In this scheme, the mechanical power of a mass in a gravitational field is balanced by the electrical power of the balance. The kilogram depends on Planck's constant, which appears in the quantum phenomena used to determine the balance's current and voltage.

Knowing the current, voltage, length, and time to measure the velocity of the coil moving within a magnetic field and the local acceleration of gravity, one defines the mass as the amount of matter required to balance a given amount of electrical power. To allow this derivation of the kilogram, the gravity acceleration must be determined at the $10^{-8}$ level by absolute gravimetry, tracking the free fall of an object or cold atoms repeatedly dropped inside a vacuum chamber [Van Camp et al., 2017].

From the Conceptual to the Practical

Since 1967, geodetic metrology is no longer required for the definition of the meter and the second. However, gravity will still be key in the new realization of the kilogram. A measurement of Avogadro's constant could be converted to a measurement of Planck's constant $h$ (and vice versa) through Rydberg's constant, which links the atomic and macroscopic properties of matter.

The new constants are not completely divorced from their historical ties. The number chosen for the numeri- accurate value for gravitational acceleration. Thus, monitoring the free fall of an object or cold atoms, as achieved in absolute gravimeters, is still a fundamental tool in geosciences and metrology.

Since last November, our meters, kilograms, and seconds are now defined by the motions and energy of electrons, atoms, and photons. However, the benchmarks by which we bring these definitions into everyday use remain rooted in measurements derived from our home planet.

\section{Acknowledgments}

This article is dedicated to the memory of Jean O. Dickey, a geodesist at NASA's Jet Propulsion Laboratory, who passed away in May 2018. She measured gravity using satellite data, and she was a great fan of the Smurfs. The authors thank Miguel Diaz Vizoso and IMPS for the beautiful cartoon.

\section{References}

Fischer, J., and J. Ullrich (2016), The new system of units, Nat. Phys., 12(1), 4-7, https://doi .org/10.1038/nphys3612

International Bureau of Weights and Measures (2006), Unit of time (second), in SI Brochure: The International System of Units (SI), 8th ed., sect. 2.1.1.3, Sèvres, France, www .bipm.org/en/publications/si-brochure/second.html. [Updated in 2014.]

Richard, P., H. Fang, and R. Davis (2016), Foundation for the redefinition of the kilogram, Metrologia, 53(5), A6-A11, https://doi.org/10.1088/0026-1394/53/5/A6.

Robinson, I. A., and S. Schlamminger (2016), The watt or Kibble balance: A technique for implementing the new SI definition of the unit of mass, Metrologia, 53(5), A46-A74, https://doi.org/10.1088/0026-1394/53/5/A46

Van Camp, M., et al. (2017), Geophysics from terrestrial time-variable gravity measurements, Rev. Geophys., 55(4), 938-992, https://doi.org/10.1002/2017RG000566.

\section{Author Information}

Michel J. Van Camp (mvc@oma.be), Seismology-Gravimetry, Royal Observatory of Belgium, Uccle; Philippe Richard, Consultative Committee for Mass and Related Quantities, Federal Institute of Metrology (METAS), Berne-Wabern, Switzerland; and Olivier de Viron, Littoral Environnement et Sociétés (LIENSsUMR 7266), Université de La Rochelle and Centre National de la Recherche Scientifique, La Rochelle, France 
By Valentin Aich, Robert Holzworth, Steven J. Goodman, Yuriy Kuleshov, Colin Price, and Earle Williams

\section{Lightning is a symptom and a cause of climate change. A task team is working to make lightning data available and useful for climate science and service applications.}

$\mathrm{t}$ starts with the gathering of clouds into a storm. In the center of the growing storm, tiny flecks of ice and supercooled water droplets collide and exchange charge, with positive charge billowing into the storm's spreading anvil. The flow of particles creates an imbalance; the system needs to neutralize. Finally, with a zap having more power than 100,000 radio stations, all concentrated at a single point, lightning strikes.

Today private and public services monitor lightning to track the locations of individual strokes and to generate warnings of severe storms and heavy precipitation [Nag et al., 2015]. Knowing where lightning strikes is important: Lightning causes many fatalities and injuries worldwide every year [Holle, 2015]. It also ignites forest fires, damages electrical infrastructure, and causes numerous 


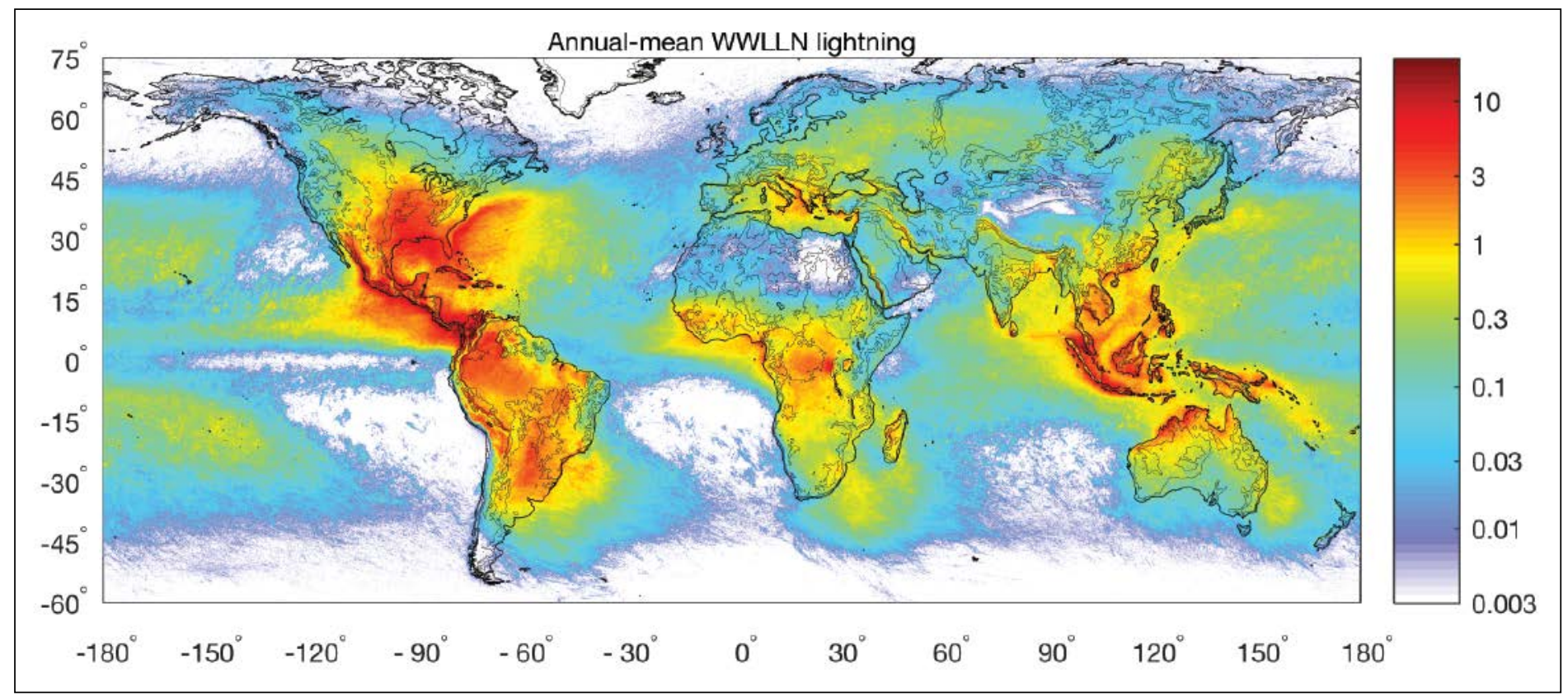

other forms of loss and damage (see, e.g., National Lightning Safety Institute [2014] for data pertaining to the United States), and the storms that come with the lightning cause even more damage.

But scientists are starting to recognize that lightning has a broader story to tell. Lightning frequency is changing as climate is changing. For example, lightning's close relationship to thunderstorms and precipitation makes it a valuable indicator for storminess, which makes lightning a particularly useful means of observing a variable and changing climate [Price, 2013; Williams, 2005].

What's more, lightning is not only an indicator of climate change; it also affects the global climate directly. Lightning produces nitrogen oxides, which are strong greenhouse gases [Price et al., 1997].

In recent years, measurements of lightning have become more extensive, and new satellite instruments have further enhanced measurement coverage [Albrecht et al., 2016; Goodman et al., 2013; Yang et al., 2017]. However, the monitoring of lightning for climate science and services is still limited on a global scale.

To overcome this gap and explore the opportunities and challenges of lightning observations for climate, the scientists involved with the Global Climate Observing System (GCOS) - a group that seeks to ensure that data necessary for climate studies are made available to the public - together with the Commission for Climatology (CCl) of the World Meteorological Organization (WMO), established a Task Team for Lightning Observations for Climate Applications (TTLOCA; bit.ly/TTLOCA-lightning) in October 2017.
Number of lightning strokes accumulated for the years 2008-2017, presented as strokes per year per square kilometer on a $0.1^{\circ} \times 0.1^{\circ} \mathrm{global}$ grid. Data are from the World Wide Lightning Location Network, and the map is an upgrade of the $0.25^{\circ} \times 0.25^{\circ} \mathrm{global}$ climatology published by Virts et al. [2013].

\section{Lightning: An Essential Climate Variable}

About 45 flashes of lightning occur every second at any given time on planet Earth [Christian et al., 2003]. However, this rate can vary by as much as $10 \%-20 \%$ across a spectrum of timescales, from seasonal to interannual [Albrecht et al., 2016; Cecil et al., 2014; Markson, 2007; Price, 1993; Williams, 1994].

In efforts to better understand how these variabilities, as well as changing lightning frequencies, affect climate change, lightning has been added to the GCOS's list of Essential Climate Variables (ECVs; bit .ly/ECV-variables) [Global Climate Observing System, 2016]. These ECVs provide the empirical evidence needed to understand and predict the evolution of climate as well as to guide mitigation and adaptation measures in support of scientists, governments, agencies, and the international climate policy in general under the United Nations Framework Convention on Climate Change (UNFCCC) and its Intergovernmental Panel on Climate Change [Bojinski et al., 2014].

\section{Goals of the Task Team}

GCOS is the dedicated body of UNFCCC for coordinating global climate observations [World Meteorological Organization (WMO), 1998]. It is cosponsored by WMO; the 
United Nations Educational, Scientific and Cultural Organization; the United Nations Environment Programme; and the International Council for Science.

The role of WMO's CCl is to "stimulate, lead, implement, assess and coordinate international technical activities to obtain and apply climate information in support of sustainable socio-economic development and environmental protection" [Commission for Climatology, 2011].

To support this mission, the new lightning task team has taken on several specific issues. The team plans to do the following:

- explore potential climate applications for lightning observations and identify related challenges

- review current requirements for lightning observations in the GCOS implementation plan in the light of potential climate applications

- define data management and metadata standards that ensure that lightning data can be reprocessed in the future and ensure that changes in observation or processing techniques are fully documented

- develop a strategy for open data access for lightning data in climate applications, including providing access to data from the private sector

- encourage space agencies and operators of groundbased systems to provide global coverage and reprocessing of existing data sets

- review current data storage facilities and explore the options of a global data center for lightning data for climate applications

The team's goal of reviewing requirements for lightning observation efforts, to ensure the quality and consistency of the data, is of particular importance. Satellite agencies have adopted WMO's observation requirements for individual ECVs and have included these requirements in their planning for current and future missions. The GCOS implementation plan includes a first attempt to set these requirements for lightning, but the task team will review these requirements.

\section{Next Steps}

The task team, which was established for an initial period of 1 year, consists of international experts from science and operational weather and climate services. Over the past year, we have almost completed our initial tasks (see bit.ly/TTLOCA-1), and we have prepared recommendations on the team's goals, including an initial set of specific requirements for lightning observations from a climate perspective. We are currently finalizing these draft guidelines, which will be presented to WMO for inclusion in its international standards. The guidelines will be published by WMO and will be available soon in WMO's online library.

We are seeking all relevant data sets to address climate questions using information about lightning. We also seek proxy lightning data sets. For instance, we started an initiative to extend lightning data into the distant past using "thunder day" data [WMO, 1953]. Identifying these and related data sets with regional or global coverage is important for the task team.

The task team has also started to address the detailed questions of who will archive these data and who should be offered access. Some of the data are naturally in the public domain, but most of the ground-based lightning network data are privately owned and copyrighted.

We encourage the community to provide comments on any of the goals listed above. These comments can be submitted to Valentin Aich (vaich@wmo.int).

\section{References}

Albrecht, R. I., et al. (2016), Where are the lightning hotspots on Earth?, Bull. Am. Meteorol. Soc., 97, 2,051-2,068, https://doi.org/10.1175/BAMS-D-14-00193.1.

Bojinski, S., et al. (2014), The concept of essential climate variables in support of climate research, applications, and policy, Bull. Am. Meteorol. Soc., 95, 1,431-1,443, https://doi .org/10.1175/BAMS-D-13-00047.1.

Cecil, D. J., D. E. Buechler, and R. J. Blakeslee (2014), Gridded lightning climatology from TRMM-LIS and OTD: Dataset description, Atmos. Res., 135-136, 404-414, https://do .org/10.1016/j.atmosres.2012.06.028.

Christian, H. J., et al. (2003), Global frequency and distribution of lightning as observed from space by the Optical Transient Detector, J. Geophys. Res., 108(D1), 4005, https:// doi.org/10.1029/2002JD002347.

Commission for Climatology (2011), Commission for Climatology: Over eighty years of service, WMO Publ. 1079, 59 pp., World Meteorol. Organ., Geneva, Switzerland, www .wmo.int/pages/prog/wcp/ccl/documents/WM01079_web.pdf.

Global Climate Observing System (2016), The global observing system for climate: Implementation needs, Tech. Rep. 200, World Meteorol. Organ., Geneva, Switzerland, https:// doi.org/10.13140/RG.2.2.23178.26566

Goodman, S. J., et al. (2013), The GOES-R Geostationary Lightning Mapper (GLM), Atmos. Res., 125-126, 34-49, https://doi.org/10.1016/j.atmosres.2013.01.006.

Holle, R. L. (2008), Annual rates of lightning fatalities by country, paper presented at the 20th International Lightning Detection Conference, Tucson, Ariz., 21-23 April, www .researchgate.net/publication/267855823_Annual_rates_of_lightning_fatalities_by country.

Markson, R. (2007), The global circuit intensity: Its measurement and variation over the last 50 years, Bull. Am. Meteorol. Soc., 88, 223-241, https://doi.org/10.1175/BAMS-88 $-2-223$.

Nag, A., et al. (2015), Lightning locating systems: Insights on characteristics and validation techniques, Earth Space Sci., 2(4), 65-93, https://doi.org/10.1002/2014EA000051. National Lightning Safety Institute (2014), Lightning costs and losses from attributed sources, Louisville, Colo., www.lightningsafety.com/nlsi_lls/nlsi_annual_usa_losses.htm. Price, C. (1993), Global surface temperatures and the atmospheric electrical circuit, Geophys. Res. Lett., 20(13), 1,363-1,366, https://doi.org/10.1029/93GL01774.

Price, C. (2013), Lightning applications in weather and climate research, Surv. Geophys., 34(6), 755-767, https://doi.org/10.1007/s10712-012-9218-7.

Price, C., J. Penner, and M. Prather (1997), NO from lightning: 2. Constraints from the global atmospheric electric circuit, J. Geophys. Res., 102(D5), 5,943-5,951, https://doi .org/10.1029/96JD02551.

Virts, K. S., et al. (2013), Highlights of a new ground-based, hourly global lightning climatology, Bull. Am. Meteorol. Soc., 94, 1,381-1,391, https://doi.org/10.1175/BAMS-D-12 -00082.1 .

Williams, E. R. (1994), Global circuit response to seasonal variations in global surface air temperature, Mon. Weather Rev., 122(8), 1,917-1,929, https://doi.org/10.1175/1520-0493 (1994)122<1917:GCRTSV>2.0.C0;2.

Williams, E. R. (2005), Lightning and climate: A review, Atmos. Res., 76(1-4), 272-287, https://doi.org/10.1016/j.atmosres.2004.11.014.

World Meteorological Organization (WMO) (1953), World distribution of thunderstorm days, WMO Rep. 21, 204 pp., Geneva, Switzerland, library.wmo.int/opac/index.php?|v| =notice_display\&id=5343.

World Meteorological Organization (WMO) (1998), Memorandum of understanding between the World Meteorological Organization, the Intergovernmental Oceanographic Commission of the United Nations Educational, Scientific and Cultural Organization, the United Nations Environment Programme and the International Council for Science, 8 pp., Geneva, Switzerland, library.wmo.int/opac/doc_num.php?explnum_id=3593.

Yang, J., et al. (2017), Introducing the new generation of Chinese geostationary weather satellites, Fengyun-4, Bull. Am. Meteorol. Soc., 98, 1,637-1,658, https://doi.org/10 .1175/BAMS-D-16-0065.1.

\section{Author Information}

Valentin Aich (vaich@wmo.int), Global Climate Observing System, World Meteorological Organization, Geneva, Switzerland; Robert Holzworth, Department of Earth and Space Sciences, University of Washington, Seattle; Steven J. Goodman, National Environmental Satellite, Data, and Information Service, National Oceanic and Atmospheric Administration, Greenbelt, Md., retired; Yuriy Kuleshov, Bureau of Meteorology and the Royal Melbourne Institute of Technology (RMIT) University, Melbourne, Vic., Australia; Colin Price, Tel Aviv University, Tel Aviv, Israel; and Earle Williams, Massachusetts Institute of Technology, Cambridge 


\section{$x=-7$}


remote location have allowed this kingdom to preserve its unique culture, these factors have also limited the development of international collaborations there, notably in the Earth sciences. This situation changed in 2009 after a damaging M6.1 earthquake that claimed 11 lives persuaded Bhutan to open its doors to exploration of the region's geophysics.

Our team studied mountain-building processes in this region after the 2009 earthquake. After 7 years of multipronged field campaigns, we learned that Bhutan's geodynamics are as unique as its culture. The region's crustal structure, seismicity, and deformation pattern are all different from what scientists had speculated previously.

During our campaigns, we found evidence that at least one $M 8$ earthquake had, in fact, occurred in Bhutan. This means that other earthquakes of this magnitude could occur in the region again [Hetényi et al., 2016b; Berthet et al., 2014; Le Roux-Mallouf et al., 2016].

\section{A Different Plate?}

Although the western and central Himalayan arc curves gently from Pakistan to Sikkim and has a low-lying foreland, the eastern third curves more sharply and has significant topographical relief south of the mountain belt, namely, the Shillong Plateau and neighboring hills (Figure 1). Previous studies proposed that these structures accommodate part of the India-Eurasia tectonic plate convergence. These earlier studies also proposed that the great 1897 Assam earthquake (M8.1) had relieved some of the strain between these converging tectonic plates, thereby lowering earthquake hazard in Bhutan.

We collected new gravity, geodetic, and seismology data, and we found that the lithosphere-the rigid top layer of Earth - beneath Bhutan and the Shillong Plateau is most likely not part of the Indian plate or, if it once was, that it is now detached from it. The demarcation between plates stretches in a NW-SE direction, without a surface trace, but it is evident in a middle to lower crustal zone of continuously active seismicity and dextral (rightlateral) motion [Diehl et al., 2017]. This fault zone most likely hosted an M7 earthquake in 1930.

Our GPS measurements confirm the relative motion of the newly defined microplate. These measurements also show that this microplate is rotating clockwise with respect to the Indian plate [Vernant et al., 2014]. The different behaviors of the two lithospheres are clearly expressed in their differences in flexural stiffness along the strike direction of the orogen (mountain belt). The flexural stiffness beneath Nepal is homogeneous [Berthet et al., 2013] but is comparatively weaker beneath Bhutan [Hammer et al., 2013].

A similar, but less well defined, deep seismicity zone, with distinct GPS vectors and flexural signatures, may mark another terrain boundary farther east along the Himalayas in Arunachal Pradesh [Hetényi et al., 2016a].

Fig. 1. Topographic map of the 2,500-kilometer-long Himalayan arc and surrounding region, with formerly (yellow) and newly (pink) cataloged seismicity. The dextral fault zone (white arrows) between Sikkim and the Shillong Plateau marks the break of the India plate, east of which a zone of complex 3-D deformation begins. Red dates mark the three largest earthquakes mentioned in the text. Green lines mark the surface trace of the megathrust along which the India plate underthrusts the Himalayan orogen, as well as the thrust faults bounding the Shillong Plateau. Political boundaries are shown for reference. Abbreviations are Pl., plateau; Pr., Pradesh; and Sik., Sikkim.

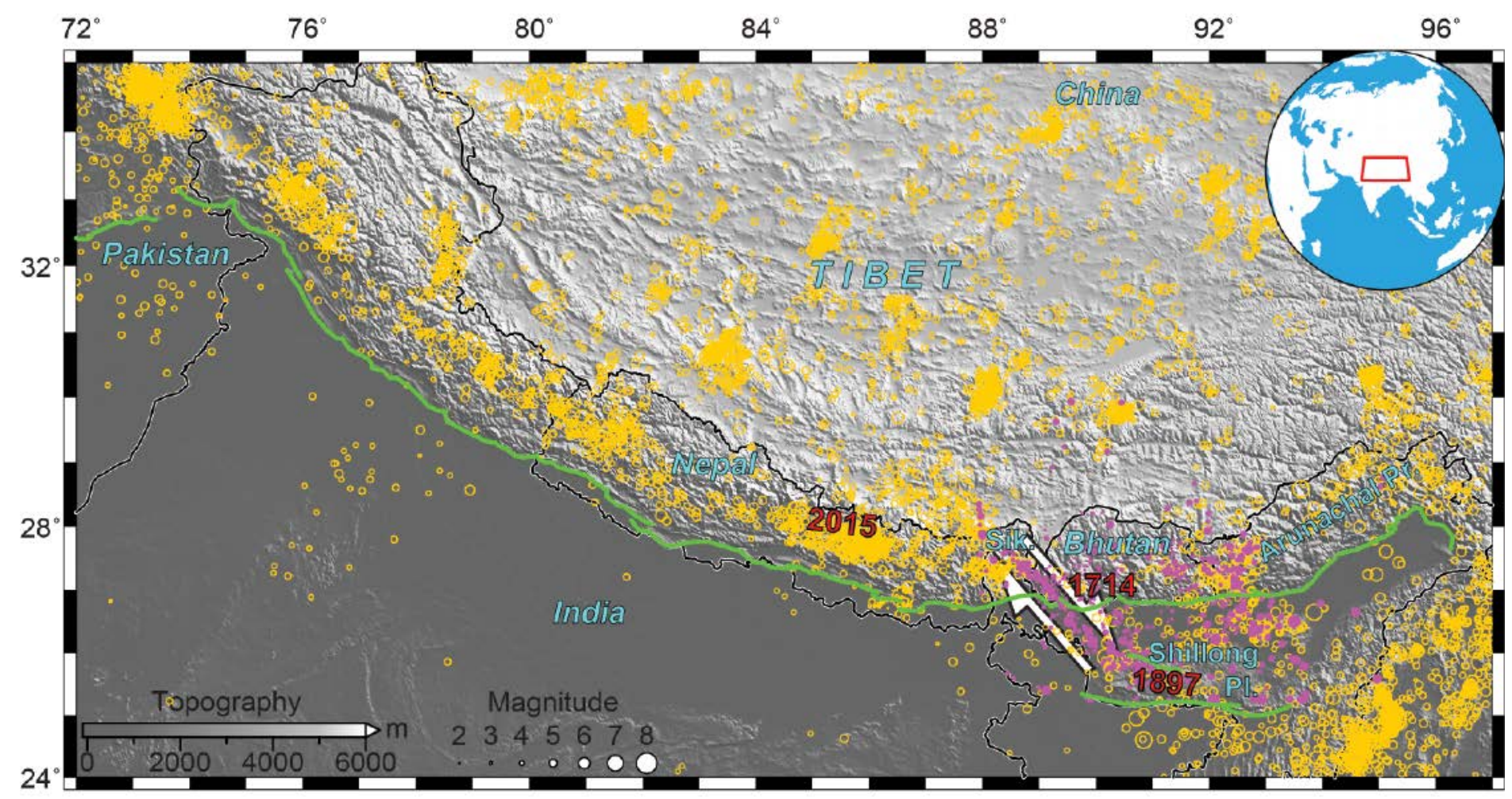




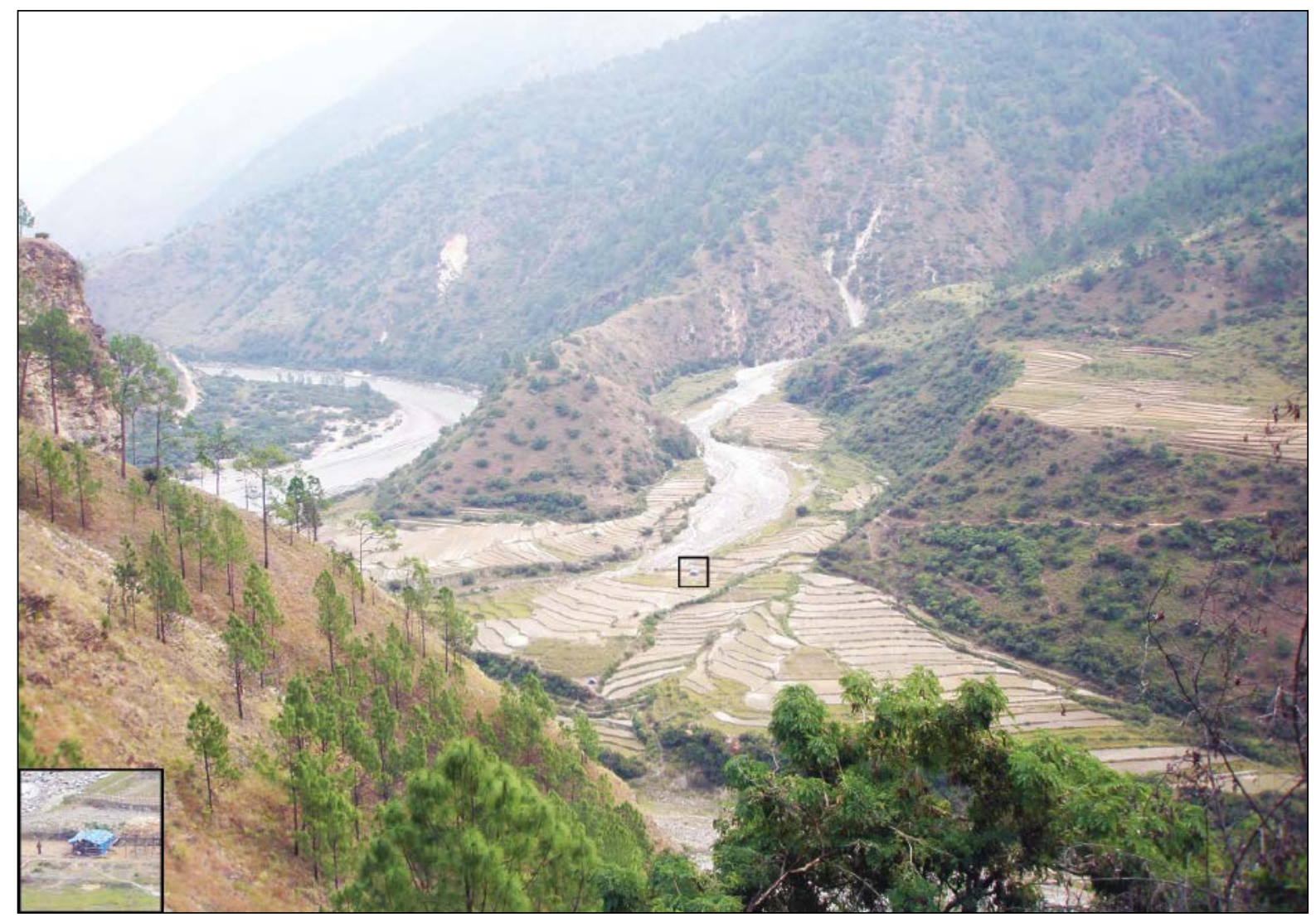

The landscape in eastern Bhutan, south of Trashigang, typically features incised valleys, steep slopes, and terraces. The hut in the center is shown in the inset for scale. The view here is to the east, and the hut is located at $27.2784^{\circ} \mathrm{N}, 91.4478^{\circ} \mathrm{E}$. Credit: György Hetényi

\section{Not a Safe Haven}

India's 1897 Assam earthquake, which occurred farther south, is only a few human generations in the past and has not completely faded from memory. No event since then has reached magnitude 7 in Bhutan, and many of the local population believe that big earthquakes cannot happen there.

However, the return period of large Himalayan events is longer than oral history: Western Nepal, for example, has not experienced a significant event since 1505 . It is true that over the past decades, the seismicity rate in Bhutan has been low, but we have found evidence of several great earthquakes in the past on the local megathrust.

Geomorphological analysis of uplifted river terraces in central Bhutan revealed two major events over the past millennium [Berthet et al., 2014]. A newly excavated paleoseismological trench has documented surface rupture during a medieval event and a 17th- to 18 th-century event [Le Roux-Mallouf et al., 2016]. Calculations based on newly translated historical eyewitness reports, macroseismic information, and reassessed damage reports have constrained a M8 \pm 0.5 earthquake on 4 May 1714 [Hetényi et al., 2016b].

Thus, the seismic gap proved to be an information gap: The entire length of the Himalayas can generate earthquakes with a magnitude greater than 7.5, and it has done so in the past 500 years.
Differences at Multiple Scales

The major change along the Himalayas occurs between their central western part (with a single convergence zone) and the eastern third (with distributed deformation including strike-slip motion), and the east-west extent of Bhutan exhibits even greater complexity. The crust appears to be smoothly descending in western Bhutan

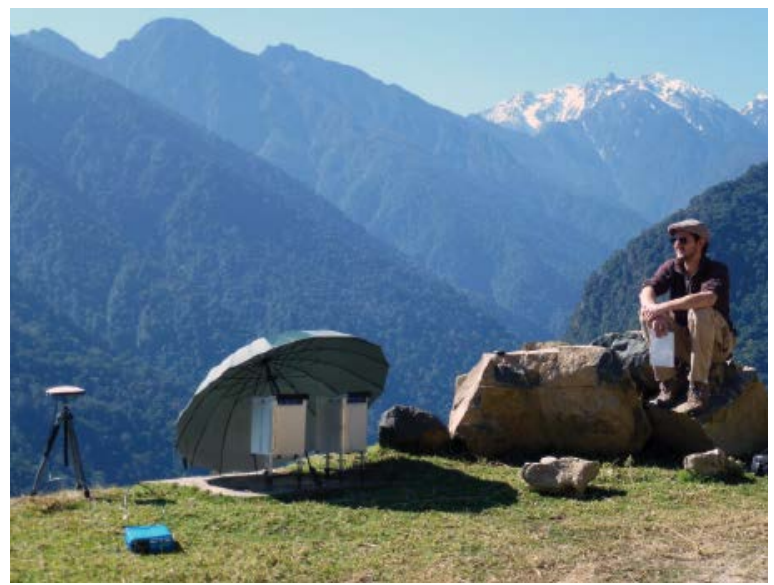

Research team member Théo Berthet monitors data collection during a campaign to a less visited region in central Bhutan. The Black Mountains, which rise to 4,500-4,600 meters, are visible in the background. Credit: György Hetényi 
and is subhorizontal in the eastern part of the country [Singer et al., 2017a]. Our measurements of seismic wave speeds in the upper crust show important changes across the country, and they coincide well with the geological structure mapped at the surface [Singer et al., 2017b] .

The most striking difference between western and eastern Bhutan is the crustal deformation pattern. In the west, the accommodation of present-day crustal shortening is very similar to the rest of the Himalayas: The plates in the megathrust region are fully locked [Vernant et al., 2014], and microseismicity (the occurrence of small events) is scattered across the crust [Diehl et al., 2017]. In the east, the locked segment of the megathrust is shorter, and it focuses most of the microseismic activity within a smaller region. Also, the fault appears to be creeping (sliding without producing significant seismicity) in both shallower and deeper segments [Marechal et al., 2016].

This variation of loading and background seismicity warrants further research along the entire Himalayan orogen because there is very little existing insight into variations of structures and processes at such short distance scales.

\section{Bhutan Is Moving Forward}

Bhutan is an exotic place that has self-imposed isolation for a long time, but the country's technology is now catching up at a rate that is higher than for the rest of the Himalayan regions. During our 2010 campaign, we used paper traveler's checks, and we lacked individual cell phones. During our 2017 campaign, we had access to ATMs and 3G Internet.

Likewise, our 7 years of field campaigns in this region have advanced our geophysical exploration and geodynamic understanding considerably. Still, there is a strong

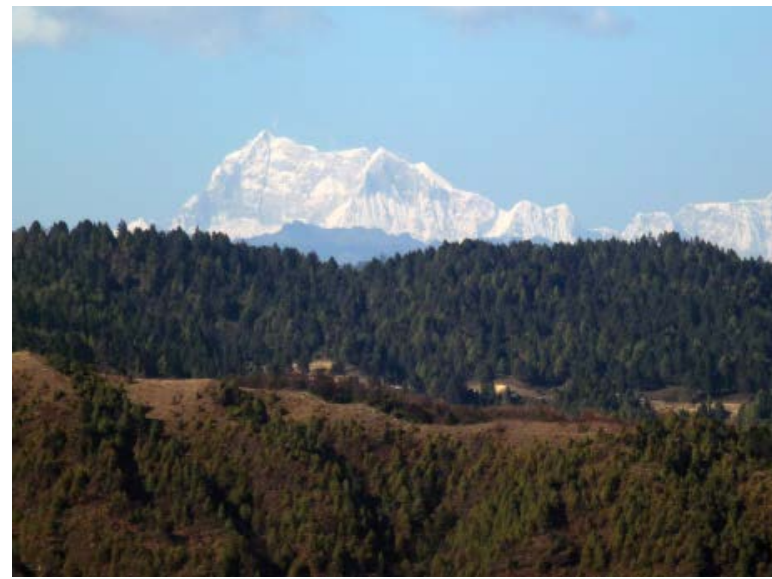

Gangkhar Puensum, a mountain in north central Bhutan, is clearly visible from the main road between Ura and Sengor, looking north-northwest. Gangkhar Puensum, at an altitude of 7,570 meters, is the highest unclimbed peak on Earth. For religious reasons, mountaineering above 6,000 meters is prohibited in Bhutan, so this record is very likely to remain. Credit: György Hetényi

need to continue and build on the existing knowledge, which includes freely available seismological, gravity, and GPS data from our projects (see bit.ly/XA-GANSSER, bit.ly/ Him-segmentation, and bit.ly/INSU-GNSS).

Focusing on three areas would help improve future development in Bhutan:

- Broadening timescales. Acquiring long-term data needed to confirm or to adjust interpretations made on relatively short timescales is possible only with national observatories. We have launched seismology and GPS 
monitoring initiatives, and we hope for long-term funding and training of local workers for all levels of operation.

- Broadening investigations. Some fields of study have advanced dramatically, including work on glacial lake outburst floods and on landslides. Others, like seismic microzonation, have been limited so far and could benefit from more extensive efforts. There is also a strong need for upto-date building codes that reflect the scientific knowledge coming from these investigations.

- Increasing public awareness of natural hazards. The Bhutanese Ministry of Home and Cultural Affairs now has a full department devoted to disaster management that includes well-trained employees and comprehensive administration. However, education is the key to reaching the broadest population possible, which requires regular adaptation of school curricula and concise, practical information that local residents from any generation can understand.

We hope that recent efforts by our teams have promoted progress in the right direction. We also hope that large portions of the population will be sufficiently aware to deal with the next natural disaster. As our research shows, the next event may come sooner than previously thought.

\section{Acknowledgments}

The authors gratefully acknowledge all scientific, fieldwork, and logistical help provided by participants of the projects GANSSER and BHUTANEPAL, carried out in collaboration with the Department of Geology and Mines and the National Land Commission, Thimphu, Bhutan, and with support of Helvetas. Research highlighted in this article became possible thanks to the seed funding of the NorthSouth Centre (ETH Zurich), followed by funding from the Swiss National Science Foundation (grants 200021_143467 and PPooP2_157627) and the French Agence Nationale de la Recherche (grant 13-BSo6-0006-01).

\section{References}

Berthet, T., et al. (2013), Lateral uniformity of India plate strength over central and eastern Nepal, Geophys. J. Int., 195, 1,481-1,493, https://doi.org/10.1093/gji/ggt357.

Berthet, T., et al. (2014), Active tectonics of the eastern Himalaya: New constraints from the first tectonic geomorphology study in southern Bhutan, Geology, 42, 427-430, https://doi.org/10.1130/G35162.1.

Diehl, T., et al. (2017), Seismotectonics of Bhutan: Evidence for segmentation of the eastern Himalayas and link to foreland deformation, Earth Planet. Sci. Lett., 471, 54-64, https://doi.org/10.1016/j.epsl.2017.04.038.

Hammer, P., et al. (2013), Flexure of the India plate underneath the Bhutan Himalaya, Geophys. Res. Lett., 40, 4,225-4,230, https://doi.org/10.1002/grl.50793.

Hetényi, G., et al. (2016a), Segmentation of the Himalayas as revealed by arc-parallel gravity anomalies, Sci. Rep., 6, 33866, https://doi.org/10.1038/srep33866.

Hetényi, G., et al. (2016b), Joint approach combining damage and paleoseismology observations constrains the 1714 A.D. Bhutan earthquake at magnitude $8 \pm 0.5$, Geophys. Res. Lett., 43, 10,695-10,702, https://doi.org/10.1002/2016GL071033.

Le Roux-Mallouf, R., et al. (2016), First paleoseismic evidence for great surface-rupturing earthquakes in the Bhutan Himalayas, J. Geophys. Res. Solid Earth, 121, 7,271-7,283, https://doi.org/10.1002/2015JB012733.

Marechal, A., et al. (2016), Evidence of interseismic coupling variations along the Bhutan Himalayan arc from new GPS data, Geophys. Res. Lett., 43, 12,399-12,406, https://doi org/10.1002/2016GL071163.

Singer, J., et al. (2017a), The underthrusting Indian crust and its role in collision dynamics of the eastern Himalaya in Bhutan: Insights from receiver function imaging, J. Geophys. Res. Solid Earth, 122, 1,152-1,178, https://doi.org/10.1002/2016JB013337.

Singer, J., et al. (2017b), Along-strike variations in the Himalayan orogenic wedge structure in Bhutan from ambient seismic noise tomography, Geochem. Geophys. Geo syst., 18, 1,483-1,498, https://doi.org/10.1002/2016GC006742.

Vernant, P., et al. (2014), Clockwise rotation of the Brahmaputra Valley relative to India: Tectonic convergence in the eastern Himalaya, Naga Hills, and Shillong Plateau, J. Geophys. Res. Solid Earth, 119, 6,558-6,571, https://doi.org/10.1002/2014JB011196.

\section{Author Information}

György Hetényi (gyorgy.hetenyi@unil.ch), Faculty of Geosciences and Environment, Institute of Earth Sciences, University of Lausanne, Lausanne, Switzerland; Rodolphe Cattin, Géosciences Montpellier, University of Montpellier, Montpellier, France; and Dowchu Drukpa, Department of Geology and Mines, Ministry of Economic Affairs, Thimphu, Bhutan
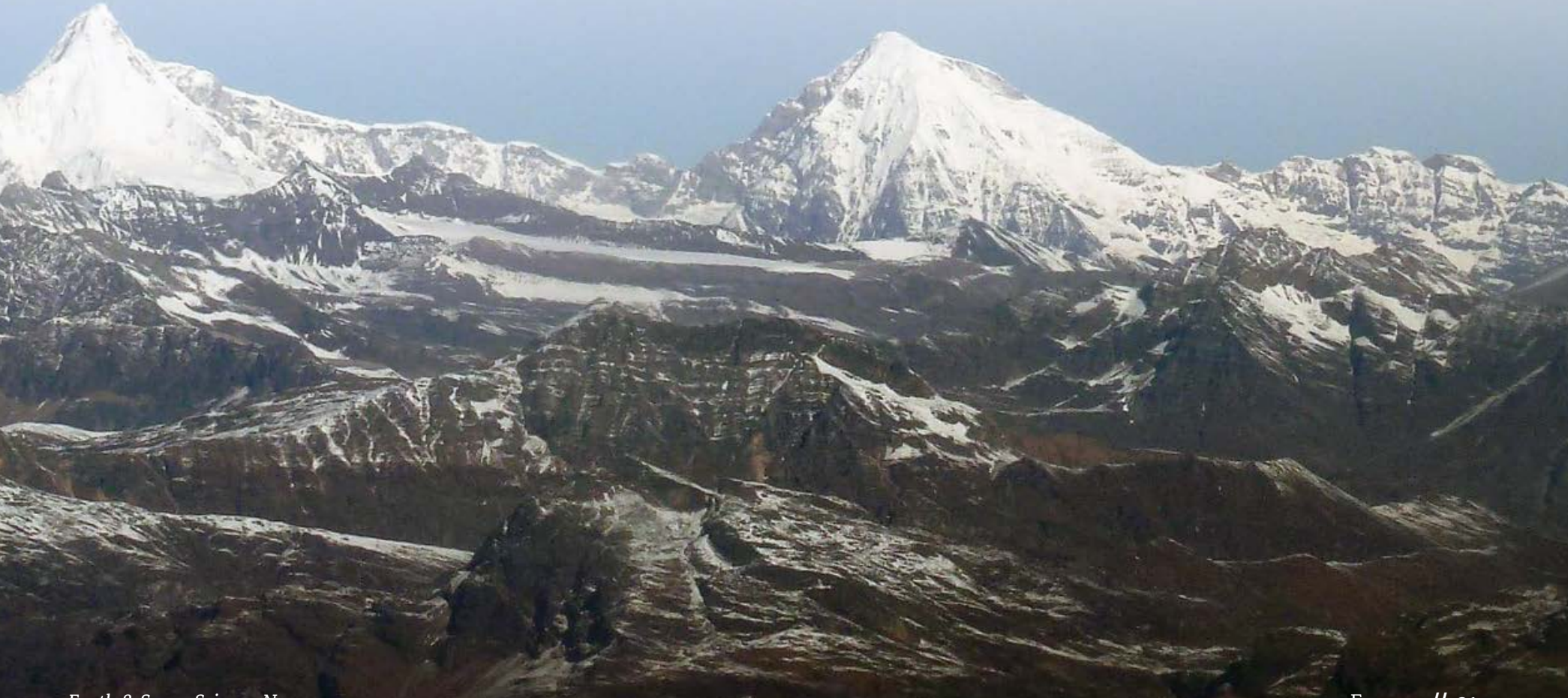


\section{Medalists Honored at 2018 AGU Fall Meeting}

\section{Daniel N. Baker Receives 2018 William Bowie Medal}

Daniel N. Baker was awarded the 2018 William Bowie Medal at the AGU Fall Meeting Honors Ceremony, held on 12 December 2018 in Washington, D. C. The medal is for "outstanding contributions for fundamental geophysics and for unselfish cooperation in research."

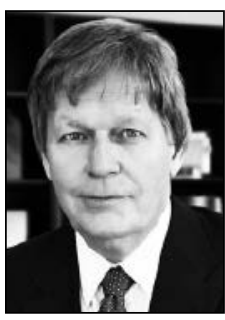

Daniel N. Baker

\section{Citation}

Daniel N. Baker's contribution to our understanding of the Van Allen radiation belts through experiment, discovery, and interpretation of observations is without peer. $\mathrm{He}$ has made major scientific contributions across a wide range of topics in space plasma physics and taken a leading role in developing the nation's space weather program, informing Congress and the public about the potential hazards to humankind of extreme space weather events. His expertise in experimental studies of energetic particle processes in space, their relationship to the radiation belts, and ensuing impacts on technical systems orbiting Earth has been amplified by his leadership at national and academic laboratories and in educating the next generation of space scientists.

Dan has led scientific investigations on numerous NASA missions, including the Solar Anomalous and Magnetospheric Particle Explorer (SAMPEX) satellite, NASA's first Small Explorer (SMEX) mission. His group provided a two-solar cycle baseline for the radiation belts and synoptic basis for interpreting the recent extreme solar minimum. Following community discussion of a potential Maunder Minimum, he demonstrated that a strong coronal mass ejection observed by NASA's Solar and Heliospheric Observatory ( $\mathrm{SOHO}$ ) spacecraft could have caused an extreme "Carrington event"-magnitude geomagnetic storm had it struck Earth in 2012. He was investigator on the Student Nitric Oxide Explorer Mission, was a lead investigator on the Mercury Surface, Space Environment, Geochemistry and Ranging (MESSENGER) orbiter mission, and is now lead investigator on the flagship four-spacecraft Magnetosphere Multiscale Mission launched in 2015 to study magnetic reconnection, the process converting magnetic into particle kinetic energy at Earth, Sun, and stars. Dan, as principal investigator for the Relativistic Electron Proton Telescope on the Van Allen Probes twin spacecraft mission launched in 2012 to study the radiation belts, has published many of the major discoveries, from the third "storage ring" early in the mission to the "impenetrable barrier" to highly relativistic electron penetration deep into the inner magnetosphere.

In addition to his scholarship in top journals, Dan has unselfishly served the space research community in significant capacities. He held leadership positions at two national laboratories, Los Alamos and NASA Goddard Space Flight Center, and since 1994 has been the director of the Laboratory for Atmospheric and Space Physics at the University of
Colorado. He served with great distinction as chair of the most recent National Academies' decadal survey in heliophysics. Dan has continued to serve as a strong advocate for new scientific missions and strengthening our technological infrastructure through greater understanding of the potential extreme variability of the natural space environment.

-Mary K. Hudson, Dartmouth College, Hanover, N.H.; also at High Altitude Observatory, National Center for Atmospheric Research, Boulder, Colo.

\section{Response}

I thank my dear friend, Mary Hudson, for her great generosity and kindness in leading my nomination. I have been blessed with many other friends, none more enduring than Louis Lanzerotti, who played a key nomination role as well and has shaped my career in countless ways.

I think back as a student at the University of lowa. James Van Allen asked me while I still was an undergrad if I'd like to build an instrument to go to Jupiter. Guess what? I said yes! How many students get such a chance? Going from the University of lowa to the California Institute of Technology with Edward Stone was a great experience. Ed showed the value of relentless hard work and precision of thinking-I thank him so much for his mentorship.
I was privileged in the 1980 s to head a unique, worldclass Los Alamos space plasma physics group. My deep sadness and regret is that my great friend from those Los Alamos National Laboratory (LANL) days-Jack Gosling-passed away this year and could not see this award. Jack had a profound influence on me and every other researcher with whom he interacted. While at LANL, I was befriended by two especially influential scientists: Atsuhiro Nishida (Institute of Space and Astronautical Science director in Japan) and Bob McPherron (University of California, Los Angeles). They got me interested in all aspects of geomagnetic activity and taught me the joy of data analysis.

From Los Alamos to NASA's Goddard Space Flight Center was quite a pilgrimage. Being chief of the Laboratory for Extraterrestrial Physics at Goddard gave me central NASA project science roles and let me interact with the leaders of U.S. and international space agencies. It got me into space policy in a big way for both NASA and for the U.S. National Academies.

In moving to the Laboratory for Atmospheric and Space Physics (LASP), I think I've had my most exhilarating scientific adventures. I am immensely proud of LASP and the outstanding people who comprise the Lab. I feel that this Bowie Medal is a recognition of each and every LASP scientist, engineer, and student. If there is a space research heaven, it must perforce look a very great deal like Boulder, Colo.

To be able to reach this very special point in my career, I've been blessed with many other amazing things. Parents who nurtured my dreams of being a space scientist and brothers who kept me grounded in practicality. Countless colleagues over the many years who stimulated my mind and ambitions. But, most of all, I have been blessed by having the most wonderful wife and amazing daughter. Vicki and Kirsten-you are the greatest among my many great friends, and I love you both so very much. Thank you from the bottom of my heart.

-Daniel N. Baker, Laboratory for Atmospheric and Space Physics, University of Colorado Boulder

\section{Davis, Immerzeel, Santos, Turner, and Ummenhofer Receive 2018 James B. Macelwane Medals}

Steven J. Davis, Walter Immerzeel, Isaac Santos, Drew Turner, and Caroline C. Ummenhofer were awarded the 2018 James B. Macelwane Medal at the AGU Fall Meeting Honors Ceremony on 12 December 2018 in Washington, D. C. The medal is for "significant contributions to the geophysical sciences by an outstanding early career scientist."

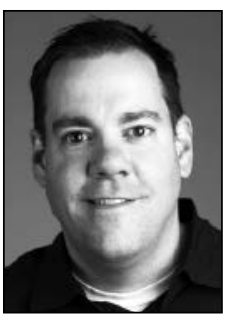

Steven J. Davis

\section{Citation for Steven J. Davis}

Davis's research combines economic and geophysical approaches that are groundbreaking. He has carved a new field relating human systems, the carbon cycle, air pollution, and climate change, thus providing solutions for some of the most significant environmental challenges of the 21 st century.

Davis developed the theory for tracking carbon dioxide $\left(\mathrm{CO}_{2}\right)$ emissions that are embodied in all the goods and services traded internationally. Davis learned econometric methods and applied them in an analysis that was timely and salient: Inter- national climate negotiations were mired in the debate over whether developing countries should be required to reduce their $\mathrm{CO}_{2}$ emissions. By quantifying emissions that are effectively "outsourced" from developed countries, his work provides a rigorous scientific foundation that has informed ongoing policy discussions. By recognizing the interconnectedness and universally shared responsibility for these emissions, his work contributed to the success of the $\mathbf{2 0 1 5}$ Paris Climate Conference, with the subsequent agreement creating a more level playing field for all nations.

Davis made another important breakthrough in tracking future global $\mathrm{CO}_{2}$ emissions from existing energy infrastructure. Even if we never build another power plant or car, assuming that existing infrastructure continues to operate for its expected lifetime causes a certain amount of emissions to 
be locked in. This new approach has focused the policy community on the implications of near-term plans by many developing countries to expand the number of fossil fuel-emitting power plants, given that normal operating lifetimes for these facilities can be $30-40$ years. In more recent work, Davis and his colleagues have quantified the health impacts (and human mortality) associated with global trade flows, leveraging his earlier breakthrough linking $\mathrm{CO}_{2}$ emissions and trade.

Davis's unique background combines a legal education, a dissertation on isotope geochemistry, work with nongovernmental agencies on life cycle assessment, and a postdoctoral analysis of energy systems. This gives Davis a diverse set of research methods. As a colleague in the Earth System Science Department at the University of California, Irvine, we truly value Davis's vision and comradery.

Steve represents a new 21st century generation of geophysicists. We are thrilled that he is this year's Macelwane Medal winner.

-James Randerson and Ellen Druffel, University of California, Irvine

\section{Response}

I'm honored and humbled to accept the Macelwane Medal. Thank you, Jim and Ellen, for nominating me and for your generous citation. I'm fortunate to have you both as role models and colleagues, and I can only hope to distinguish the award as you both have.

I'm also grateful to AGU and the medal committee for selecting me among so many deserving young scientists. In doing so, they highlight the breadth of modern geophysical research in a way that I hope encourages and emboldens others to color outside the lines.

As Jim and Ellen mention, my path has been winding, and though they portray my varied background in a flattering light, it was less strategic building of experience than following my interests and trusting they would lead me to somewhere I wanted to be. Luckily, I happened into some terrific mentors who were audacious enough to give me a chance. Without them, I would never have become the scientist I am today.

Still a corporate lawyer, I walked into Page Chamberlain's Stanford office one afternoon and did my best to convince him that I wanted to be a geologist. In retrospect, I was incredibly naïve, and I can't for the life of me understand what he saw in me that day, but he took me on as a graduate student and over the next 4 years transformed me from an attorney with a philosophy degree into an isotope geochemist.

Ken Caldeira enabled yet another leap, hiring me as a postdoc at the Carnegie Institution to work on $\mathrm{CO}_{2}$ embodied in international trade on the basis of a fun lunchtime conversation we had-again despite my knowing almost nothing about the subject. What was supposed to be a few months turned into nearly 5 years in productive pursuit of the interesting and important.

Perhaps as important as the opportunities these men afforded me, they taught by example how to balance careful execution of science with bold hypotheses, how to resist common knowledge, to be more critical of yourself than you are of others, and that data are lifeless without a good story. These lessons were bolstered by other outstanding collaborators and mentors like Rob Socolow, Jen Burney, David Lobell, Glen Peters, Dabo Guan, Qiang Zhang, Rob Jackson, and Noah Diffenbaugh. My colleagues at the University of

California, Irvine, have also been constant supporters of my work. I am indebted to them all. I hope that my mentorship can inspire and enable other students and postdocs as theirs has me.

Most of all, though, I am thankful for the love and unwavering support of my wife, Kristen; my parents; and my daughters. They have given me both the confidence to chase big ideas and the reason for the chase.

\section{-Steven J. Davis, University of California, Irvine}

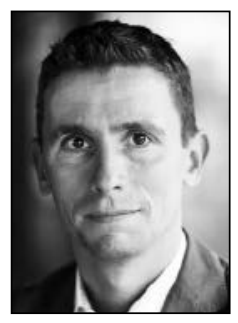

Walter Immerzeel
Citation for Walter Immerzeel Since obtaining his Ph.D. in 2008, Walter Immerzeel has established himself as an influential scientist in the field of mountain hydrology and glaciology. He focuses his research on the impact of global warming on snow and glaciers in High Mountain Asia (HMA) and how it affects future water resources in the downstream, densely populated areas. His unique interdisciplinary research line combines innovative fieldwork techniques, remote sensing, and mesoscale meteorological modeling to elucidate glaciohydrological processes at the catchment scale. His most influential study to date (Science, 2010) uses the above techniques to show that contrary to what was previously believed, the contribution of HMA glacial melt to downstream runoff in most Southeast Asian rivers is smaller than a few percent, the exception being the Indus, for which up to $60 \%$ of the downstream discharge has its origin in HMA snow and glacial melt. This process understanding is used to predict the effects of climate change on the glaciohydrology and water resources of HMA as a whole. Walter and his group showed that for realistic climate scenarios maximal glacial melt is expected around 2050 in the western HMA, after which increased rainfall will compensate for the decreased meltwater runoff. In a 2017 study in Nature Walter's group predicted that HMA glaciers could lose up to $65 \%$ of their mass by 2100 .

The research of Walter and his group has been highly visible among his colleagues and in the international press. For instance, they were the first to use unmanned airborne vehicles (UAVs, or drones) in HMA glacier research, showing that locally, debris-covered glacier melt rates can even be larger than those of debris-free glaciers as a result of lakes and exposed ice cliffs. To draw attention to the detrimental changes that await the region under climate change and how scientific research can help to mitigate these changes, he has used part of his research funds to make brief, insightful documentaries. During his years working in the region, Walter has built up a strong relation with the local Nepali people and scientists. During his Ph.D. track he was employed by the International Centre for Integrated Mountain Development (ICIMOD) and lived in Kathmandu for 2 years. Currently, he still is a guest researcher at ICIMOD. Right after the April 2015 Nepal earthquake Walter joined forces with people in his remote sensing network to provide the Nepali authorities, through his link with ICIMOD, with inventories of earthquakeinduced landslides as seen from space.

-Michiel R. van den Broeke, Utrecht University, Netherlands

\section{Response}

Dear Michiel, many thanks for this wonderful citation, and I look forward to link the three poles together by working with you. I am also very grateful to AGU, the Macelwane Medal Committee, and esteemed colleagues for the nomination letters.

As someone from the Netherlands, where the highest point is $\mathbf{3 2 2 . 4}$ meters above sea level, it may seem strange to be awarded the Macelwane Medal on research in highmountain Asia, and an explanation is justified. After trekking for 3 months through Nepal with my wife, Hilde, during our honeymoon in 1999, the mountains and its people were permanently imprinted in my system. This resulted in a job at the International Centre for Integrated Mountain Development (ICIMOD) in Kathmandu, where I lived and worked for 2 years. I met Dr. Roberto Quiroz there, who inspired me to pursue a Ph.D. in this field, and it turned out to be a life changer.

I am still working closely with ICIMOD with a unique group of mountain-loving people who dedicated their careers to the understanding and protection of this beautiful region. I specifically mention David Molden, Arun Shrestha, Anna Sinasalo, and Inka Koch. Without your support, many of the scientific achievements would not have been possible. The joined expeditions in the Himalayas have also sparked new friendships and long-lasting international collaborations. Working with incredible scientists, such as Joseph Shea, Patrick Wagnon, and Francesca Pellicciotti, has been a great inspiration and motivation and a lot of fun.

At Utrecht University in the Netherlands, I feel privileged to work with a great group of people. A special thanks to Marc Bierkens, who has been my mentor for years. Our brainstorm sessions formed the basis for many successful papers and proposals, and I hope we can continue like this for years! This medal is not the result of only my work, but it was true team work, and big thanks to Arthur, Emmy, Jakob, Maxime, Philip, Pleun, Remco, Sonu, and René. I also thank my family; my friends; and my wife, Hilde, in particular for making sure I realize what is really important in life and for making me realize what the red thread in my research really is.

There are huge scientific and societal challenges ahead associated with mountains and the millions of people that depend on their resources. I am proud and looking forward to keep working on them.

-Walter Immerzeel, Department of Physical Geography, Utrecht University, Netherlands

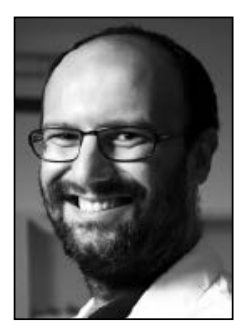

Isaac Santos
Citation for Isaac Santos

Isaac Santos is not only an outstanding Earth scientist but also a brilliant science communicator and student mentor. With training in chemical oceanography at Florida State University under Bill Burnett, Isaac recognizes the interdisciplinary nature of our field and works collaboratively at the edge of conventional disciplinary boundaries.

Isaac uses geochemical tracers to resolve the drivers and biogeochemical implications of submarine groundwater discharge (SGD). He made elegant demonstrations that SGD is a major source of greenhouse gases and carbon to the coastal ocean and developed substantial arguments for the importance of SGD at a variety of coastal 
sites, including mangroves, coral reefs, estuaries, and beaches. Isaac's innovative research relies on his vision of taking the lab to the field. He combined automated observations of radioactive and stable isotope tracers to obtain real-time and high-precision data in situ. These techniques allowed Isaac to collect unique data sets to address complicated and important interdisciplinary questions in hydrology, biogeochemistry, and oceanography. His diverse research has inspired colleagues and government agencies to consider the implications of SGD to coastal biogeochemical cycles and water quality.

Isaac's dedication to science goes beyond the quest for new knowledge. Isaac should also be recognized for his broader contribution to our community and gregarious approach to work and student supervision. $\mathrm{He}$ is an unselfish colleague leading a large and productive research group. He always shares his best ideas and projects with his students. His leadership, combined with his great ability in developing collaboration and building first-class infrastructure, will help to ensure long-lasting impacts of his work. Isaac is a candid and idealistic advocate on issues of public interest. By engaging with the public and the mainstream media, his research has influenced public opinion and is helping to manage and preserve valuable coastal waterways while encouraging the fossil fuel industry to prevent greenhouse gas leakages from aging infrastructure.

With balance in research, teaching, and outreach as well as life outside academia being a desire of all, Isaac has achieved just that. Achieving balance extends his positive influence to our future generation of scientists. His outstanding track record of discovery, focus on student development, collaborative mindset, and engagement with the broader society are fully in line with AGU's values and mission. His many and important contributions published in $>100$ papers, commitment to the well-being of his students, and spirit of generosity make him a well-deserved winner of the James B. Macelwane Medal.

-Ling Li, Westlake University, Hangzhou, China

\section{Response}

Winning an AGU medal makes me feel nostalgic and grateful. It brings memories from where I come from and all the people who supported me along the way. It enlightens a path to the future.

As an undergrad in Rio Grande (Brazil), I would read AGU journals as I learned English. I would dream about publishing there. I didn't dream about winning a medal. As a Brazilian working in regional Australia, being singled out with a medal takes me a step closer to overcoming a self-diagnosed impostor syndrome.

I am thankful for Ling's generous nomination and honored to have worked with him. He mentions the achievement of work-life balance, but I am afraid my wife, Ana, may occasionally disagree with this. On these occasions, I often apologize and remind her that a 20 -year marriage requires true love. Instead of balance, I have blended work and life as I care for my young family and students at the same time. I would achieve nothing without family encouragement and understanding.

Investigating submarine groundwater discharge requires truly interdisciplinary approaches and collaboration. My lifelong mentors Bill Burnett, Jeff Chanton, Thorsten Dittmar, Felipe Niencheski, and Emmanoel Silva-Filho have been role models inspiring me along the way. Thanks to my friends and collaborators Guilherme Lima, Rick Peterson, Christian Sand-

ers, Damien Maher, Doug Tait, and many others whom I cannot mention in $\mathbf{4 0 0}$ words.

It is an exciting time to work on submarine groundwater discharge! I often say that submarine groundwater discharge has been put on the "to-do list" or in the "too hard basket" for long enough. Our new tools are revealing leaky shorelines worldwide, helping us to quantify the invisible, and demonstrating major implications to marine biogeochemistry. We are learning how the underground routes of biogeochemical cycles provide climatic feedbacks as groundwater releases soil carbon and nutrients to the oceans.

Macelwane was deeply interested in education. He saw himself as a servant to students, and I am proud to be associated with his vision. As researchers, we often strive for independence and can easily become too self-centered. Students unconsciously remind me of what research is all about. Their seemingly simple but penetrating questions, fresh perspectives, and full commitment to improving our world give real meaning to my research. Thanks to current and past students for raising the bar every day, keeping me grounded, and pushing me outside comfort zones-l owe this medal to you!

$$
\text { -Isaac Santos, Southern Cross University, Lismore, }
$$

\section{Australia}

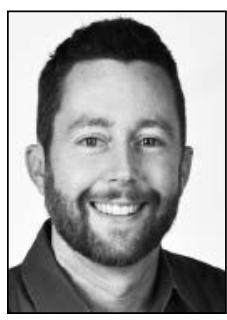

Drew Turner work revealed how those processes work in systems from the Van Allen radiation belts to the

boundaries of the magnetosphere and solar wind.

Drew Turner began his work at the University of Colorado under the supervision of Xinlin Li. Among many excellent students, Drew stood out for his enthusiastic questions, deep professional engagement, and creative problem solving. In those years, Drew started a string of important papers related to NASA's Time History of Events and Macroscale Interactions during Substorms (THEMIS) and Van Allen Probes satellite missions. In particular, Drew developed novel methods for disentangling complicated co-occurring processes that can either enhance or deplete the radiation belts. That work culminated in a 2012 Nature paper just 2 years after his Ph.D.

After the University of Colorado Drew moved to the University of California, Los Angeles, and, more recently, to the Aerospace Corporation. In his career, Drew has consistently come up with creative ways to answer some of the most important questions in our field-whether it is understanding the complicated balance of acceleration, transport, and loss processes in the radiation belts, understanding particle dynamics at the magnetopause and foreshock, or unraveling the complex processes that couple fast flows, dipolarization fronts, and energetic particle injections in storms and substorms.

Drew is able to synthesize information from different measurements, different instruments, and multiple satellite missions. One recent paper combined observations from dozens of instruments on $\mathbf{1 5}$ satellites making up five very different space missions. Drew also draws on his experience with spaceflight hardware to develop new data reduction and analysis routines that frequently become the basis for analysis done throughout the community. As a result, Drew's papers are able to explore, simultaneously, the important processes that happen on local scales and the global context for those processes.

In the 8 years since his Ph.D. Drew has published over 110 papers, including 3 in Science, 4 in Nature, and 32 in Geophysical Research Letters. One factor leading to his remarkable publication record is that people seek out Drew's insights and contributions. His body of work reflects his creativity and talent but also generosity with his ideas, his time, and his energy.

Drew Turner truly embodies values that AGU promotes and the qualities that the Macelwane Medal recognizes.

-Geoffrey D. Reeves, Los Alamos National Laboratory, N.M.

\section{Response}

Let me put first things first: Geoff Reeves, Jacob Bortnik, Joe Fennell, and Xinlin Li, I can never thank you enough for your nomination and the ongoing tutelage and support you've offered to me throughout my career. I have learned so much from each of you, whether it be leadership skills and new physical perspectives from Geoff and Jacob, open-mindedness and spaceflight instrumentation from Joe, or good mentorship and the finer points of critical thinking and strategy from Xinlin. I owe much of my success in many ways to each of you, and I hope you each know how much that is appreciated.

Next, I would like to thank AGU and the Macelwane Medal Committee for this incredible honor. I will do my very best to live up to this distinction and embody the commitment to excellence in research, career development, and education that James B. Macelwane represented.

My research relies heavily on data provided by various satellite missions, and I know well that it takes teams of hundreds or more to ensure the successful development, launch, and operations of each mission. I want to say a special thank you to the teams for NASA's THEMIS, Van Allen Probes, and Magnetospheric Multiscale (MMS) missions for providing such high-quality and scientifically rich data to the world.

Professionally, I wouldn't be where I am today without the help, tutelage, and support of so many of my colleagues. It is impossible here to thank each personally, but I want several of you to know the especially positive impacts you've made on my life. Thank you, Drs. Angelopoulos, Azeem, Blake, O'Brien, Shprits, and Sivjee, for your mentorship. To Drs. Blum, Claudepierre, Cohen, Drozdov, Gabrielse, Gkioulidou, Hartinger, Hietala, Jaynes, Kellerman, Kiehas, Maget, Millan, Plaschke, Schiller, Tu, Ukhorskiy, Usanova, and Wilson, thank you so much not only for your professional advice and contributions to my research but also for your invaluable friendship.

With the few words I have left here, I must thank my family and friends for their unending and unconditional support. Mom, Dad, Shona, and my full extended family: thank you all so very much for your love and encouragement. Mom and Dad, I have pursued a career that makes me happy, just like you told us.

Finally, Krista, my love, partner, and best friend, thank you so much for the love, positivity, and kindness that you give me every day.

-Drew Turner, The Aerospace Corporation, El Segundo, Calif. 


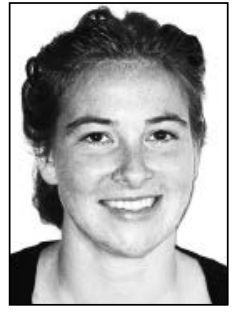

Caroline $\mathrm{C}$

Ummenhofer
Citation for Caroline $C$. Ummenhofer

Caroline Ummenhofer is at the forefront of developing a dynamic understanding of how the ocean affects the climate system. She has done particularly creative work in helping to understand the mechanisms of how ocean properties give rise to changes in large-scale atmospheric circulation that impact rainfall on land. Her core research dis-

coveries have been in tropical climate variability, particularly in the Indian Ocean; the linkages between ocean variability and atmospheric blocking outside the tropics; and the connections between the Hadley Circulation and the ocean's eastern boundaries. In each area, Caroline has made very substantial contributions. For example, prior to her highly cited 2009 paper in Geophysical Research Letters, it was thought that the most damaging droughts experienced in Australia were caused by Pacific Ocean conditions. However, she showed convincingly that conditions in the Indian Ocean were the real cause.

Caroline has worked with a variety of colleagues on a wide array of climate problems over millennial timescales to modern seasonal predictions. She introduces new techniques and concepts in her work and always has an eye toward the implications for society. She has taken a particular interest in showing the connections between ocean conditions and the extremes of drought and flood that influence crop yields. She has made exceptional contributions to understanding the ocean's influence on rainfall in Australia, the United States, Southeast Asia, and Africa. She is a leading expert on the expansion of the tropics and drying of the subtropics predicted with global warming. She has taken on leadership roles in national and international projects like Climate and Ocean: Variability, Predictability and Change (CLIVAR) while maintaining a truly remarkable production rate of original scientific research. Her dynamical insights are deep, the problems she tackles are hard, and her approaches are novel and creative. She is a rising star in ocean and climate science and has already had a global impact.

On a personal level, I have to say that it has been a wonderful experience to have Caroline as a colleague for the past 6 years. I marvel at her productivity, her prodigious travel schedule, her skill at building collaborative teams, her teaching ability, and her generosity to students, colleagues, and the community at large. I am certain that you will be hearing her name in connection with important discoveries about the climate system for many years to come. Please join me in congratulating Caroline for her well-deserved honor of the James B. Macelwane Medal.

-Raymond W. Schmitt, Woods Hole Oceanographic Institution, Mass.

\section{Response}

Thanks, Ray, for your kind words-and your relentless support and encouragement over the years. I also want to thank my nominators and the AGU Macelwane selection committee for their time and efforts.
Science, and especially climate science, has become an intrinsically collaborative effort. The research leading to this medal was only possible through contributions from many colleagues around the world. I am continuously inspired by the wealth of groundbreaking research findings by the climate and geoscience community-many of whom are at least as deserving of this medal.

The interdisciplinary nature of the field is what first drew me to ocean sciences and my degree in marine biology/ oceanography at the School of Ocean Sciences, University of Wales, United Kingdom. Three individuals there in particular opened my eyes to the attraction of interdisciplinary research in biophysical interactions and paleoclimate that enjoy at the Woods Hole Oceanographic Institution (WHOI) today, namely, Dave Bowers, David Thomas, and James Scourse.

From north Wales to New South Wales, half way around the globe, an 8-week internship in Sydney, Australia, turned unexpectedly into the best 8-year Ph.D. and postdoc experience I could have wished for. I am deeply grateful to my adviser, Matthew England, for his unstinting support and generous mentorship ever since that email about hosting my internship-and for teaching me how to be a productive, creative, and collaborative scientist. I also found a wonderful team of close colleagues-turned-friends at the University of New South Wales, particularly with Alex Sen Gupta and Andrea Taschetto.
My research on Australian rainfall and Indian Ocean dynamics was greatly enriched by interactions with colleagues at CSIRO (Peter McIntosh, Gary Meyers, Mike Pook, James Risbey). Long-standing collaborations with colleagues at the Lamont Doherty Earth Observatory (Rosanne D’Arrigo, Brendan Buckley), Claus Böning and Arne Biastoch (GEOMAR Helmholtz-Zentrum für Ozeanforschung Kiel), Jerry Meehl (National Center for Atmospheric Research), and Rhawn Denniston (Cornell College) also shaped my research.

I've been fortunate over the years to be able to rely on wonderful administrative staff and would like to thank them for all their hard work that supports all our scientific endeavors.

At WHOI, I found a stimulating collaborative environment ideal for exciting new interdisciplinary research, made so by the individuals working there. Too numerous to all name here, I am indebted to Ray Schmitt as my key mentor and also thank my close collaborators Young-Oh Kwon and Hyodae Seo, as well as a dynamic group of postdocs and students.

It feels like I receive this award as a representative of a larger collective-and I constantly cherish the opportunities to work with many inspiring researchers from different disciplines to tackle key questions in the field of climate science and its societal applications.

-Caroline C. Ummenhofer, Woods Hole Oceanographic Institution, Mass.

\section{Forrest S. Mozer Receives 2018 John Adam Fleming Medal}

Forrest S. Mozer was awarded the 2018 John Adam Fleming Medal at the AGU Fall Meeting Honors Ceremony, held on 12 December 2018 in Washington, D. C. The medal is for "original research and technical leadership in geomagnetism, atmospheric electricity, aeronomy, space physics, and/or related sciences."

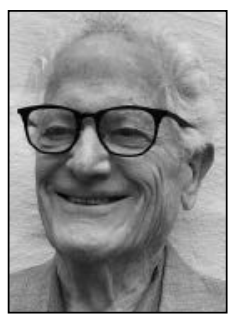

Forrest S. Mozer

\section{Citation}

It was recognized at the very outset of the space age that a complete description and understanding of plasmas in space would only be achieved if electric fields (from DC to high frequencies) could be measured together with the particle fluxes and the magnetic fields. Professor Forrest Mozer, an eminent and groundbreaking space physics member of AGU, is the recipient of the 2018 John Adam Fleming Medal. Professor Mozer invented and pioneered the flight of the spherical doubleprobe techniques that revolutionized experimental space plasma research, techniques that are continuing to make major advances in the field to the present.

Without the electric fields, essential physical quantities such as the Poynting flux could not be determined in the plasmas. Unlike most particle fluxes and magnetic fields, electric fields are generally much more difficult to measure because spacecraft carrying instruments can easily disturb the fields. Early space-age discussions involved the possible feasibility of using electron beams and long antennae of various types. However, double probes proved from the outset to be far superior. In addition to his double-probe innova- tions, Professor Mozer also was the first to develop and fly (on the International Sun-Earth Explorer 1 (ISEE-1) Earthorbiting spacecraft) a burst memory device for the capture of waveform bursts (electric and magnetic), which included the first microprocessor flown in space in a science experiment. Such waveform capture, generally triggered by a large-amplitude wave, has become essential in experimental magnetosphere research to return electric (and magnetic) field data that would otherwise be lost and thus not available for complete physical interpretation and application to theory.

Professor Mozer, his students and his colleagues, and, eventually, investigators around the world have employed his electric field and waveform capture inventions and subsequent improvements to make fundamental contributions in many areas of space plasma physics. For example, it was long recognized that electrons and ions produce aurora emissions. Professor Mozer and his students and colleagues, using data from his instruments, discovered that electrostatic shocks (at altitudes of 1 Earth radius) accelerated the electrons downward into the atmosphere to make discrete auroras. He also discovered double layers and solitary waves in the plasmas in auroral regions and their relevance for acceleration processes.

Without Mozer's double-probe and waveform burst techniques flown on many spacecraft (including the recent Clus- 
ter, Time History of Events and Macroscale Interactions during Substorms (THEMIS), Van Allen Probes, and Magnetospheric Multiscale (MMS) missions), instances of space plasma reconnection and their physical nature would not have been identified or understood. The very first measurements of the Hall electric field at Earth's magnetopause were possible because of the double-probe technique. More recently, on the MMS spacecraft, he and his colleagues measured the parallel acceleration of electrons by Fermi reflection from time domain structures in reconnection regions.

In addition to his pioneering contributions over more than 5 decades in space plasma physics, Professor Mozer invented and patented in 1974 the first integrated circuit speech synthesizer in a commercial product. This was motivated in part by his mentoring of a sight-challenged physics graduate student. As an entrepreneur he has cofounded two companies to develop and market speech systems. Professor Mozer, a true Renaissance physicist, amply deserves the John Adam Fleming Medal recognition by AGU.

-Louis J. Lanzerotti, New Jersey Institute of Technology, Newark; also at Alcatel-Lucent Bell Laboratories (retired), Murray Hill, N.J.

\section{Response}

I thank the American Geophysical Union and the Fleming Committee for the honor and satisfaction associated with my receiving the Fleming Medal. I accept it on behalf of the students, postdocs, researchers, engineers, and software developers who did the heavy lifting for which I am being honored. I thank every one of them for making our research both fun and exciting.

This all started in the 1960s when it was known that electrons were accelerated to relativistic energies in the Van Allen radiation belts and auroras but the electric fields responsible for this acceleration were neither measured nor understood. It occurred to me that one might use Langmuir probe theory to put a bias current on a pair of separated spheres and to then measure their potential difference to determine the electric field. The sensors were required to be spherical in order to symmetrize their responses in the directed sunlight, magnetic field, and plasma flow. We tried this detection scheme for the first time on a French sounding rocket flown from Andenes, Norway, in October 1966, and we made the first electric field measurements in the ionosphere. My colleagues in this endeavor were Arne Pedersen, Ulf Fahleson, Carl-Gunne Fälthammar, Mike Kelley, and Paul Bruston.
We continued this research at Berkeley by flying many sounding rockets and more than 100 electric field measuring balloons. Then, in 1976, we had the opportunity of flying a three-axis double-probe electric field experiment on an Air Force piggyback satellite called S3-3. On this flight, we made the first $D C$ and low-frequency electric field measurements above the ionosphere. We observed extremely large parallel electric fields that we called electrostatic shocks and that accelerated electrons to make the discrete auroras that are featured in most auroral pictures. Our team of graduate students and postdocs at that time included Mary Hudson, Bill Lotko, Bob Lysak, John Wygant, Cindy Cattell, Roy Torbert, Bob Ergun, and Gar Bering, all of whom went on to distinguished careers as faculty members at other universities.

Our electric field research continues actively to this day with collaborations involving Ivan Vasko, Oleksiy Agapitov, Vladimir Krasnoselskikh, Solène Lejosne, Ilan Roth, and many others.

And last, I want to thank the group that made all of this seem worthwhile: my children, Mike, Todd, Dana, Laura, Sam, and H.K. Thanks, kids, I love you.

-Forrest S. Mozer, Space Sciences Laboratory and Physics Department, University of California, Berkeley

\section{Philip England Receives 2018 Walter H. Bucher Medal}

Philip England was awarded the 2018 Walter H. Bucher Medal at the AGU Fall Meeting Honors Ceremony, held on 12 December 2018 in Washington, D. C. The medal is for "original contributions to the basic knowledge of the crust and lithosphere."

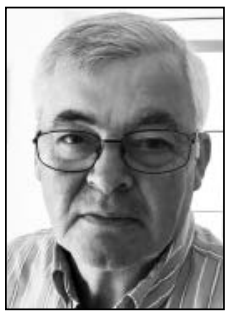

Philip England

\section{Citation}

Philip England recognizes that the goal of science is to understand nature's processes, the essence of understanding is the ability to predict from general conditions, bringing understanding to Joe Sixpack requires simplicity, and simple understanding can be expressed most clearly by algebraic expressions, or scaling laws. With Steve Richardson and later with Margaret Moore (and Carslaw and Jaeger), he showed how erosion affects crustal temperatures. With Alan Thompson, he showed how the thermal history of buried rock, and therefore metamorphism, depends on rates and depths of burial and exhumation. With Tim Holland (and Archimedes), he revealed the conditions required for ultrahigh-pressure rock to return to the surface in the face of subduction shear. With Greg Houseman, Dan McKenzie, and Leslie Sonder, he combined the two major forces that limit elevations of deforming lithosphere-friction or viscosity and gravity-into one dimensionless number, the Argand number. With this simplification, he then explained many aspects of the large-scale distribution of active deformation, like present-day velocities and strain rates, rotations about vertical axes, crustal thicknesses, and subcrustal seismic anisotropy. With Stephen Bourne and Barry Parsons, he showed how slip rates on faults can scale simply with the spacing between faults. With Richard Katz and Catherine Wilkins, he showed how the positions of volcanoes at subduction zones depend simply on the subduction rate and the dip of the downgoing slab. In a counterintuitive, homely analogy, the faster you thrust ice beneath your bed, the warmer you will be (provided that the movement of your ice forces a circulation of warm water above it)! Not just a theorist who has reduced nonlinear differential equations to algebraic scaling laws, he has also led efforts to obtain new data, especially GPS measurements. Finally, as a public servant, he organized a multidisciplinary program, Earthquakes Without Frontiers, to study both the science and the societal impacts of earthquakes in continental regions, where they have taken their greatest toll but are least well understood.

Philip England has brought simple understanding to a wide variety of thermal and mechanical processes in the solid Earth. Young scientists could benefit from examining how he chooses, then poses, and finally solves problems.

-Peter Molnar, Department of Geological Sciences, Cooperative Institute for Research in Environmental Sciences, University of Colorado Boulder

\section{Response}

Thank you, Peter. Your nomination and the support of friends who must have written unreasonably kind letters embody what I value most. Receiving the Bucher Medal evokes many memories of interactions with the dynamic and inclusive community that is AGU.

Nothing of worth that I have done would have been possible without Pam; doing justice to her support would require volumes, which she would not want me to write. Our children provide a counterpoint: By their unremitting ridicule and disrespect, they inspire me constantly to question the value of what I do.
I have been extraordinarily fortunate in the people who influenced me. I cannot imagine a better introduction to research in the Earth sciences than Stephen Richardson and Ron Oxburgh provided. They had inexhaustible curiosity about the Earth, and encouraged their students to employ whatever tools were available to solve problems of interest. Few who know Dan McKenzie would dispute that an exchange of views with him is one of the most bracing experiences our discipline has to offer; 4 years of Dan's stimulation and generosity were an outstanding experience.

Decades ago, when you and I first grouched together, the search for simplicity in geology seemed natural. The facility with which computer models now spin seductive webs of "realistic" images has made that view unfashionable. I nevertheless remain convinced that nature does leave clues lying around that reveal her working through their simplicity. It has been immense fun to pursue those clues with friends much smarter than I, particularly you, Greg Houseman, and Rich Katz. I've had equal fun, with added scenery, in the company of Haris Billiris, James Jackson, Demitris Paradissis, Barry Parsons, and George Veis (whose understanding of satellite geodesy predates satellites themselves). It has been stimulating and sobering to work with James, and new friends in other disciplines, on the far from simple challenges of seismic risk across Eurasia. Lack of space prevents mention of many others; I hope you know who you are.

For what it's worth, my advice to young scientists is embedded above. Choose a nascent field and seek the best mentors; I was fortunate, but your choice now is even richer. Lastly, for the not-so-young: Pressures from has-been counters, from those who mindlessly equate universities with businesses, and from bigots of all shades imperil the openness, inclusivity, and liberality that are essential to the flourishing of young minds. Resist.

-Philip England, University of Oxford, U.K. 


\section{Nicklas G. Pisias Receives 2018 Maurice Ewing Medal}

Nicklas G. Pisias was awarded the 2018 Maurice Ewing Medal at the AGU Fall Meeting Honors Ceremony, held on 12 December 2018 in Washington, D. C. The medal is for "significant original contributions to the ocean sciences."

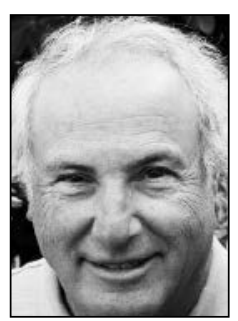

Nicklas G. Pisias

\section{Citation}

Dr. Nicklas George “Nick” Pisias's deep and broad understanding of paleoceanography and climate dynamics coupled with novel applications of rigorous mathematical and statistical techniques has been the hallmark of his sustained and transformative contributions to our understanding of the history of global-scale ocean processes and their linkages to climate change.

Nick's most important contributions include his innovative work that laid the foundation for the acceptance and understanding of orbital forcing in explaining the ice age cycles, his extraordinary insights into the role of carbon dioxide in these cycles, and his novel application of phase lags and nonlinear interactions to paleoclimatic time series that significantly improved our understanding of the behavior of the climate system. Over the years, Nick has also given selflessly to the ocean sciences community in innumerable ways, a prime example being his role in providing strong and steady leadership to the Ocean Drilling Program through difficult times.

Early in his career, Nick transformed the new and mostly qualitative field of paleoceanography with seminal papers on the identification of climate periodicities. He explained spectral analysis to a geologic audience, then used it to identify millennial-scale climate oscillations and identify a "flipping or state changing of the climate." Almost 40 years later, these concepts remain central to understanding natural variability in the context of future climate change. Nick applied these methods to test and further develop the orbital (Milankovitch) climate theory. This work laid the framework for the concept of orbital "tuning" of the geologic timescale, which was a major step forward in developing global stratigraphy and gave birth to the Spectral Mapping Project (SPECMAP) of the 1970s and 1980s. Orbital tuning continues today as the primary stratigraphic method for extending high-resolution chronologies beyond the range of precise radiometric dating.

Given all that Nick has provided to ocean sciences in research and service, he is remarkably modest about his accomplishments. Despite this modesty, the rest of the community has long recognized that Nick is a scientist of the highest caliber and that he brings to all of his research and service an extraordinarily high level of rigor and integrity. His research contributions over the last 40 years represent a sustained level of excellence that has led to many new and profound insights into our understanding of the oceans and climate system, and his central role in developing and leading international programs in ocean sciences has been essential to the sustained health of the discipline. Nick Pisias has clearly achieved the expectations of being selected as a Maurice Ewing Medalist.

- Larry A. Mayer, School of Marine Science and Ocean Engineering, University of New Hampshire, Durham

\section{Response}

I have few simple life rules; one is, If you are the smartest person in the room, you're in the wrong room. My corollary is that if I were the smartest person in the collaboration group, I was in the wrong group. I started practicing this when I was a new graduate student and convinced Ross Heath and Ted Moore to take me on as their student to be funded by the newly funded Climate: Long-Range Investigation, Mapping, and Prediction (CLIMAP) project. Annually, the CLIMAP investigators and students would gather at Lamont Hall at Doc Ewing's Lamont Doherty Earth Observatory. Here I was given the opportunity to start a long collaboration with Jim Hays, John Imbrie, and Nick Shackleton. I was with some of the key founders of the field of quantitative paleoceanography. To keep me focused on the bigger picture of geological oceanography, I managed to share graduate student offices with David Rea and Margaret Leinen. Dave kept me being a geologist by teaching me the structural geology of ocean basins, and Margaret introduced me to some of the details of sediment geochemistry.
Just as I was leaving Rhode Island, I crossed paths with Larry Mayer. We again met on Deep Sea Drilling Project (DSDP) Leg 85 to start a long collaboration in ocean drilling. Going to sea with Larry proved to be an education in not only how to map the seafloor and the overlying sediment section but truly seeing the seafloor and understanding what makes up the paleoceanographic records we rely on for our research. When we ultimately drilled our selected sites, we recovered "gold."

After arriving at Oregon State University (OSU), I managed to convince the dean that we needed to hire a young Alan Mix. This started our 30 odd years of working on projects ranging from the Strait of Magellan to the fjords of Alaska. Alan's arrival at OSU was ultimately followed by Peter Clark and Ed Brooks. Our group was completed when we added atmospheric and ocean modelers Steve Hostetler and Andreas Schmittner.

With this group of collaborators how could I not come up with some clever ideas about the geologic history of the ocean. Enough, I guess, to earn this honor as the recipient of the Maurice Ewing Medal. They are not just my collaborators but my friends.

The best thing in all of this is that I had fun doing my work.

Do I have advice for young scientists? Be sure you're in the right room.

-Nicklas G. Pisias, College of Earth, Ocean, and Atmospheric Sciences, Oregon State University, Corvallis

\section{Dennis P. Lettenmaier Receives 2018 Robert E. Horton Medal}

Dennis P. Lettenmaier was awarded the 2018 Robert E. Horton Medal at the AGU Fall Meeting Honors Ceremony, held on 12 December 2018 in Washington, D. C. The medal is for "outstanding contributions to hydrology."

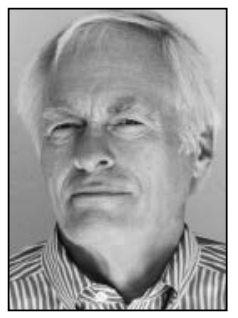

Dennis P. Lettenmaier

\section{Citation}

Over the past 3 decades, Dr. Lettenmaier has grown into the foremost pioneer in hydrologic land surface modeling. His key overall contribution in this evolution has been to take the lead in the macroscale parameterization of land surface variability, as it controls runoff production, integrated with a full land surface energy balance, including the effects of vegetation. With newly available global data sets, this combination of energetics appropriate for different scales has represented the critical step toward the study of continental and global hydrology, a challenge made by Eagleson in the 1980s to the hydrologic community. The foundational references by him and his collaborators have been widely used by scientists from as many as 54 different countries.

In parallel, Dr. Lettenmaier led major breakthroughs regarding the effects of climate and climate change on the hydrologic cycle. This work indicated how climate change issues can result in vastly different responses in the timing and amount of surface runoff, allowing the development of strategies for threatened arid-region basins. In systematic analyses of climate change in cold regions, he and his team developed a quantitative basis for estimating the fraction of snowmelt in the annual runoff of major river basins, and they explored the relative controls of temperature and precipitation changes on mountainous snow packs, causality of flood frequency changes, snowpack-associated runoff, evaporation, and, most recently, novel algorithms for frozen soils and permafrost representations and for snow interception and blowing snow.

Beside these two main lines of enquiry, Dr. Lettenmaier has made successful explorations of other areas as well. For instance, regarding the hydrologic aspects of the Anthropocene, he investigated and evaluated the relative impacts of climate change and land cover changes in coastal lowlands. In a major improvement in drought assessment, with his associates he put forth a severity-area-duration method, allowing unbiased comparison of envelope droughts over large continental areas.

These scientific contributions are widely acknowledged, and Dr. Lettenmaier has already been recognized with several prestigious awards. In addition, he has distinguished himself by his unselfish cooperation and leadership initiatives, as borne out by the numerous committee and editorial responsibilities he has assumed over the years. The Horton Medal is awarded in recognition for "outstanding contributions to hydrology." Unquestionably, Dr. Lettenmaier is a perfect embodiment of this ideal: His superior contributions through his intense dedication in scholarship and service place him among the very best in our hydrologic community.

-Wilfried H. Brutsaert, Cornell University, Ithaca, N.Y.

\section{Response}

I want to thank my nominator, Wilf Brutsaert, for his kind words, and Dan Cayan, Randy Koster, and Soroosh Soroosh- 
ian, who wrote in support of Wilf's nomination. I also thank the many students, postdocs, and staff who've worked with me over the years. This award is really about them.

I was lucky that my career coincided with a major transformation in hydrology and that it came about at an opportune time for me. In the mid-1980s, I was asked to participate in Environmental Protection Agency's (EPA) report to Congress on the effects of climate change on the United States. EPA wanted a study of climate change effects on California's water resources. I thought we could investigate a single reservoir to which we would perturb inputs on the basis of assumed changes in precipitation and evaporative demand. The response was "not good enough, we need you to do all of California." I really had no idea how, but with postdoc Thian Yew
Gan doing the hydrologic modeling and Dan Sheer the reservoir operations, we glommed something together. The exercise made clear to me that we simply didn't have the tools to do large-scale hydrologic prediction at that point. Shortly thereafter, discussions with Eric Wood led to conceptualization of the VIC model, followed shortly thereafter by Xu Liang's dissertation work that developed the first version of the model. That in turn led to further development work by many students and postdocs at the University of Washington and Princeton University. It also led to a host of studies on topics we (or at least I) hadn't begun to think of in those early daysdrought work (Kostas Andreadis and Kingtse Mo), data assimilation (Kostas Andreadis), and Arctic hydrologic processes and change (Laura Bowling, Fengge Su, and Jenny Adam), among just a few. In more recent years, we've turned our attention from "what will happen if" questions to "what has and is happening" in the spirit of what Rich Vogel has termed hydromorphology. In that vein, I think in particular of Phil Mote's declining mountain snowpack papers and current student Mu Xiao's recent Water Resources Research paper on causes of declining Colorado River streamflows. All told, it's been a great ride.

In closing, I want to thank AGU, which has been my professional home for well over $\mathbf{4 0}$ years. I think especially of AGU's motto "unselfish cooperation in research," which typifies the many collaborators I've worked with over the years; it's their shoulders on which I stand. Thank you to all.

-Dennis P. Lettenmaier, University of California, Los Angeles

\section{Timothy L. Grove Receives 2018 Harry H. Hess Medal}

Timothy L. Grove was awarded the 2018 Harry H. Hess Medal at the AGU Fall Meeting Honors Ceremony held on 12 December 2018 in Washington, D. C. The medal is for "outstanding achievements in research on the constitution and evolution of the Earth and other planets."

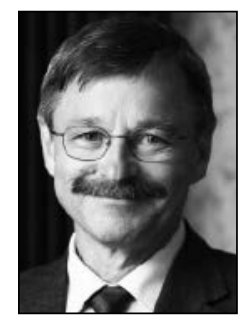

\section{Citation}

The formation of igneous rocks is the fundamental process of planetary differentiation. Tim Grove is one of the world's experts in igneous petrogenesis, having used a unique blend of fieldwork and laboratory experiments to make several key conceptual breakthroughs about the Earth and extraterrestrial bodies.

Mid-ocean ridge basalt (MORB), formed at divergent plate boundaries, is the most voluminous volcanic rock type on Earth. Tim experimentally mapped out the compositional space of MORB melts and developed a quantitative model that predicts the composition of magmas produced by mantle melting as a function of mantle composition, pressure, and temperature. This work showed that MORB compositions can be explained by low-degree melting over variable pressures and temperatures. This is perhaps the single most important body of experimental work in defining the nature of primary magmas of mid-ocean ridge magmatism.

Subduction zones constitute another major tectonic setting on Earth where magmas form. It has long been recognized that the compositions of most igneous rocks formed at convergent plate boundaries define a "calc-alkaline" trend, characterized by increasing alkali content without iron enrichment. Guided by fieldwork and phase equilibrium experiments, Tim showed that the calc-alkaline trend can be explained by the presence of magmatic water. This work serves as a foundation of our modern understanding of the role of water in the evolution of subduction zone magmas. Tim extended his knowledge of modern subduction zone processes to the Archean, showing that komatiite magmas were produced by hydrous melting in a subduction environment.

Tim has also made major contributions to our understanding of petrogenesis on the Moon and asteroids. He demonstrated that Apollo mare basalts were simple extrusions without extensive episodes of ponding on the lunar surface. His studies of lunar mafic glasses showed that the lunar mantle is compositionally heterogeneous, consistent with it being a frozen relic of the ancient magma ocean. He also showed that different meteorite classes can be related to one another by igneous differentiation processes and that these rocks sample different zones of differentiated planetesimals.

On top of his outstanding research achievements, Tim has an exceptional record of service, including as AGU president when he oversaw significant changes in AGU's governance structure. Tim's legacy continues beyond his own research through his education of a large number of extraordinary students who are successful and influential scientists in their own right.

-Benjamin P. Weiss and Oliver E. Jagoutz, Mas sachusetts Institute of Technology, Cambridge

\section{Response}

I feel very honored to be receiving the Hess Medal. The citation is almost exclusively about scientific accomplishments,

\section{Get Eos highlights in your inbox every Friday.}

Visit bit.ly/Eos_Buzz to sign up for the Eos Buzz newsletter. and I would like to take some time to talk about how all that science happened. One of the most rewarding things for me has been working with many graduate students, postdocs, and collaborators as together we have moved science forward. I have always thought that mentoring and training the next generation of scientists is one of my primary responsibilities. I am very proud of you all and feel that you are also an important part of my work and that we all share this award.

And there is a Harry Hess connection that relates to mentoring. Harry Hess was one of my first scientific heroes. In 1970 at University of Colorado Boulder, we went on a field trip to the Stillwater layered igneous complex in Montana. I asked my professor/mentor, Bill Braddock (Princeton, Ph.D., 1959), if there was something I could read before the trip. He replied, Hess's 1960 memoir. So I did, and I saw the remarkable breadth of approach that Hess had taken. Hess tied together excellent field observations with careful characterization of mineralogy and petrology to tell an amazing story of the crystallization processes that led to the development of this layered series. In it, Hess discussed phase equilibria of the pyroxene minerals, compositional evolution of the crystallizing melts, and the fluid dynamics of magma chamber processes.

In 1971 I went to graduate school at Harvard, where we studied lunar samples newly returned by the Apollo missions that Harry Hess helped to plan. Then it was off to a postdoc at Stony Brook, where Don Lindsley (Princeton, AB, 1956, who worked for Harry) taught me everything he knew about experimental petrology. Next was a job as a professor at the Massachusetts Institute of Technology/Woods Hole Oceanographic Institution, where we studied the processes that led to the formation of the rocks on the ocean floor, an area where Hess was a pioneer.

Hess inspired new thinking in many areas of the Earth and planetary sciences, and he mentored outstanding geologists like Braddock and Lindsley, who, in turn, mentored me.

In closing, it has also been deeply satisfying to help AGU move into a new era of governance and engagement with society. Also, I have had incredible support from my wife and sons, Matthew and Michael, while I have embarked on my scientific adventures. Thanks to you all.

-Timothy L. Grove, Department of Earth, Atmospheric and Planetary Sciences, Massachusetts Institute of Technology, Cambridge 
Isaac M. Held Receives 2018 Roger Revelle Medal

Isaac M. Held was awarded the 2018 Roger Revelle Medal at the AGU Fall Meeting Honors Ceremony, held on 12 December 2018 in Washington, D. C. The medal is for "outstanding contributions in atmospheric sciences, atmosphere-ocean coupling, atmosphere-Iand coupling, biogeochemical cycles, climate or related aspects of the Earth system."

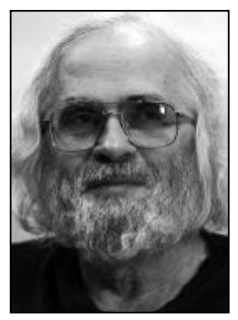

Isaac M. Held

\section{Citation}

Isaac Held is recognized for his outstanding scientific contributions to the understanding of the dynamics of the Earth's atmosphere and climate and for his pioneering insights into the structure of atmospheric circulation patterns and the interplay with the Earth's hydrologic cycle. He is one of the deepest thinkers and a leading authority in climate dynamics, with his innovative science yielding novel perspectives on fundamental aspects of the atmospheric general circulation such as the width of the Hadley cell, relation between large-scale temperature gradients and eddy fluxes, and partitioning of heat transport in the tropics between the oceans and atmosphere. His achievements include development of a hierarchy of dynamical models of increasing complexity that have provided new pathways toward unraveling the complexity of the climate system.

Isaac's insightful exposition of the spatial pattern of the response of the hydrological cycle to a warming of the climate, developed from basic thermodynamic and dynamical considerations, has established a firm quantitative basis. This has now become an essential component in our understanding of how, in a warming world, changes in the hydrological cycle and other related properties of the climate system, such as the global distribution of winds and storms, can be related to physical principles.

His exceptional scientific leadership at the National Oceanic and Atmospheric Administration's (NOAA) Geophysical Fluid Dynamics Laboratory (GFDL) has included playing a key role in the development and application of state-of-the-art atmosphere and climate models to address major questions, e.g., the timescales of response to anthropogenic forcing and changes in tropical storms and Southern Hemisphere circulation under climate change.

Isaac is member of the National Academy of Sciences and a Fellow of AGU and the American Meteorological Society (AMS). He has received the AMS Carl-Gustaf Rossby Research Medal, Banco Bilbao Vizcaya Argentaria (BBVA) Frontiers of Knowledge Award for Climate Change research, and Presidential Rank Award of Distinguished Senior Professional.

Isaac's scientific citizenship spans an amazing range. His elegant articulation of how global warming can enhance hydrological extremes, both wet and dry, was pivotal in the Intergovernmental Panel on Climate Change's assessment (2007). His essays on large-scale dynamics, global warming, and climate modeling are lucid, thought provoking, and influential. His blog on climate dynamics is widely acclaimed for its wisdom and clarity. As a lecturer with the rank of professor in the Atmospheric and Oceanic Sciences Program at Princeton University, he has mentored more than $\mathbf{2 0}$ doctoral students and 30 postdoctoral scientists.
Isaac's outstanding scientific accomplishments in atmospheric and climate dynamics make him one of the world's foremost experts in climate science, a scientist extraordinaire truly worthy of Roger Revelle's giant legacy in climate science and leadership.

-V. Ramaswamy, Geophysical Fluid Dynamics Laboratory, Office of Oceanic and Atmospheric Research, National Oceanic and Atmospheric Administration, Princeton, N.J.

\section{Response}

Thanks, first of all, to my nominators and the selection committee. The Revelle Medal is a wonderful honor.

I have had the great fortune of working at GFDL, a very distinctive NOAA laboratory, for $\mathbf{4 0}$ years, with the freedom to pursue my interests in atmospheric dynamics and climate change. I especially need to thank the lab directors who have supported me in interpreting NOAA's mission-to understand and predict changes in climate, weather, oceans, and coasts-as encompassing even my most theoretical research. Let me first thank Ram, Dr. Ramaswamy, for his support in the most recent decade and, working backward in time, Ants Leetmaa, Jerry Mahlman, and, of course, Joe Smagorinsky.
I was first drawn to GFDL and Princeton in the 1960 s by reading Suki Manabe's papers on climate modeling and global warming. Simply stated, Suki has the best holistic understanding, the best intuition, for how the climate system works of anyone I have ever met. Whatever success I have had has resulted in large part from some of Suki's understanding and intuition rubbing off on me over the years.

My motivation when I originally switched fields from theoretical physics was to focus on global warming. But I first went on a multidecade journey through basic atmospheric dynamics, searching for a more fundamental understanding of the general circulation of the atmosphere, before gradually turning to aspects of climate change. I would like to interpret this award as recognizing the journey as a whole and not a few discrete stops along the way. At every step on this journey, my work has depended on my graduate students at Princeton, my postdocs, and, of course, my colleagues within and outside of GFDL. I have accumulated too many debts over the years to mention individual names.

Finally, let me thank my wife, Joann, who has received her share of awards for her environmental work, not on the global scale but rather on the scale of our township. She recently was officially designated a Force of Nature by a local environmental group. I haven't figured out how to incorporate this force into the equations of motion in our models, but perhaps it is something that we can work on together in the future.

-Isaac M. Held, Geophysical Fluid Dynamics Laboratory, National Oceanic and Atmospheric Administration, Princeton, N.J.

\section{Yoshio Fukao Receives 2018 Inge Lehmann Medal}

Yoshio Fukao was awarded the 2018 Inge Lehmann Medal at the AGU Fall Meeting Honors Ceremony, held on 12 December 2018 in Washington, D. C. The medal is for "contributions to the understanding of the structure, composition, and dynamics of the Earth's mantle and core."

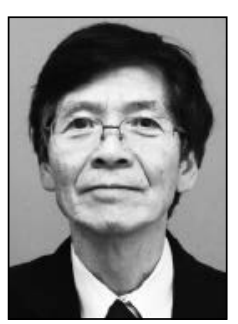

Yoshio Fukao

\section{Citation}

Yoshio Fukao is a deep thinker with influential ideas who has made outstanding observational and theoretical contributions to solid Earth geophysics using seismological tools.

He has been a leader on imaging of subducted slabs in the mantle transition zone. His interest in processes related to subduction started with the characterization of

the sources of large and, in particular, deep earthquakes. Later, he clarified the depth extent of subducted oceanic basaltic crust before its transformation to eclogite, thus providing insights on the physical conditions in the slab down to 60 kilometer $(\mathrm{km})$ depth. In the 1990s, he showed two classes of behavior of slabs around the world: those that lie horizontally above the 660-km discontinuity, which he coined "stagnant slabs," and those that penetrate deeper and are not as directly connected to present-day subduction. This showed that the Earth's mantle is in an intermediate state between two highly debated dynamic extremes: one-layer and two-layer convection. Recently, analysis of the latest high-resolution $P$ wave global model developed with former student Masayuki Obayashi led them to demonstrate that most slabs either stagnate above $660 \mathrm{~km}$ or flatten out deeper, around $1,000 \mathrm{~km}$ depth. These results have turned the attention of the community to a possible rheological boundary around $1,000 \mathrm{~km}$ depth and have inspired further studies in geodynamics and mineral physics, aiming at understanding the nature and significance of this potential redefinition of an extended transition zone.

Yoshio Fukao has also worked extensively on Earth's free oscillations and contributed to another important discovery: that of the presence, in the absence of earthquakes, of a low-frequency "hum" continuously excited by sources in the oceans and/or the atmosphere, which, when applied to planets without earthquakes, may provide a powerful way to study their internal structure.

He has been an exceptional mentor to younger scientists. He has also been a leader in the establishment of research infrastructure in Japan, such as the "Earth simulator" and the Institute for Frontier Research on Earth Evolution, and has been a driving force for the Japanese contribution to international infrastructure in broadband seismology, notably on the 
ocean floor with programs such as the Ocean Hemispheres Project.

Even though he had to retire from teaching already in 2004, Yoshio Fukao remains impressively active in research, trying out new directions, as evidenced by his latest papers on ocean bores and fine-scale structure in the ocean column.

-Barbara A. Romanowicz, University of California, Berkeley; also at Collège de France, Paris

\section{Response}

It is my great honor to be awarded the 2018 AGU Inge Lehmann Medal in recognition of my seismological contributions to solid Earth geophysics. I am especially grateful to Barbara Romanowicz for her citation and would like to thank all who supported my nomination.

My research career started with an experimental study of thermal properties of mantle minerals at the University of Tokyo about 50 years ago. This was to become the backbone of my seismological studies later on. I thank my colleagues in mineral physics, from whom I learned a lot about the rock physics view of Earth. I am deeply indebted to my thesis advisers, Seiya Uyeda and Hiroo Kanamori, for their continued thoughtful advice and encouragement. I spent a year in the 1970s as a postdoc at the University of Cambridge, where I learned a lot from Dan McKenzie about the plate tectonic view of Earth. I then spent 20 years at the early stage of my career at Nagoya University, where I enjoyed everyday discussions and conversations through which we shared surprise and excitement among the colleagues and students in different fields.

$\mathrm{I}$, as a seismologist, have been interested in subduction dynamics and interaction of the solid Earth with the atmosphere and oceans. My findings in the first category include near-trench occurrence of tsunami earthquakes, subduction of untransformed oceanic crust, and, most importantly, stagnant slabs in the mantle transition region. Findings in the second category include Earth's background free oscillations (Earth's hum). Most of these findings were made in collabora- tion with my colleagues. In particular, I am grateful to Masayuki Obayashi, Kiwamu Nishida, and Hiroko Sugioka for thei long-continuing collaborations in seismic tomography, Earth hum analysis, and ocean bottom seismology, respectively.

About 20-30 years ago I was involved in building a broadband seismographic network in the western Pacific in a Japanese initiative as part of the international collaborative effort of covering Earth's surface with broadband seismic stations. I now belong to the Japan Agency for Marine-Earth Science and Technology (JAMSTEC), where I am excited about deploying geophysical instruments at the ocean bottom in the hope to expand the scope of seismology beyond the solid Earth.

As such, I would have been unable to conduct my research without generous support from many people. I express my sincere gratitude to all of them, including my family.

-Yoshio Fukao, Japan Agency for Marine-Earth Science and Technology, Yokohama

\section{David Sandwell Receives 2018 Charles A. Whitten Medal}

David Sandwell was awarded the 2018 Charles A. Whitten Medal at the AGU Fall Meeting Honors Ceremony, held on 12 December 2018 in Washington, D. C. The medal is for "outstanding achievement in research on the form and dynamics of the Earth and planets."

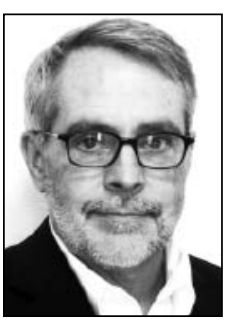

David Sandwell

\section{Citation}

David Sandwell is the preeminent leader in applying satellite altimetry data to determine the marine gravity field and seafloor topography to elucidate the thermal and mechanical behavior of the oceanic lithosphere. Through his deep knowledge of space-based radar mapping and altimetry he has made fundamental contributions to understanding the form and

dynamics of Venus and the icy moons of Jupiter. When satellite radar interferometric imaging of earthquake processes became possible in the early 1990s, David had just the skill set to enter this field and make both methodological and fundamental contributions that continue to this day.

$\mathrm{He}$ is a master of detail and thoroughness, and the methods he has developed have become standard. Through his selfless generosity he has made both codes and data sets publicly available for wide use by his colleagues. However, David is not primarily a methods person. For example, he developed powerful interferometric synthetic aperture radar (InSAR) analysis tools to enable insightful research exploring fundamental processes of crustal deformation. These include characterizing coseismic rupture, postseismic relaxation, and the nature of interseismic strain accumulation. He recognized the potential of InSAR to capture both fine details of deformation and broad-scale coverage. His group was the first to develop a plate-boundary-zone-wide InSAR data set spanning the San Andreas fault system that, when integrated with GPS, provided the most comprehensive characterization of distributed deformation along this continental transform zone.
One of David's greatest accomplishments is becoming a truly outstanding scientist while retaining a healthy work-life balance. He is modest and unassuming, living proof it's not necessary to be a one-dimensional workaholic to be a successful scientist. He is as comfortable on a surfboard as on a keyboard and makes time for his family and his surfing. He is a positive role model to his students, his postdocs, and his colleagues and has left in his wake a trail of happy collaborators from all over the world.

In summary, David Sandwell has, through is research, placed the fields of marine gravity, planetology, and earthquake deformation on a firm quantitative basis; developed rigorous and innovative new methods; discovered hitherto unknown processes; and trained a cadre of graduate students and postdoctoral scholars who now pursue their own research agendas. The arc of David's career path and his central scientific contributions are nicely described by AGU's statement of the qualifications for the Whitten Medal, "outstanding achievement in research on the form and dynamics of the Earth and planets."

\section{-Wayne Thatcher, U.S. Geological Survey, Menlo} Park, Calif.

\section{Response}

Thank you, Wayne, for this generous citation, and I also thank the scientists who supported this nomination. This is a real honor for an aging geophysicist with some geodetic skills.

As a graduate student at the University of California, Los Angeles, I was fortunate to study under Jerry Schubert, who taught me the importance of physics-based models; Jerry also encouraged my forays into space geodetic data analysis that were inspired by Bill Kaula, Byron Tapley, Dick Rapp, and many other pioneers. Because of their vision and persever- ance, we now have tools such as GPS, radar interferometry, and satellite altimetry to study all types of Earth processes at unprecedented spatial and temporal resolutions; these include plate tectonics, ocean currents, and changes in the cryosphere. The past 3 decades have offered a real data feast for Earth scientists, and I was fortunate to be able to help prepare the recipes and be thrilled by the discoveries. I hope we can improve the tools and research opportunities for the next generation.

I began my geodetic career using radar altimeter data from NASA, U.S. Navy, and European Space Agency (ESA) satellites to study the tectonics of the deep oceans. This was a 20-year collaboration with Walter Smith and several talented graduate students. In the late 1990s I began a new research direction to study continental crustal deformation using radar interferometry (InSAR) and GPS. Wayne Thatcher inspired this conversion by taking a sabbatical to learn InSAR from Didier Massonnet and colleagues at ESA. Howard Zebker, Masanobu Shimada, and others at the Jet Propulsion Laboratory, ESA, and the Japan Aerospace Exploration Agency got us started in the development of SAR processing algorithms that utilize precise satellite orbit methods developed by the altimetry community. Paul Segall, Yuri Fialko, and others laid out the models needed to digest the wealth of crustal deformation data provided by GPS and InSAR. All of this relied on the dramatic increases in computer capabilities that we have witnessed over the past 40 years.

Scripps Institution of Oceanography has provided the stimulating intellectual environment and freedom to participate in basic research as well as to train, and learn from, extraordinary students. Moreover, Scripps has one of the best surfing beaches in the world, and as Wayne mentioned, I have often used a midmorning surfing session to clear my thinking. I thank my wife, Susan, who takes care of most of the practical aspects of our life, and also my family, who have tolerated many absences, both physical and mental, that are typical of scientists.

-David Sandwell, University of California, San Diego, La Jolla 


\section{Bachmann and Yizengaw Receive 2018 Joanne Simpson Medal}

Olivier Bachmann and Endawoke Yizengaw were awarded the 2018 Joanne Simpson Medal at the AGU Fall Meeting Honors Ceremony on 12 December 2018 in Washington, D. C. The medal is for "significant contributions to the Earth and space sciences by an outstanding mid-career scientist."

Olivier Bachmann

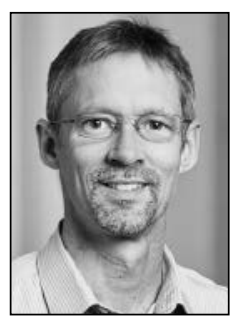

Citation for Olivier Bachmann It is my great pleasure to introduce one of the two inaugural recipients of the Joanne Simpson Medal, Olivier Bachmann. Olivier has made important contributions to the field of volcanology using a combination of field work, geochemistry and petrology, geochronology, and physical modeling. It is this ability to combine various disciplines and address fundamental questions

regarding the physical and chemical evolution of magmas that is the hallmark of Olivier's research.

Olivier's intellectual curiosity and boundless energy caught the attention of Michael Dungan and Peter Lipman (at the U.S. Geological Survey) as he started a Ph.D. on the eruption sequence of the Fish Canyon magma body (Pagosa Peak Dacite and the Fish Canyon Tuff). Integrated over his graduate studies, Olivier spent over a year in the field in southern Colorado, mapping and sampling these units. The publications that resulted have had a deep impact and opened new perspectives in our understanding of the systems that feed caldera-type eruptions. Olivier's early research also highlighted the importance of magmatic mushes in controlling the physicochemical evolution of magma reservoirs.

As Olivier established himself as a leader in petrology and geochemistry of silicic magmas, he decided to develop a new and complementary set of skills, a courageous choice that is typical of Olivier's mindset. He joined forces with George Bergantz (University of Washington) to develop physical models for magmatic processes and published two landmark papers on the generation of high-silica rhyolites and the reactivation of magmatic mushes preeruption. Olivier's ability and willingness to push beyond the boundaries of his own field are a recurring theme; the same spirit led him later to take an active role in the Imaging Magma Under St. Helens (iMUSH) project, whose aim is to combine petrology and geophysics to better constrain the state of active volcanic centers in the Cascades.

Since 2012, Olivier has been the chair of the Institute of Geochemistry and Petrology at Eidgenössische Technische Hochschule (ETH) Zürich. His group is working on a variety of exciting and creative projects combining magmatic petrology, geochemistry, geochronology, and numerical modeling. On a more anecdotal note, Olivier holds now another distinction: He has taught the principles of volcanology in three different languages. Olivier's enthusiasm and passion, as well as his unfaltering support, have had a deep influence on the career of many researchers in and outside his own group. I am proud to present my dear friend and inspiring collaborator as a recipient of the Joanne Simpson Medal.

-Christian Huber, Brown University, Providence, R.I.

\section{Response}

Thank you, Christian, for your nomination, your kind citation, and your boundless support over all these years. Clearly, without you, my route would have followed a much less exciting path, and your amazing creativity, breadth, and understanding of the laws that control our fates (in science and other fields) have been, for me, powerful sources of inspiration. Being able to work with a such a friend is a chance I truly cherish.

I am, of course, deeply honored to receive such a medal, remembering the remarkable achievements of a woman and celebrating diversity within AGU. I am indebted to the letter writers and committee of this honors program, who make a tremendous effort to encourage our community to become better.

As Christian mentions in

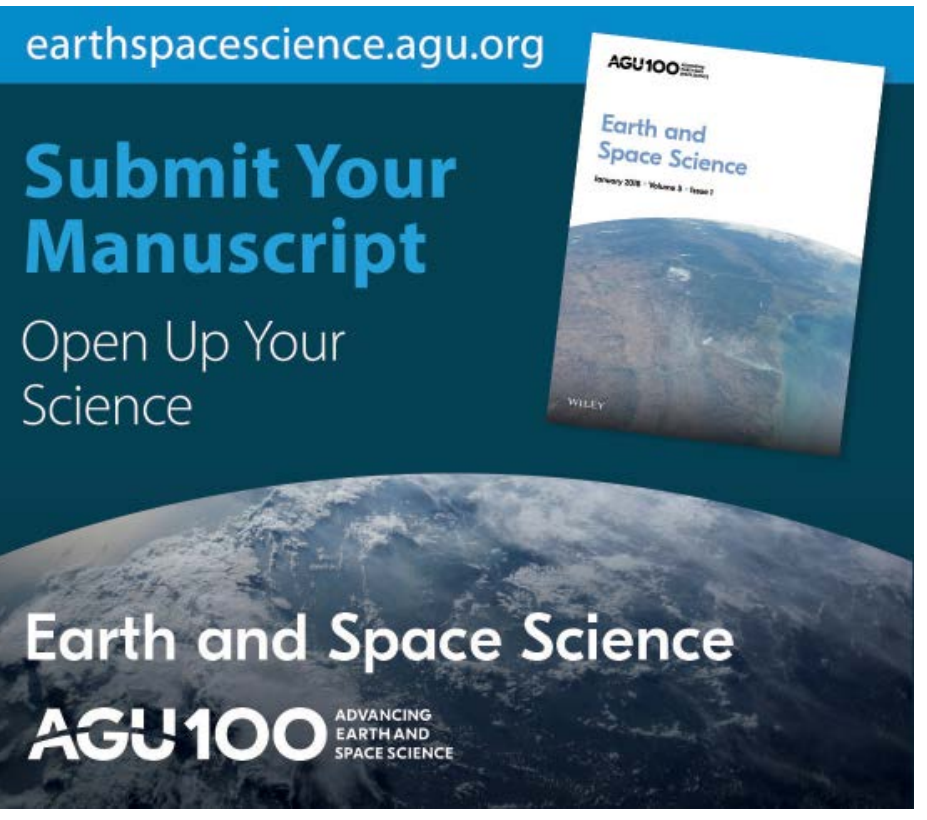

his citation, I am interested in coupling different fields to try and shed light on interesting aspects of our planet. In this endeavor, collaboration is key, and much of what I have been able to achieve over the years relies on people who have given me their trust and worked with me. Obviously, there are too many people I should thank for this list, but allow me to single out a few. First, I send my deepest appreciation to my mentors over the years, first at the University of Geneva (Mike Dungan), at the U.S. Geological Survey (Peter Lipman), and at the University of Washington (George Ber-

gantz). Their support and the motivating atmosphere they fostered were key in the first steps of my career. I also want to thank all the students and postdocs (in particular, in the postdoc crowd, Chad Deering, Andrea Parmigiani, Wim Degruyter, Ozge Karakas, Ben Ellis, Matthieu Galvez, and Jörn Wotzlaw) who have shared their enthusiasm for magmas and volcanoes with me over the years; the working atmosphere in the group, particularly these last few years at ETH, has been fantastic, and their energy and creativity have been some of the most fulfilling rewards I have received.

As Joanne Simpson reputedly said, combining a career in academia and strong family ties is an amazing challenge; I am more than indebted to my own house team, my parents, my sister, my wife, and my three beautiful children, for turning this challenge into an everyday pleasure. This medal is for my dad, in memory of his boundless tolerance, enthusiasm, and humility.

-Olivier Bachmann, Eidgenössische Technische Hochschule Zürich

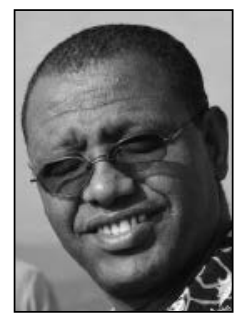

Endawoke Yizengaw

\section{Citation for Endawoke Yizengaw}

Endawoke Yizengaw is the epitome of the AGU Joanne Simpson Medal. He has demonstrated scientific excellence in space science research; performed active outreach to the international space weather community; and dedicated strong commitment to his colleagues, students, and postdocs.

I've come to know Endawoke not only for his scientific prowess but also for his life story, how he became a great scientist and a great man after very humble beginnings in Ethiopia. Endawoke was born the youngest child of a large Ethiopian family in a rural village where herding and animal care were his primary activities. School was attended by walking long distances every day. His brilliance was recognized by his teachers, who encouraged him (and his family) to stay in school and later to attend university. He obtained a B.S. in physics at Addis Ababa University, a M.S. in atmospheric physics from the University of Tromsø, and a Ph.D. in space physics from La Trobe University in Australia. Since then, he has done much to advance space physics exploration with a keen interest to develop infrastructure and education in space science in developing countries. Considering his humble beginnings, these are admirable accomplishments.

Endawoke has contributed significantly to the scientific literature on the complexities of ionospheric electrodynamics. He has published scores of high-impact papers using multiple instrument techniques from ground and space. Two of his early papers were selected for the cover of Geophysical Research Letters. One of those papers proved a long-standing conjecture that the ionospheric trough is the signature of a boundary in the magnetosphere. More recent publications describe work where he used ground-based measurements to demonstrate that dayside electrodynamics display not only temporal and seasonal variations but also very strong gradients versus longitude. In addition, Dr. Yizengaw developed the African Meridian B-field Education and Research (AMBER) network of magnetometer instruments in more than 10 countries. 
Besides his scientific contributions, Endawoke has played a vital role in the expansion of space science education and research in developing countries. He participates in the International Space Weather Initiative (ISWI), was active in the International Heliophysical Year (IHY) program, and has performed scientific outreach programs for young scientists in the United States and developing nations. He has coconvened conferences and schools in Africa, including an AGU Chapman Conference and a number of ISWI and IHY programs. Endawoke has also mentored postdocs and Ph.D. students who have gone on to develop research programs in developing countries.

To summarize, Dr. Yizengaw is an eminent mid-career scientist with attributes emphatically worthy of the AGU Joanne Simpson Medal.

-Patricia H. Doherty, Boston College, Mass.

\section{Response}

Thank you, Pat, for those overly kind words. It is my great honor to receive this award. The fortunate start of my career has depended intensely on the support of family members. I grew up as the youngest of seven children in my family in Amber, a village in northwestern Ethiopia. Although my primary task as a child was to look after the family's cattle, I joined the nearby elementary school through the influence of my grandfather. However, my parents envisioned me taking over the family farm and eventually forced me to stop my education at grade 4. Two years later, two policemen came to our home with a letter from the principal of my school. It was a warning letter that urged my father to send me back to school or face a legal penalty. It was shocking news for my parent but for me a miraculous gift. Later, I learned that it was my brother Gelaye Leyikun, an elementary school teacher, who used his friend (the principal) to force his own father and pave my way back to school.

My interest in science began in middle school, and I became interested in space science after I listened to a radio interview with an Ethiopian aerospace scientist. It motivated me to search for opportunities around the world to study space science, and I joined Troms $ø$ University in Norway for M.Sc. studies and La Trobe University in Australia for my Ph.D. degree. In May 2004 I joined the University of California, Los Angeles, as a postdoc with Mark Moldwin, who showed me all the necessary tools to be a good scientist and poured everything he had into me to boost my visibility in the space science community. I joined Boston College in 2009 and became fortunate to work very closely with very talented scientists. Specifically, I am indebted to Pat Doherty, our director, for her enthusiastic support of my research and international outreach activities. I am also so grateful to the funding agencies that made my dream a reality.

Last, but not least, this would have not been possible without the love and friendship of my wife, Yemisirach, and hugs from my kids, Hanna and Yoseph. There are also so many more family members, friends, and colleagues l'd like to thank but cannot name. Most importantly, I simply would not be here without the enthusiastic support of my late parents and brother (Gelaye Leyikun), who nurtured my academic success not only to be a scientist but also to see the world at large and to imagine and research even far from the horizon.

-Endawoke Yizengaw, Boston College, Mass.

\section{Mentoring365: New and Improved Mentoring Interface}

A s we embark upon AGU's Centennial, we reflect back on a century of discoveries, innovations, solutions, and collaborations and look forward to the next century of exciting possibilities. From this contemplation, it is clear that our mission to promote discovery in Earth and space science for the benefit of humanity will soon rest in the hands of the next generation of scientists.

What will that generation of scientists look like, and what challenges will they face?

Mentorship provides a critical opportunity for professionals at any stage to learn from the insights and experiences of established scientists as they navigate their careers and define their professional goals. To help enable a diverse community of Earth and space scientists to succeed in their chosen fields, AGU and its partners, the Society of Exploration Geophysicists, the Association for Women Geoscientists, the American Meteorological Society, and the Incorporated Research Institutions for Seismology, are proud to offer a suite of enhancements to the successful Mentoring365 program.

Mentoring That Transcends Boundaries Mentoring opportunities can often be inaccessible to many because of socioeconomic constraints, limited local scientific networks, or an inability to attend annual society meetings where professional relationships are often forged. Enter Mentoring365. First launched in 2017, Mentoring 365 is a year-round program that brings together early- and advanced-career Earth and space scientists to help facilitate the sharing of professional knowledge, expertise, skills, and insights. As of 3 December 2018, the program had already matched 262 mentors and mentees via its online platform. Key to the program's success is its ability to transcend geographic boundaries. More than half of mentees $(51 \%)$ and $38 \%$ of mentors came from outside the United States. Furthermore, nearly two thirds of mentees chose a mentor from a different country, helping connect scientists from all over the world.

\section{Improved Facilitation of Mentorship}

Now, a year after its inception, Mentoring365 is getting an upgrade. The improved platform offers a more diverse mentor pool with expertise spanning industry, academia, and government. The new Mentoring365 platform uses algorithms to match mentees with scientists whose research interests and mentoring goals more closely align with their own. The update also offers inplatform messaging and a mobile app. In addition, mentors and mentees can track progress toward goals and receive messages from Mentoring365 that help enhance resource sharing and discussion facilitation.

Free to all members of the Mentoring365 partner societies, the improved platform creates a high-impact sharing experience that will prove vital in ensuring that the geosciences promote an increasingly inclusive, interconnected, and knowledgeable workforce prepared to face the challenges of the next 100 years.

\section{Give Back to the Scientific Community} If you are an early-career scientist looking for career guidance in your field, or if you are an experienced Earth and space scientist looking to give back to your scientific community, I hope that you will consider becoming a part of Mentoring365. The effectiveness of our science on the world around us, including economic, environmental, and human health conditions around the globe, will depend upon growing a diverse and inclusive community of researchers ready to lead the way.

There is more to this transition than simply passing a baton across generations. Effective mentoring can help open doors to new possibilities for a new generation of scientists to lead us into our next century of scientific discovery for the benefit of humanity.

Learn more about Mentoring365 at bit.ly/ mentor-365.

By Eric A. Davidson (president@agu.org), President, AGU 


\section{Invasive Freshwater Mussels Drive Changes in Estuary Sediments}

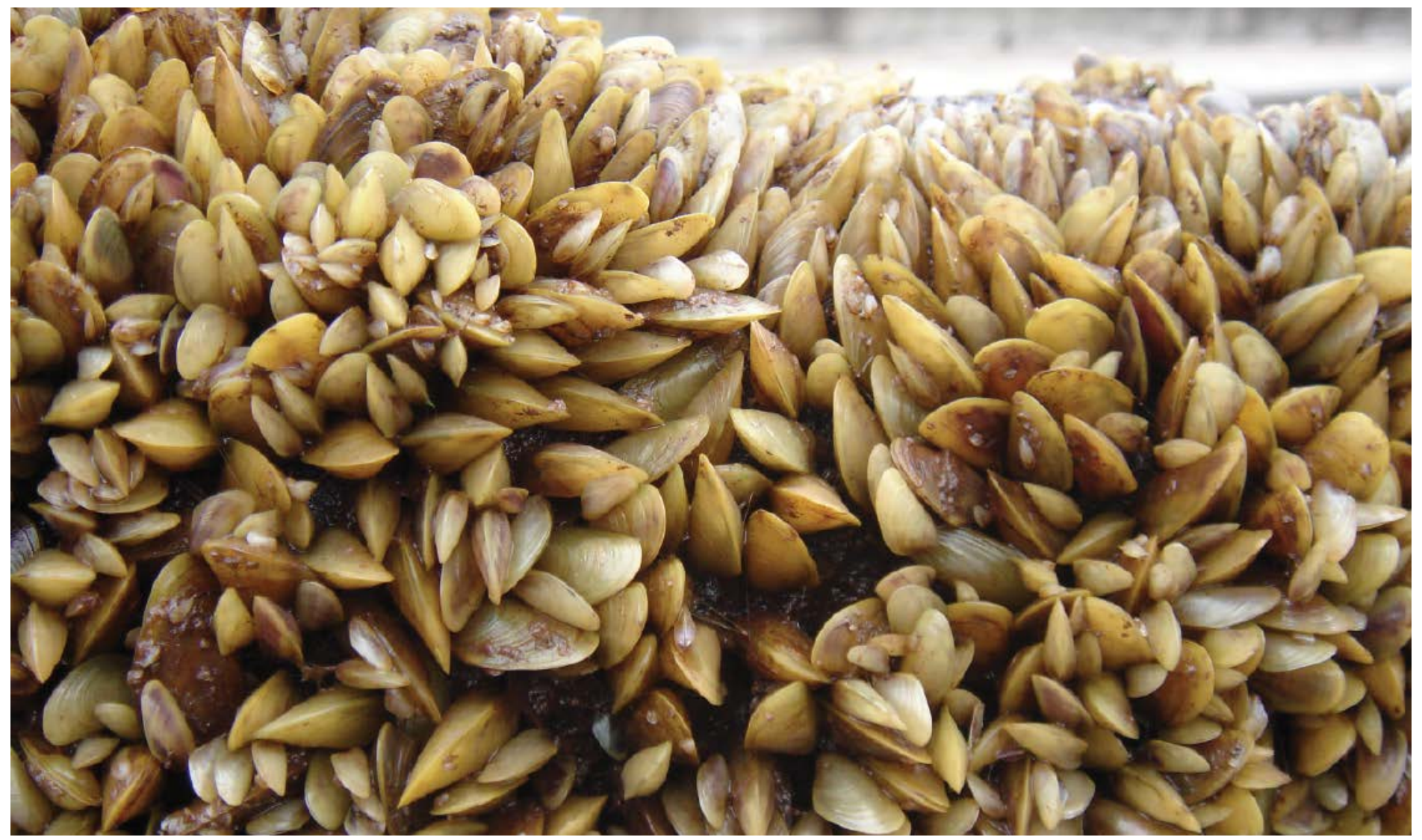

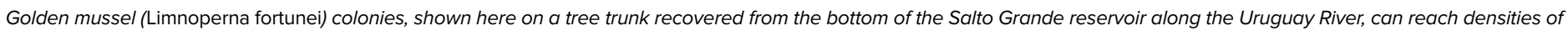
over 200,000 individuals per square meter. Credit: Boltovskoy, CC BY-SA 4.0 (bit.ly/ccbysa4-0)

$\mathrm{T}$ he rapid expansion of human transportation networks in the latter half of the 2oth century yielded unprecedented economic and cultural exchange between nations but also ushered in a new era of human-mediated biological introductions. On land and in water, exotic species are reshaping the ecology of ecosystems around the world.

One such invader is the golden mussel (Limnoperna fortunei). The freshwater mollusk arrived in South America around 1990 from China and quickly spread up the Paraná and Uruguay Rivers from the Río de la Plata estuary in Argentina. By 2017, it had reached densities exceeding 200,000 individuals per square meter in waterways across five countries. In less than 30 years, the mollusk became a major biofouling agent in industrial cooling systems and a benthic invader.

The mussel's rapid invasion has transformed the aquatic environment, both bio- logically and physically. Biologically, the mollusk has reshaped species interactions thousands of years in the making. Physically, however, its impact is less clear. To better understand the environmental effects of the invasive species, Tokumon et al. studied how the mussel influences the sediments and geochemistry of the Río de la Plata estuary near Buenos Aires.

Over the course of 1 year, the researchers fed estuary water through 18 containers that contained water intake and outlet pipes. Half the units included mussels; half did not. The study monitored the changes in the accumulated sediment-concentrations of organic matter, nitrogen, and phosphorus - in the experimental units at monthly, biannual, and annual intervals.

The results indicate that golden mussels doubled the rate of sediment buildup and strongly enhanced the amount of organic matter and nitrogen in the sediment. The data largely align with previous findings on the effects of zebra mussels and other filterfeeding mollusks.

The mussels did not significantly alter phosphorus concentrations in the sediment, however. The broader body of research contains many conflicting conclusions on the effects of mollusks on sediment phosphorus levels, and this research contributes another data point to the still unresolved question.

Although the study's conclusions should be viewed in the context of experimental conditions and carefully extrapolated to field conditions, they nevertheless offer new insights into how the golden mussel changes aquatic sediments and affects bottomdwelling fauna. (Journal of Geophysical Research: Biogeosciences, https://doi.org/10 .1029/2018JG004399, 2018) -Aaron Sidder, Freelance Writer 


\section{Karst Groundwater Contributes to Deformation in Eastern Alps}

$\mathrm{M}$ ost seismicity on Earth comes from the classic movement of tectonic plates sliding and colliding above the planet's mantle, but other, more localized forces can deform the crust as well. In a new study, Serpelloni et al. used GPS measurements from the Eastern Alps to monitor how rainfall and hydrological conditions con-

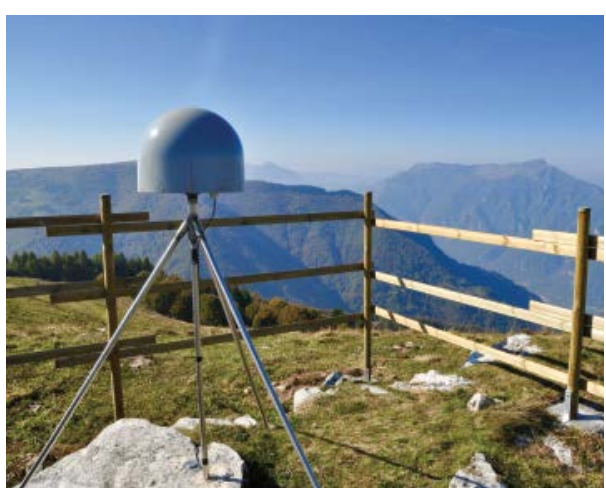

A GPS station located at the top of an anticline hosting a karst aquifer, looking north toward the Belluno Valley and the Dolomites. Credit: Enrico Serpelloni tribute to ground deformation in this tectonically active region.

The Eastern Alps and the Dinarides feature areas characterized by classic karstic geography, in which water has gradually dissolved the limestone foundation that underlies the region's mountains and valleys. As a result, the terrain is marked by abundant sinkholes, caves, and aquifers. The researchers suspected that the karst, especially changes to aquifer water levels, might produce a measurable strain in the region .

Fortunately, the Eastern Alps are also rife with GPS stations that can precisely track ground displacement over time. Using data from these stations, the researchers applied a "blind source separation" algorithm that allowed them to isolate ground displacement in the region that was caused by forces other than classic plate tectonics. They eventually uncovered several different displacement signals across multiple spatial and temporal scales. In particular, the scientists found a nonseasonal signal showing horizontal deformation that correlated to rainfall in the region on monthly timescales. They attribute this signal to pressure changes resulting from fluctuating water levels within the vertical fractures of different karst systems.

The researchers say that together, the results demonstrate that this technique can be used to measure millimeter-scale transient deformations caused by changes to groundwater flow and precipitation. The team also suggests that in addition to giving more accurate measurements of tectonics in karst regions, similar studies may be useful for measuring groundwater resources. (Journal of Geophysical Research: Solid Earth, https://doi.org/10.1002/2017JB015252, 2018)

-David Shultz, Freelance Writer

\section{Read it first on EOS.org}

\section{Articles are published on Eos.org before they appear in the magazine.}

\section{Visit https://eos.org daily for the latest news and perspectives.}

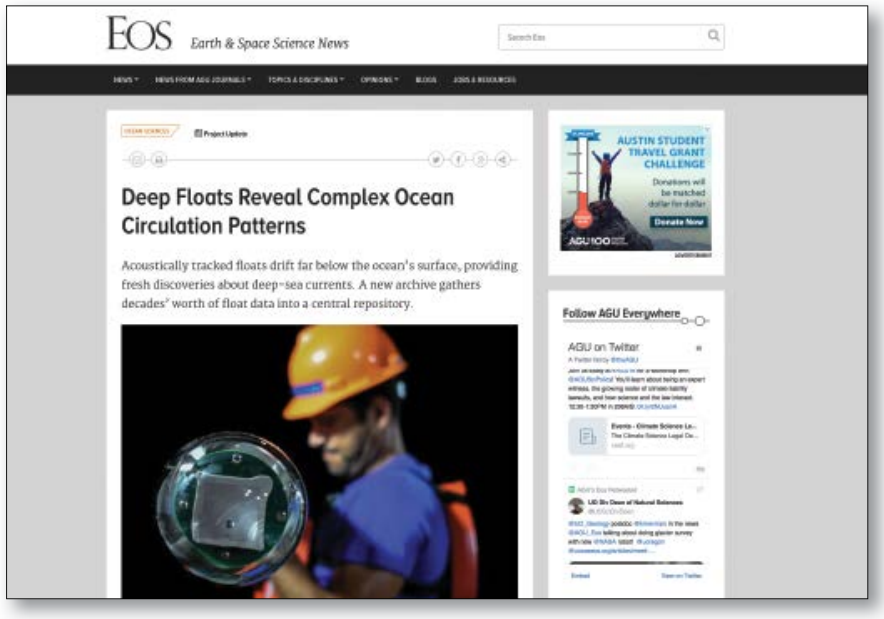

Deep Floats Reveal Complex Ocean Circulation Patterns bit.ly/Eos_deep-floats

World off Course to Meet Emissions Reduction Goals

bit.ly/Eos_emissions-reduction

Can You Express Your Science in 17 Syllables?

bit.ly/Eos_science-haiku

Advancing FAIR Data in Earth, Space, and Environmental Science bit.ly/Eos_FAIR-data

Brine Pools Emerge as a New Place to Search for Life on Mars bit.ly/Eos_life-on-Mars

\section{Unraveling the Origins of Australia's} Ancient Mountain Chains bit.ly/Eos_Australia-mtns 


\section{A Closer Look at Turbulent Transport in Gravel Streambeds}

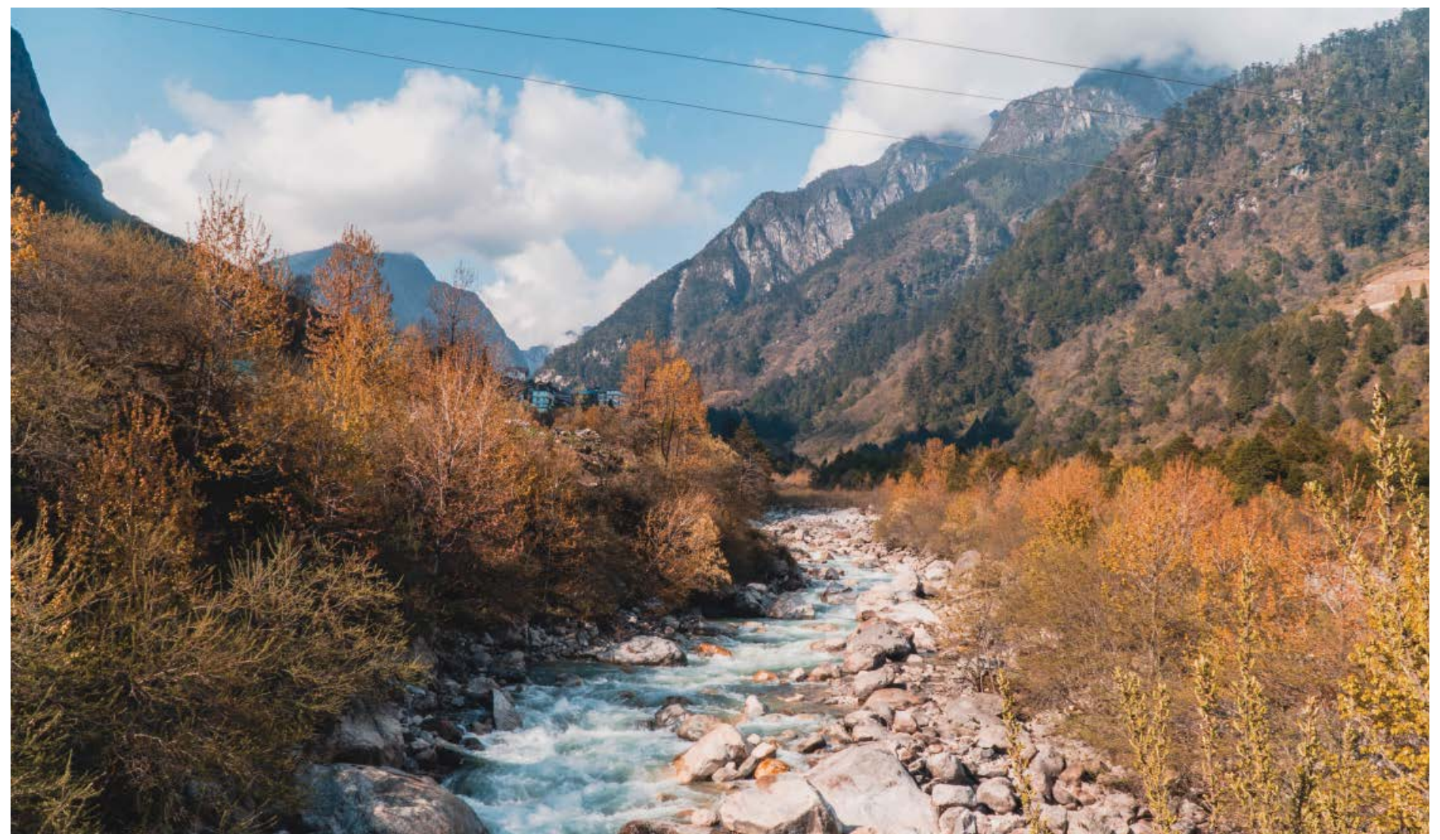

New research takes a closer look at how nutrient exchange in gravel streambeds is affected by turbulence. Credit: Debarshi Bhaumik, CC BY 2.0 (bit.ly/ccby2-0)

$\mathrm{B}$ elow rivers and streams lies a layer of sediment known as the hyporheic zone. There water carrying nutrients, pollutants, and other dissolved substances soaks into the streambed and mixes with groundwater. Meanwhile, water in the pores of the hyporheic zone, along with any materials dissolved in it, can rise to join the stream's flow.

This exchange of dissolved materials across a streambed helps to shape the stream ecosystem, including life in the hyporheic zone itself, as well as downstream ecosystems. In a new study, Roche et al. probe how turbulent streamflow influences this exchange process in streams with coarse, gravel-like beds.

Previous research has shown that turbulent flow of stream water enhances transport across a streambed, but the details of that process have remained unclear because of the difficulty of capturing it in action. For the new study, the researchers addressed this challenge by constructing artificial streams with tightly controlled water flow and sensors built into the streambeds.

The artificial streambeds consisted of coarse spherical beads roughly 4 centimeters in diameter, similar in size to gravel or cobbles. In the first of two series of experiments, the research team used endoscopic particle image velocimetry to visualize the flow of water in the pores between the beads. In this technique, a camera captured the flow pat- terns of numerous 14-micrometer-diameter glass spheres suspended in the pore water, which were illuminated by a laser.

In the second series of experiments, the scientists installed tiny salt concentration sensors over a full cross section of the 4 -centimeter beads. The sensor-equipped beads were all located at the same longitudinal location in the laboratory streambed but at varying depths. Salt tracer was injected into an upstream pore, and the sensors captured its downstream transport and vertical mixing over time.

The researchers conducted both series of experiments under a range of flow conditions. The analysis revealed that patterns of concentration fluctuations closely matched patterns of turbulent velocity fluctuations in the hyporheic zone. Mixing between the salt water and freshwater was strongest in regions where turbulent eddies penetrated into the streambed.

These findings show that turbulent flow of stream water strongly links the water column to the hyporheic zone, supporting theoretical arguments that hyporheic exchange models must include turbulent surface-subsurface interactions to simulate the transport of nutrients and pollutants in streams and rivers accurately. Additional research into a wider range of streamflows and streambed geometries could provide further insight. (Water Resources Research, https://doi.org/10 .1029/2017WR021992, 2018) -Sarah Stanley, Freelance Writer 


\section{The Case of the Missing Lunar Heat Flow Data Is Finally Solved}

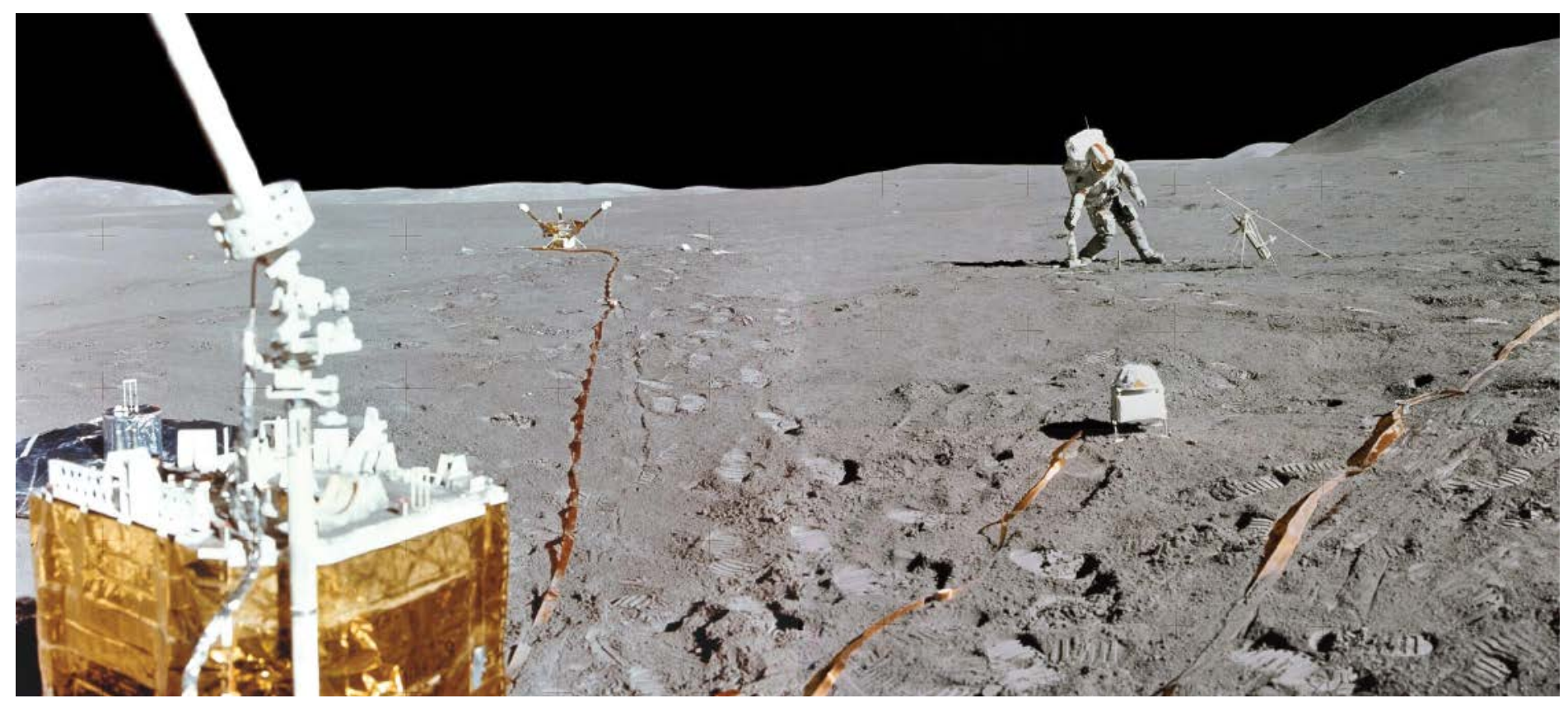

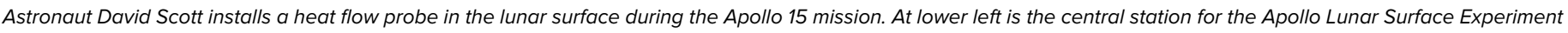
Package, which the heat flow probes were part of. The seismometer, covered by a silver Sun shield, is behind the central station. Credit: NASA

$\mathrm{D}$ uring the Apollo 15 and 17 missions, astronauts installed four temperature-sensing probes in shallow, 1.0- to 2.4 -meterdeep holes drilled into the Moon. They aimed to measure how much of the Moon's heat was lost to space, which could provide insights into the origin and the differentiation history of the Moon.

The Apollo Heat Flow Experiment ran from 1971 to 1977, but the original researchers analyzed and archived only the data collected between 1971 and December 1974. The rest of the records were lost. Nagihara et al. have now recovered, restored, and evaluated major portions of the missing data, finding that a warming trend observed from 1971 to 1974 continued through 1977.

To track down the missing data, the authors retraced the original data-recording process. Raw data from Apollo lunar surface experiments were captured on open-reel magnetic tapes at NASA's Johnson Space Center, but for unknown reasons, many were never sent to NASA's archives at the National Space Science Data Center. After the Apollo program ended, the tapes disappeared.

In 2011, the researchers reported that they had found about $10 \%$ of the missing tapes at the Washington National Records Center in Maryland. The tapes were somewhat degraded, but with the help of data recovery experts and old documents outlining how the data were organized, the researchers were able to restore much of the data, including measurements from the Heat Flow Experiment. They also found that some of the data were also recorded in the weekly performance logs kept at the Johnson Space Center.

To analyze the recovered heat flow data, the scientists needed just one more missing piece: calibration records for the temperature sensor probes. They found this information in old reports and memos from companies hired to help develop the instruments. With enough missing information recovered, the researchers were finally able to analyze the heat flow data.

They found that from 1974 until the Heat Flow Experiment concluded in 1977, the lunar subsurface warmed up, with greater warming occurring at shallower depths. This continued the warming trend observed by the original researchers in data collected between 1971 and December 1974. The measurements indicate that the observed warming began near the surface and spread downward.

The researchers then evaluated several previously proposed explanations for the warming, which have been debated in recent years. These include slow cyclical changes in the Moon's orbital axis, radiation from Earth, solar radiation into the drilled holes, and increased solar heat absorption by the surface after astronauts disturbed it with their activities.

Calculations from heat conduction models suggest that the timing and amount of warming seen at different depths are best explained by a rapid increase in surface temperature at the time of probe installation. This finding supports the hypothesis that disturbance of the lunar surface by astronauts' footprints and other activities increased its roughness, reducing the amount of solar radiation reflected back to space. Thus, increased absorption of solar heat caused the observed warming.

These findings suggest that to accurately measure heat flow in a planetary body, future experiments should aim either to minimize or to better account for surface disturbances. (Journal of Geophysical Research: Planets, https://doi.org/10.1029/2018JE005579, 2018) -Sarah Stanley, Freelance Writer 
AGU's Career Center is the main resource for recruitment advertising.

All Positions Available and additional job postings can be viewed at

eos.org/jobs-support.

AGU offers printed recruitment advertising in Eos to reinforce your online job visibility and your brand.

Visit employers.agu.org to view all of the packages available for recruitment advertising.

\section{SIMPLE TO RECRUIT}

- online packages to access our Career Center audience

- 30-day and 60-day options available

- prices range $\$ 475-\$ 1,215$

CHALLENGING TO RECRUIT

- online and print packages

to access the wider AGU

community

- 30-day and 60-day options

available

- prices range $\$ \mathbf{7 9 5}-\$ 2,691$

DIFFICULT TO RECRUIT

- our most powerful packages

for maximum multimedia

exposure to the AGU community

-30-day and 60-day options

available

prices range $\$ 2,245-\$ 5,841$

FREE TO RECRUIT

- these packages apply only to student and graduate student roles and all bookings are subject to AGU approval

- eligible roles include: student fellowships, internships, assistantships, and scholarships

- Eos is published monthly.Deadlines for ads in each issueare published at sites.agu.org/media-kits/ eos-advertising-deadlines/.

\section{- Eos accepts employment and} open position advertisements from governments, individuals, organizations, and academic institutions. We reserve the right to accept or reject ads at our discretion.

\section{- Eos is not responsible for} typographical errors.

\section{Atmospheric Sciences}

POSTDOCTORAL/RESEARCH SCIENTISTS

\section{ATMOSPHERIC AND OCEANIC SCI-} ENCES

\section{PRINCETON UNIVERSITY/GFDL}

In collaboration with NOAA's Geophysical Fluid Dynamics Laboratory (GFDL), the Atmospheric and Oceanic Sciences Program at Princeton University solicits applications to its Postdoctoral Research Scientist Program funded by the Cooperative Institute for Modeling the Earth System (CIMES).

The AOS Program and GFDL offer stimulating environment with significant computational and intellectual resources in which to conduct collaborative or independent research for the modeling, understanding and predictability of the Earth System from weather to centennial time scales. We primarily seek applications from recent Ph.D.s for postdoctoral positions but will accept applications from more experienced researchers. Appointments are made at the rank of Postdoctoral Research Associate or more senio initially for one year with the possibility of renewal for a second year based on satisfactory performance and continued funding. A competitive salary is offered commensurate with experience and qualifications.

We seek applications in all areas of earth system science within the three research themes of CIMES: 1) Earth System Modeling; 2) Seamless prediction across time and space scales; 3) Earth System Science: Analysis and Applications. Current areas of particular interest include: high-spatialresolution global modeling of weather and climate; predictability of highimpact weather events on global and regional scales; prediction of subseasonal to decadal hydroclimate variations, changes, and extremes; coupled system data-initialization and assimilation; ice sheet-ocean and ocean-sea ice-climate interactions; development of comprehensive biogeochemical and ecological models of the marine and terrestrial systems, and studies of their interactions with climate; development of atmospheric physics parameterizations, and study of convection-cloudsmicrophysics-radiation interactions; role of atmospheric chemistry and aerosols in the Earth System; climate sensitivity and past-to-present-tofuture variations/changes in climate; detection and attribution of changes in the Earth System; regional downscaling; and machine learning applications in climate science.

Further information about the Program may be obtained from: http://aos .princeton.edu. Applicants are strongly encouraged to contact potential hosts at GFDL and Princeton University prior to application to discuss areas of possible research.

Complete applications, including a $\mathrm{CV}$, copies of recent publications, contact details for 3 letters of recommen- dation, and a research proposal including the project title, should be submitted by January 15, 2019 for full consideration. Applicants must apply online to https://www.princeton.edu/ acad-positions/position/9843. We would like to broaden participation in earth system scientific research and therefore encourage applications from groups historically under-represented in science.

These positions are subject to the University's background check policy.

Princeton University is an equal opportunity employer and all qualified applicants will receive consideration for employment without regard to age, race, color, religion, sex, sexual orientation, gender identity or expression, national origin, disability status, protected veteran status, or any other characteristic protected by law.

Visiting Faculty Exchange Fellowships, Cooperative Institute for Modeling the Earth System at Princeton University

Princeton University's Cooperative Institute for Modeling the Earth System (CIMES), a collaboration between the Atmospheric and Oceanic Sciences (AOS) Program of Princeton University and NOAA's Geophysical Fluid Dynamics Laboratory (GFDL), invites applications for the CIMES Visiting Faculty Exchange fellowship program, to support collaborative visits to Princeton of up to 3 months from faculty based at US academic institutions. These fellowships are intended to broaden participation in climate and earth-system science, and individuals with experience working with students from groups under-represented in science are therefore particularly encouraged to apply. CIMES faculty fellows, appointed at the rank of Visiting Fellow or other visiting rank commensurate with education and experience, will work with host scientists at AOS and/or GFDL, a world-leading center of earth system modeling, research and predic tion, with the aim of establishing continuing research and educational links between AOS/GFDL scientists and the fellow's home institution. Faculty conducting research in areas relevant to CIMES, including physics, dynamics and chemistry of the atmosphere, ocean and climate, earth system science, and societal impacts, are encouraged to apply. CIMES visiting faculty fellows will work on a scientific problem of mutual interest in collaboration with their AOS/GFDL host, and benefit from resources and activities at GFDL and AOS.

Fellows will receive reimbursement for roundtrip travel from their home institution and housing costs incurred during their visit, and a stipend or partial summer salary if required. Applicants should submit a 2-page proposal for activities to be conducted during the fellowship, and are encouraged to identify one or more AOS faculty or GFDL scientists as potential hosts prior

to application. Complete applications, including proposal (with budget if requesting summer salary/stipend), curriculum vitae, cover letter, and names including contact information for two reference letter writers, must be submitted to https://www.princeton edu/acad-positions/position/9841 by January 15, 2019. Cover letters should include an explanation of the applicant's contributions to increasing diversity in science, and describe how this fellowship will enable the applicant's research and education goals, benefit interactions between their home institution and GFDL and Princeton University's AOS program, and lead to broader participation in climate and/ or earth-system science.

Princeton University is an Equal Opportunity/Affirmative Action Employer and all qualified applicants will receive consideration for employment without regard to age, race, color, religion, sex, sexual orientation, gender identity or expression, national origin, disability status, protected veteran status, or any other characteristic protected by law.

\section{Biogeosciences}

\section{Aquatic Ecosystem Modeler}

The University of California, Santa Barbara (UCSB) is recruiting a postdoctoral researcher to participate in development of a model of aquatic metabolism and associated atmospheric gas exchange that integrates hydrological, hydrodynamic, biogeochemical and ecological characteristics of Amazon floodplains. The model will be based on mechanistic understanding, empirical relations and will be applicable on a regional scale. Appointees should have published scientific papers, and have experience working independently and collaboratively within a multidisciplinary team.

Anticipated start date April 1, 2019. For primary consideration apply by January 15, 2019. Position is open until filled. To apply, please upload a cover letter, CV, statement of research, two representative publications and arrange for two letters of recommendations, to:

https://recruit.ap.ucsb.edu/apply/ JPFo1403. All qualified applicants will receive consideration for employment without regard to race, color, religion, sex, sexual orientation, gender identity, national origin, disability status, protected veteran status, or any other characteristic protected by law.

Email John Melack (melack@lifesci ucsb.edu) with any questions related to the position.

\section{Geochemistry}

FACULTY POSITION IN ISOTOPE GEOCHEMISTRY AND GEOCHEMISTRY

The Department of Earth and Planetary Sciences, University of Tennessee, Knoxville, invites applications for a nine-month, tenure-line position in 
Isotope Geochemistry and Geochemistry to be hired at the rank of Associate Professor. The successful candidate will develop a successful program of externally funded research in isotope geochemistry and geochemistry that includes supervision of undergraduate and graduate students, post-doctoral researchers, and technical staff. The candidate will provide primary oversight of a newly created ICP-MS core facility, which will include quadrupole and multi-collector ICP-MS instruments, a laser ablation system, and a clean laboratory housed in the Department of Earth and Planetary Sciences, located within the newly constructed Strong Hall. All laboratory spaces are new and purpose-built for the core facility, with significant university resources available for equipment purchase. Associated responsibilities include financial oversight and subsequent set-up, operation, and maintenance of a recharge-based, multiinstrument facility available for department, university, and external users. In addition, the candidate is expected to perform rank-appropriate departmental and university service. The successful candidate will instruct undergraduate courses, as well as graduate courses in the candidate's specialty.

Applicants must hold a Ph.D. (or equivalent) degree in solid-earth geoscience or a related discipline, and demonstrate excellence and innovation through publications and grants/contracts in isotope geochemistry (radiogenic and/or non-traditional stable isotope) or geochemistry, with the capacity to lead research in isotope geochemistry. The specific research specialty is open. The candidate must have a minimum of 7 years of research experience beyond the Ph.D. degree, and must have first-hand experience in setting up, running, and maintaining a multiple instrument ICP-MS facility and clean laboratory.

To apply, please email the following to epsicpms@utk.edu, with the subject line "Isotope geochemistry search:" full curriculum vitae, cover letter describing research and teaching experience, philosophy, and plans, and names of 4 references with contact information. Applications received by 7 January, 2019, are ensured review, but earlier submission is highly encouraged. The position will remain open until filled. Questions about the position should be directed to Dr. Chris Fedo (cfedo@utk.edu).For those attending, we will meet with selected candidates at the 2018 GSA Annual Meeting in Indianapolis and the 2018 AGU Fall Meeting in Washington DC. Please contact Dr. Chris Fedo, chair, with any questions at cfedo@utk.edu

The University of Tennessee is seeking candidates who have the ability to contribute in meaningful ways to the diversity and intercultural goals of the University. The University is an EEO/
AA/Title VI/Section 504/ADA/ADEA institution in the provision of its education and employment programs and services. All qualified applicants will receive equal consideration for employment without regard to race, color, national origin, religion, sex, pregnancy, marital status, sexual orientation, gender identity, age, physical or mental disability, or covered veteran status.

\section{Hydrology}

\section{Assistant Professor-Water} Resources Engineering-Tenure Track.

The Biological and Agricultural Engineering Department at Texas A\&M University seeks qualified applicants to establish an integrated teaching and research program of national recognition that will positively address the water resource needs in Texas, the nation, and/or internationally, This ten-month, $45 \%$ teaching, $45 \%$ research, and $10 \%$ service position will teach undergraduate and graduate courses, direct graduate research, establish a publication record, and attract extramural funding. Applicants should possess an earned Ph.D. in an appropriate engineering discipline.

Required Experience: Demonstrated potential for leading a research and teaching programs, with documented expertise in water resources engineering. Experience in one or more of the following areas: surface or subsurface hydrology (skilled in observational techniques, process modeling, or stochastic modeling), water resources systems, irrigation and drainage, water system resilience under climate change, or integration of big data and artificial intelligence tools into water management/hydrologic systems.

Preferred Experience: Experience in applying advanced computer modeling or field observational techniques, multi-scale hydrologic process understanding, or systems analysis tools to water resource applications. Demonstrated success in grantsmanship, innovative and effective instruction in related subject matter; experience in two or more of the areas listed for required experience.

For details and application instructions go to https://baen.tamu.edu/ about/employment.

Review of applications begins January 7, 2019 .

The Texas A\&M System is an Equal Opportunity/Affirmative Action/Veterans/Disability Employer committed to diversity.

\section{Graduate Research Opportunities at} Utah State University

The Utah Water Research Laboratory (UWRL) at Utah State University (http:// uwrl.usu.edu), a multidisciplinary laboratory in the Department of Civil and Environmental Engineering, attracts students from a variety of STEM back-

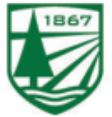
THAYER SCHOOL OF
ENGINEERING
AT DARTMOUTH

\section{EVANS FAMILY PROFESSORSHIP IN ARCTIC ENGINEERING}

The Thayer School of Engineering at Dartmouth seeks an outstanding candidate to be the inaugural holder of the Evans Family Professorship, which will be filled at the Assistant, Associate or Full Professor level. The Thayer School of Engineering is undertaking a significant expansion of faculty and programs: this position is the first of three new hires at Dartmouth in an interdisciplinary cluster focused on "Ice, Climate, and Energy".

The successful candidate, who will have a doctorate in engineering or a related field, will contribute to Dartmouth's well-established research effort in cold regions science and engineering by leading a strong externally-funded research program in engineering related to the Arctic, including but not limited to: the behavior of ice, snow and permafrost, and developing Arctic-related technologies. The successful candidate will also be a gifted teacher with motivation and expertise that complements the Thayer School's interdisciplinary approach to engineering education. Facilities include Thayer School's long-established Ice Research Laboratory, and there is strong potential for collaborations with Dartmouth's Arthur L. Irving Institute for Energy and Society, Dartmouth's Institute for Arctic Studies, and with the nearby U.S. Army's Cold Regions Research and Engineering Laboratory. Dartmouth is part of the University of the Arctic.

Review of applications will begin on January 1st, 2018 and will continue until the position is filled. Interested candidates should submit a cover letter, complete CV, statement of research and teaching interests, and contact information for three references via Interfolio at: apply.interfolio.com/45797.

Inquiries about the position should be directed to Professor Ian Baker, Ian.Baker@Dartmouth.edu. 
grounds and is engaged in a wide range of challenging national and international research efforts. See https://cee .usu.edu/students/graduate/apply for application information. Funded opportunities in the following research groups are described below:

WATER INFRASTRUCTURE AND THE ENVIRONMENT. PhD assistantship is available for highly motivated students. Potential research areas include but are not limited to fluvial hydraulics, computational fluid dynamics, hydraulic structures, scour and erosion, fluid mechanics and experimental techniques, and energy dissipation. Inquiries are encouraged and may be directed to brian.crookston@usu.edu.

HUMAN-NATURAL WATER MANAGEMENT. PhD and MS assistantships are available within the USU WET Lab (www.usuwetlab.org) at the intersection of hydrologic science, fluvial hydraulics, and water resources management, with a focus on data-driven solutions for the West's growing water management challenges. Potential research areas include integrating ecological and climate uncertainty in water management, investigating multi-scale topographic and streamflow controls on river functioning to inform restoration, and quantifying the utility of synthetic terrain generation for ecohydraulic applications. Students with various backgrounds are encouraged to apply (e.g., hydrology, civil engineering, earth sciences, biology, statistics). Experience with programming, geospatial and statistical analysis strongly desired. Inquiries may be directed to belize.lane@usu.edu.

AGRICULTURAL WATER AND BIG DATA. PhD and MS assistantships available to develop solutions involving multi-resolution, high/low frequency data sources for agricultural characterization, monitoring, and forecasting.

Potential research areas include but are not limited to remote sensing vertical integration, beyond line-of-sight UAV technology, data mining and Big Data applications in agriculture. Experience in HPC systems, data mining, remote sensing, water and energy balance, spatial statistics, and field data collection desired. Google Earth Engine experience is a plus. Inquiries may be directed to alfonso.torres@usu.edu.

MACHINE LEARNING AND HYDROLOGY. $\mathrm{PhD}$ research assistantship is available in machine learning applications in hydrologic (emphasis on groundwater) modeling. Potential research areas include but are not limited to data-driven modeling of hydrologic systems, uncertainty analysis, and integrated hydrologic modeling. Proven experience with programming and statistics strongly desired. Inquiries may be directed to tianfang.xu@usu.edu.

HUMAN IMPACT ON HYDROLOGY

MODELING AND PREDICTION. PhD and MS assistantships are available in understanding watersheds as coupled nature-human systems and providing scientific support for water resources management. Specific focus areas are
(1) human activities impact assessments (e.g., irrigation, resource consumption, renewable energy generation) using insitu measurements and remote sensing products with machine-learning or statistical techniques and

(2) hydrologic model refinements by improving the human dimension. Students with various backgrounds are encouraged to apply (e.g., civil engineering, hydrology, earth sciences, remote sensing, mathematics and statistics). Experience with numerical simulation, statistics and spatial data analysis strongly desired. Inquiries may be directed to ruijie.zeng@usu.edu.

Application Deadline: March 15, 2019 (for full funding consideration for graduate studies starting fall 2019)

*Communication with respective contacts is encouraged before applying

USU is an AA/EO Institution

\section{Interdisciplinary}

Assistant Professor in Ecosystem Science - Biogeochemistry, Department of Ecosystem Science and Sustainability, Colorado State University, Fort Collins, CO 80523

Description: Tenure track, 9-month academic faculty position

The Department of Ecosystem Science and Sustainability at Colorado State University (Fort Collins, Colorado) is recruiting a new tenure-track faculty member at the rank of ASSISTANT PROFESSOR in ecosystem science with biogeochemistry and sustainability expertise. The position is expected to start at the beginning of fall 2019 Semester. We seek candidates with expertise related to (but not restricted to) land-use change and ecosystem services of global systems, human-modified and managed landscapes, or social-ecological systems. The research foci can encompass small-scale mechanism to larger, integrative global processes. Research approaches could include (but are not limited to) trace gas and/or biogeochemical processes, the use of stable isotopes, use of large data sets, molecular microbial tools, modeling, experiments, and inter- or trans-disciplinary studies. Applicants should be interested in working in a highly collaborative department and enthusiastic about teaching at both the undergraduate and graduate levels, while contributing to the land grant mission of Colorado State University. Teaching responsibilities will include courses in ecosystem ecology and biogeochemistry. We envision an independent researcher who will develop a strong, extramurally-funded research program. The department of ESS has a commitment to actively contributing to developing a diverse and inclusive environment within the department, college, and university, and will expect the candidate to contribute to this vision.

To apply and view a full announcement please visit http://jobs.colostate edu/postings/61686 by January 4, 2019 for full consideration.
CSU is an EO/EA/AA employer and conducts background checks on all final candidates.

Graduate Student Research and Teaching Assistantships in Env. Earth \& Atmo. Science at Umass Lowell

The Department of Environmental, Earth and Atmospheric Sciences (EEAS) at the University of Massachusetts Lowell offers exciting graduate research and teaching assistantships for motivated students for the Fall 2019 semester. The following 4 positions are currently open:

\section{GEOCHRONOLOGY AND ISOTOPE} GEOCHEMISTRY

Prof. Richard Gaschnig specializes in geochemistry, petrology, and geochronology, and uses elemental and isotopic measurements to answer questions about how the Earth's continents have formed and evolved. His laboratory is currently recruiting M.S. students who are interested in these topics.

Dr. Gaschnig has several potential projects in the fields of geochemistry, geochronology, and petrology, including.

- Distribution of Mo, $\mathrm{U}$, and $\mathrm{Tl}$ and their isotopic behavior in metamorphic rocks

- Provenance of Precambrian sedimentary sequences in the western US

- Tectonic origin of orthogneiss complex in central Idaho

Several of these projects involve fieldwork and all involve lab work. For further information, please contact Prof. Richard Gaschnig: Richard

Gaschnig@uml.edu

HYDROGEOLOGY

A research opportunity is available for a graduate student who has an interest in coastal hydrogeology field work or numerical groundwater modeling. The project aims to understand surface water- groundwater interactions in the Merrimack River. The student will conduct field research and install groundwater wells and piezometers and deploy sensors in surface water and coastal aquifers, or numerically model groundwater processes at the coast.

If interested, please send an email to james_heiss@uml.edu and include your resume. Motivated students who can work independently, take the initiative, and have a quantitative background are encouraged to apply.

ASSESSING ATMOSPHERIC MERCURY DEPOSITION AND POLLUTION IN FORESTS

The group of Prof. Daniel Obrist is looking for a graduate student to work on a project aimed to assess the deposition of atmospheric mercury to forests. Mercury is a potent neurotoxic pollutant affecting ecosystems worldwide. The dominant source of mercury on land is likely derived from plant uptake of gaseous atmospheric mercury, which subsequently is transferred to soils. From there, it is transported to rivers, lakes and oceans downstream via runoff processes and negatively affects

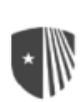 Stony Brook University \\ Tenure-Track Assistant Professor Geochronology \\ Department of Geosciences}

The Department of Geosciences at Stony Brook University invites applications for a tenure-track Assistant Professor Faculty position in the field of Geochronology, one of five Presidential TBI faculty lines being created across campus, for researchers whose interests intersect with the goals and resources of the Turkana Basin Institute. We seek a candidate with the potential to augment or build upon the Department's current research strengths across the geosciences and related sciences on campus while taking advantage of Stony Brook's unique relationship with the Turkana Basin Institute, located in a premier site for the study of hominid and vertebrate evolution during the Cenozoic.

Applicants should apply by January 15, 2019.

Those interested in this position should submit a State Employment Application, cover letter, teaching statement, research statement and contact information for three references, along with resume/CV to Academic Jobs Online at: https://academicjobsonline.org/ajo/jobs/12554. Electronic submission via Academic Jobs Online is highly preferred. Alternately, you may submit your application package to the departmental address below. Please also fill out an online Applicant Information Survey. Do not submit this survey to the department.

\section{Faculty Search Committee \\ Professor Troy Rasbury \\ Department of Geosciences \\ Stony Brook University \\ 255 Earth and Space Sciences Building (ESS) \\ Stony Brook, NY 11794-2100}

For a full position description, or application procedure, visit: www.stonybrook.edu/jobs (Ref. \# F-9959-18-10)

Stony Brook University is an affirmative action equal opportunity employer and educator. 
aquatic food webs. In this project, we will quantify net atmosphere-surface exchange of atmospheric mercury in two remote forests for one full year each, net atmosphere-surface exchange of atmospheric mercury in two remote forests for one full year each, providing the first such records in forests. Atmospheric mercury deposition will be measured using micrometeorological methods deployed on large towers, in collaboration with Columbia University, Harvard University, and Texas A\&M. Contact Daniel_Obrist@uml.edu.

\section{ATMOSPHERIC AND CLIMATE} SCIENCE

The Climate System Dynamics Group in the Department of Environmental, Earth and Atmospheric Sciences at the University of Massachusetts Lowell (https://www.uml.edu/ Sciences/EEAS/) is recruiting graduate students interested in atmospheric and climate science for funded M.S. positions starting in Fall 2019.

Motivated students interested in working with large climate datasets and climate models to study wideranging earth system topics, including weather extremes and hydrologic changes in modern, future, and paleo climates are encouraged to apply.

Applicants should have a background in Atmospheric Science, Physics, or a related field. Experience with Python, Matlab, NCL, R, or other programming languages is essential.
Interested applicants should email Christopher Skinner (Christopher _Skinner@uml.edu) to learn more about the M.S. program at UMass Lowell, and to discuss potential research projects. Please include a CV and a brief summary of research interests in your initial email. Examples of past and ongoing research projects within the Climate System Dynamics Group can be found at: https://www .christopherbskinner.com.

Further TA opportunities are available in the department on a competitive basis. If interested in applying for a TA position, please apply to the Graduate program and contact EEAS faculty (www.uml.edu/sciences/eeas) about your interest in joining their research groups.

You may further contact the EEAS Graduate Program Coordinator, Prof. Kate Swanger: Kate_Swanger@uml .edu.

Hydrogeochemist (Assistant Scientist or early career Associate Scientist)

HYDROGEOCHEMIST - Geohydrology Section - Kansas Geological Survey - The University of Kansas, Lawrence. Full-time position to lead KGS hydrogeochemical investigations. Faculty-equivalent, sabbatical-eligible position at the rank of Assistant or entry-level Associate Scientist.

Requires Ph.D. with an emphasis on aqueous geochemistry related to water resources and scientific leadership potential. Emphasis on state-of-thescience field studies and complementary theoretical research. Complete announcement/application info at www.kgs.ku.edu/General/jobs.html. Review of applications will begin March 4, 2019.

Apply online at http://employment .ku.edu/academic/13299BR. For further information contact Geoff Bohling (geoff@kgs.ku.edu) or Don Whittemore (donwhitt@kgs.ku.edu).For further information about other aspects of the position, contact Annette Delaney, HR, at adelaney@ kgs.ku.edu or $785-864-2152$.

$\mathrm{KU}$ is an EO/AAE, http://policy.ku .edu/IOA/nondiscrimination.

\section{Associate Director for Research- Kansas Geological Survey (KGS)- University of Kansas, Lawrence}

Full-time position to provide strategic collaborative research leadership that supports the KGS mission. The Associate Director for Research (ADR) will report to the Director and interact with Senior-rank academic staff; oversee approximately 14 Kansas Geological Survey (KGS) Assistant and Associate-rank academic and scientific research staff, and their research programs; align the unique strengths of current KGS research programs with research trends and new innovative research opportunities. The ADR also will be expected to lead an externally funded, active research program in an area relevant to Kansas. The KGS is research and service division of the University of Kansas, and the successful candidate will have the opportunity to collaborate with KU faculty and students in other departments and research groups. Complete announcement/application info at www.kgs.ku .edu/General/jobs.html. Review of applications will begin Jan. 15, 2019.

Apply online at http://employment ku.edu/academic/13077BR. For further information about the position contact Rolfe Mandel, mandel@ku. edu, 785-864-2171. For further information about other aspects of the position, contact Annette Delaney, HR, at adelaney@ku.edu or 785-8642152.

$\mathrm{KU}$ is an EO/AAE, http://policy.ku .edu/IOA/nondiscrimination.

\section{Matthews Endowed Professor in} Earth Sciences

Position No. 50601. The Roy M. Huffington Department of Earth Sciences announces a search to fill a named tenured professorship honoring C.W. Matthews. We are seeking midcareer applicants with active research programs in the area of the dynamics of fluid-rock interaction. The crossdisciplinary nature of fluid-rock interaction is such that the successful candidate may apply techniques from petrology, hydrology, general geochemistry, isotope geochemistry, or

\title{
圆TEXAS Geosciences
}

\author{
The University of Texas at Austin
}

Jackson School of Geosciences

\section{DIRECTOR OF THE UNIVERSITY OF TEXAS AT AUSTIN INSTITUTE FOR GEOPHYSICS}

The Institute for Geophysics at The University of Texas at Austin (UTIG), one of the three principal units in the Jackson School of Geosciences, seeks applications for the position of Director, which may include a concurrent faculty appointment in the Department of Geological Sciences (qualifications for faculty position must be commensurate with rank). UTIG is a world leader in expeditionary-scale geophysical research, numerical modeling and computational-enabled discovery, conducting research in four broad themes: climate; energy; marine geosciences, seismology and tectonophysics; and polar and planetary geophysics. It has a staff of about 75 research scientists and support staff. Both graduate and undergraduate students play important roles in the UTIG research mission. The science vision of the Institute is described in more detail at http://ig.utexas.edu/utig-science-vision-plan/.

An accomplished leader is sought to provide strategic vision and outstanding operational management, to foster high-quality research programs, and to guide the UTIG community to the next level of accomplishment and impact. The UTIG Director will maintain and strengthen the culture of collaboration and innovation in the Jackson School of Geosciences, expand the reputation of the institute, promote diversity within the institute and demonstrate commitment to a high-quality student experience.

The ideal candidate will possess a Ph.D. in a relevant scientific field (e.g., geology, geophysics, oceanography, planetary sciences, etc.), and will have experience in the administration of complex organizations and research programs, a demonstrated record of high-quality research and publications, and excellence in people management and communication skills. Involvement in international and/or large federal programs, and leadership in academic and professional activities is desired.

An applicant should submit a letter of interest, a vision statement (including your perspectives on how to advance both scholarly excellence and diversity in the workplace at UTIG), CV, and list of four references (with titles and email addresses) electronically to https://apply.interfolio.com/56029. Additionally a resume must be submitted at the UT Austin Jobs website: https://utdirect.utexas.edu/apps/hr/jobs/nlogon/180920010382. Questions should be directed to Dr. Gail Christeson or Dr. Sean Gulick, co-chairs, UTIG Director Search Committee at gail@ig.utexas.edu and sean@ig.utexas.edu. References will only be contacted with permission of the candidates.

Review of applications will commence on Jan. 15, 2019; however, applications will be accepted until the position is filled. The desired target date for the new director to assume duties is Sept. 1, 2019. 
economic geology. The successful applicant will exhibit the ability to (1) maintain programs with external funds obtained from a diverse portfolio of funding agencies, (2) oversee professional staff, and (3) mentor students at both the undergraduate and graduate level. The successful applicant will have a commitment to full participation in the educational mission of the department, which is to provide professional training in the Earth Sciences in a liberal arts environment. As the third holder of the Chair, which was established in 1979, the successful candidate must demonstrate strong potential to strengthen and expand the existing departmental research focus. The current focus includes research on problems in the national interest such as natural hazards, earthquake seismology - including induced seismicity, nuclear test ban treaty monitoring, natural and problems in global environmental change. Applications can be submitted electronically to https://apply.interfolio .com/55725.

Applicants should include a curriculum vitae, statements of teaching and research interests, and contact information for three references. To insure full consideration, applications must be received by January 15, 2019, but the committee will continue to accept applications until the position is filled. The committee will notify applicants of its decisions after the position is filled. Ph.D. is required at the time of appointment.

Southern Methodist University will not discriminate in any program or activity on the basis of race, color, religion, national origin, sex, age, disability, genetic information, veteran status, sexual orientation, or gender identity or expression. The Executive Director for Access and Equity/Title IX Coordinator is designated to handle inquiries regarding nondiscrimination policies and may be reached at the Perkins Administration Building, Room 204, 6425 Boaz Lane, Dallas TX 75205, 214-768-3601, accessequity@ smu.edu

Hiring is contingent upon the satisfactory completion of a background check.

Tenure-Track and Postdoc Positions in Dept. of Atmospheric and Oceanic Sciences, Peking University

The Dept. of Atmospheric and Oceanic Sciences of Peking University invites applications for multiple tenure-track faculty positions in atmospheric and oceanic sciences. Three positions are available in physical oceanography, particularly in the areas of ocean general circulation and dynamics, air-sea interaction and climate, ocean biogeochemical cycle, ocean model development, and satelavailable in atmospheric sciences, particularly in the areas of climate resources such as geothermal energy lite oceanography. Four positions are dynamics and modeling, synoptic and meso-scale meteorology, radiation and remote sensing, atmospheric chemistry, cloud physics, atmospheric boundary layer, land-air interaction, tions are at the tenure-track assistant professor level under the "Young Qianren" or "Bairen" programs. For exceptional cases, a more senior starting position may be considered. Recruiting is conducted semi-annually (in spring and fall), until all positions are filled. The deadline for this round of recruiting is February 28, 2019. For application qualifications, benefits, required materials, and contact information, visit https://atmos.pku.edu .cn/rczp/87145.htm.

Meanwhile, all disciplines of our department are hiring postdocs with different application deadlines and compensation packages; see http:// www.atmos.pku.edu.cn/rczp/395.htm.

Tenure Track Position in Solid Earth Geosciences or Engineering Seismology

The Center for Earthquake Research and Information (CERI) at the University of Memphis invites applications for a tenure-track faculty position at the Assistant Professor level to begin in August 2019. We are searching broadly and seeking an individual to complement our existing strengths in seismology, geodesy, computational tectonics, earthquake physics and seismic hazard. We particularly encourage applicants with research interests related to Active tectonics, Continental/Lithospheric dynamics, Computational Geophysics, Exploration Geophysics, or Engineering Seismology. Applicants must have a Ph.D. at the time of employment, and show a demonstrated record or strong promise of research productivity. The successful candidate is expected to build a vigorous, externally funded research program, mentor M.S. and Ph.D. graduate students, and teach graduate courses in her or his specialty. As part of a University interdisciplinary research center, CERI faculty are engaged in a variety of regional, national, and international research projects (https://www.memphis.edu/ceri/). More information about this position can be obtained by contacting the chair of the search committee, Eunseo Choi (echoi2@memphis.edu).

Applicants should submit an application letter, full curriculum vitae, statements of research and teaching interests, and the names and addresses (with phone numbers and email) of at least three references. To receive full consideration, applications must be submitted through the University of Memphis WorkForUM online application system (https:// workforum.memphis.edu) by December 17, 2018. The University of Memphis is an Equal Opportunity/Affirmative Action employer. and planetary atmospheres. All posi-

\section{Ocean Sciences}

\section{VISITING RESEARCH SCIENTISTS} ATMOSPHERIC AND OCEANIC SCIENCES

PRINCETON UNIVERSITY/GFDI

In collaboration with NOAA's Geophysical Fluid Dynamics Laboratory (GFDL), the Atmospheric and Oceanic Sciences Program at Princeton University solicits applications to its Visiting Research Scientist Program funded by the Cooperative Institute for Modeling the Earth System (CIMES).

The AOS Program and GFDL offer a stimulating environment with significant computational and intellectual resources in which to conduct collaborative or independent research. Independent researchers and more senior scientists who wish to visit GFDL for the purpose of collaboration, for sabbatical or short visits, will be considered for partial support. We seek applications in all areas of earth system science within the three research themes of CIMES: 1) Earth System Modeling; 2) Seamless prediction across time and space scales; 3 ) Earth System Science: Analysis and Applications.

Further information about the Program may be obtained from: http://aos .princeton.edu/. Applicants are strongly encouraged to contact potential hosts at GFDL and Princeton University prior to application to discuss areas of possible research.
Complete applications, including a $\mathrm{CV}$, copies of recent publications, contact details for 3 letters of recommendation, and a research proposal including the project title, should be submitted by January 15th, 2019 for full consideration. Applicants must apply online at https://www.princeton.edu/ acad-positions/position/9842. Advanced degree is required. We would like to broaden participation in earth system science and therefore encourage applications from groups historically under-represented in science.

Princeton University is an equal opportunity employer and all qualified applicants will receive consideration for employment without regard to age, race, color, religion, sex, sexual orientation, gender identity or expression, national origin, disability status, protected veteran status, or any other

Tenure Track Positions(s) in Planetary Science

The Department of Earth, Atmospheric, and Planetary Sciences (EAPS), within the College of Science at Purdue University, invites applications for one or more tenure-track faculty positions in planetary atmospheres and/or planetary physics. These appointments will be at the level of Assistant or Associate Professor. Growth in planetary science is part of large-scale interdisciplinary characteristic protected by law.

\section{Planetary Sciences}

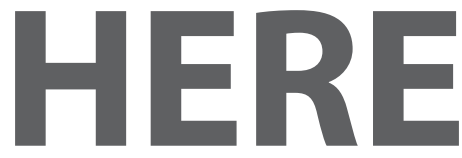

Visit employers.agu.org to learn more about employment advertising with AGU

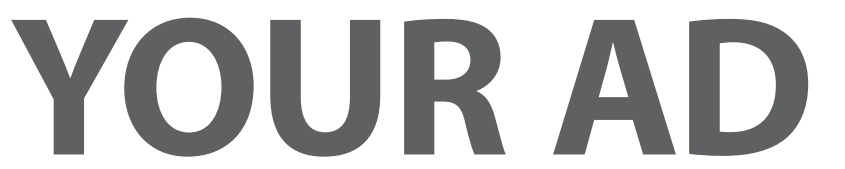




\section{Assistant Professor (Tenure Track) of Space Geodesy and Navigation}

\author{
$\rightarrow$ The Department of Civil, Environmental and \\ Geomatic Engineering (www.baug.ethz.ch) at ETH \\ Zurich invites applications for the above-mentioned \\ position.
}

\section{$\rightarrow$ The professorship covers space geodetic and navigation techniques including the data processing} methods required for their application to positioning, navigation and earth observation. The research focus should be linked to multi-GNSS, sensor fusion of GNSS and other sensors, terrestrial reference frames, gravity and mass transport, relativistic geodesy or related fields. The new professor is expected to teach at the undergraduate level lin German or English) and graduate level (in English) and to lead a research group. He or she should have a doctoral degree in any area related to the above professorship and at least two years of postdoctoral research experience. An excellent record of research accomplishments is expected, as well as successful acquisition of third party research funding.

\section{$\rightarrow$ Assistant professorships have been established} to promote the careers of younger scientists. ETH Zurich implements a tenure track system equivalent to other top international universities.

\section{$\rightarrow$ Please apply online: www.facultyaffairs.ethz.ch}

\section{$\rightarrow$ Applications should include a curriculum vitae, a} list of publications, a statement of future research and teaching interests, and a description of the three most important achievements. The letter of application should be addressed to the President of ETH Zurich. The closing date for applications is 15 February 2019. ETH Zurich is an equal opportunity and family friendly employer and is responsive to the needs of dual career couples. We specifically encourage women to apply. hiring effort across key strategic areas in the College of Science. This position comes at a time when the College is under new leadership and with multiple commitments of significant investment.

Candidates should be able to develop a vigorous, externally funded, internationally recognized theoretical, experimental, and/or observational research program that addresses research questions of fundamental importance. Possible areas of study in planetary atmospheres could include observing and/or modeling of the atmospheres of jovian, terrestrial, exosolar planets or small bodies, and/or the origin of life and habitability. Possible areas of study in planetary physics could include computer modeling of impact processes, planetary origins, or planetary interiors.

Candidates are expected to develop a program that is complementary to existing research within the department and teaching needs at the undergraduate and graduate levels. The potential to develop interdisciplinary, collaborative research that cuts across specialty areas within the department, the College of Science, and Purdue's research community is desirable. Candidates must have completed their Ph.D. in Planetary Sciences or related field at the time of employment. Within EAPS and Purdue, candidates will find supportive colleagues, a diverse and vibrant academic community, with ample opportunities for professional and personal growth.

Purdue University's Department of Earth, Atmospheric, and Planetary Sciences is committed to advancing diversity in all areas of faculty effort, including scholarship, instruction, and engagement. Candidates should address at least one of these areas in their cover letter, indicating their past experiences, current interests or activities, and/or future goals to promote a climate that values diversity and inclusion.

Interested applicants should visit https://hiring.science.purdue.edu, submit a curriculum vitae, a research statement, a teaching statement, and complete contact information for at least 3 references. Review of applications will begin January 2, 2019, and will continue until the position is filled. Questions related to this position should be sent to David Minton (daminton@purdue.edu). Applications will be accepted until the position is filled. A background check will be required for employment in this position. Purdue University is an ADVANCE institution.

Purdue University is an EOE/AA employer. All individuals, including minorities, women, individuals with disabilities, and veterans are encouraged to apply.

\section{Seismology}

Assistant Professor of Seismology, Purdue University

The Department of Earth, Atmospheric, and Planetary Sciences (EAPS), within the College of Science at Purdue University, invites applications for a tenure-track faculty position at the rank of Assistant Professor in the area of seismology. As part of a large-scale interdisciplinary hiring effort across key strategic areas in the College of Science-Purdue's second-largest college, comprising the physical, life, and computing sciences-this position comes at a time when the College is under new leadership and with multiple commitments of significant investment.

EAPS has strengths in exploration geophysics, seismic imaging, geophysical modeling, earth material properties, geodesy, and tectonics. We seek to add a quantitative seismologist interested in addressing questions on the solid earth at a range of scales. Areas of specialization could include earthquake geophysics, and/or natural/active source seismic imaging. Candidates are expected to develop a vigorous, externally funded, internationally recognized research program, that is complementary to existing research and teaching needs at the undergraduate and graduate levels. The potential to develop interdisciplinary research that cuts across specialty areas within the department, the College of Science, and Purdue's research community is desirable. Candidates must have completed their $\mathrm{Ph}$.D. in the area of Geophysics or a related field by the time of employment. Within EAPS and Purdue, candidates will find supportive colleagues, a diverse and vibrant academic community, with ample opportunities for professional and personal growth.

Purdue University's Department of Earth, Atmospheric, and Planetary Sciences is committed to advancing diversity in all areas of faculty effort, including scholarship, instruction, and engagement. Candidates should address at least one of these areas in their cover letter, indicating their past experiences, current interests or activities, and/or future goals to promote a climate that values diversity and inclusion.

Interested applicants should visit https://hiring.science.purdue.edu, submit a curriculum vitae, a research statement, a teaching statement, and complete contact information for at least 3 references. Review of applications will begin December 20, 2018, and will continue until the position is filled. Questions related to this position should be sent to Douglas Schmitt (schmitt@purdue.edu) or Christopher Andronicos (candroni@purdue.edu). Applications will be accepted until the position is filled. A background check will be required for employment in this position. Purdue University is an ADVANCE institution.

Purdue University is an EOE/AA employer. All individuals, including minorities, women, individuals with disabilities, and veterans are encouraged to apply. 


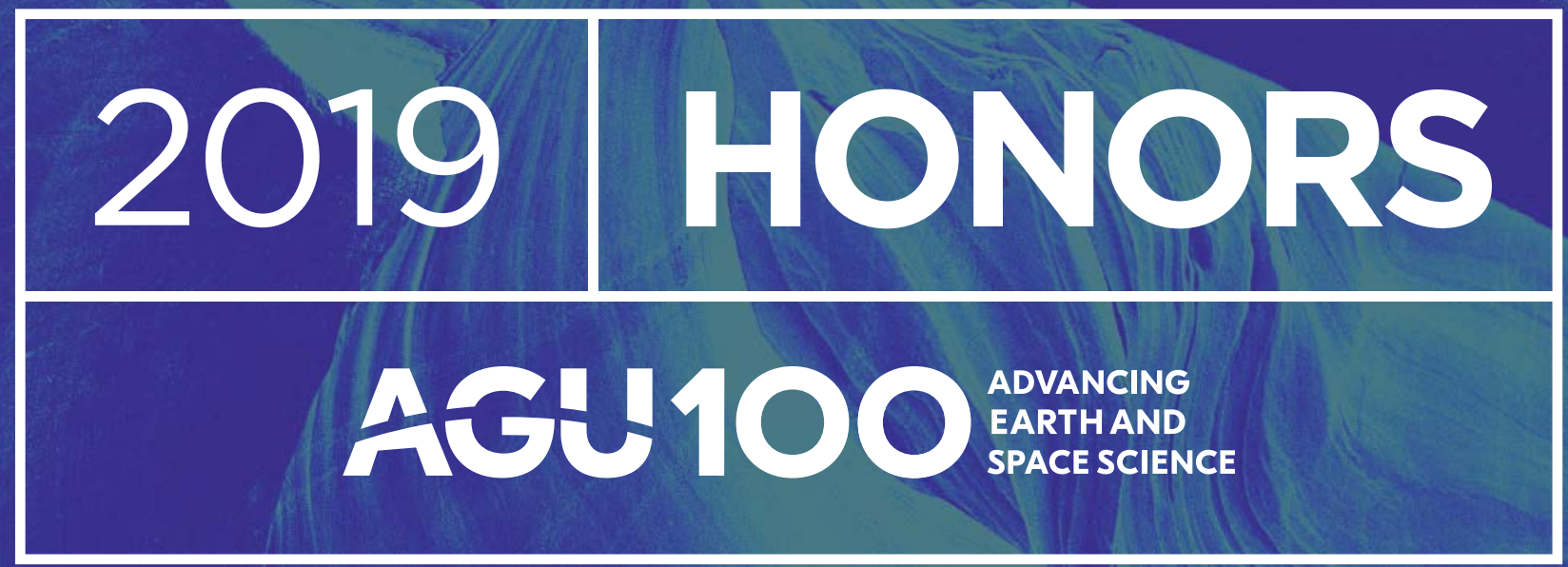

Recognize a colleague, mentor, peer, or student for their achievements and contributions to the Earth and space sciences.

- Union Medals - Union Awards

- Union Fellowship - Sections Awards

- Union Prizes and Lectures

Nominations Open 15 January

honors.agu.org 